\title{
The role of white noise speech illusions in indicating risk for psychotic disorders
}

Citation for published version (APA):

Schepers, E. A. W. (2021). The role of white noise speech illusions in indicating risk for psychotic disorders. [Doctoral Thesis, Maastricht University]. Maastricht University. https://doi.org/10.26481/dis.20210617es

Document status and date:

Published: 01/01/2021

DOI:

10.26481/dis.20210617es

Document Version:

Publisher's PDF, also known as Version of record

\section{Please check the document version of this publication:}

- A submitted manuscript is the version of the article upon submission and before peer-review. There can be important differences between the submitted version and the official published version of record.

People interested in the research are advised to contact the author for the final version of the publication, or visit the DOI to the publisher's website.

- The final author version and the galley proof are versions of the publication after peer review.

- The final published version features the final layout of the paper including the volume, issue and page numbers.

Link to publication

\footnotetext{
General rights rights.

- You may freely distribute the URL identifying the publication in the public portal. please follow below link for the End User Agreement:

www.umlib.nl/taverne-license

Take down policy

If you believe that this document breaches copyright please contact us at:

repository@maastrichtuniversity.nl

providing details and we will investigate your claim.
}

Copyright and moral rights for the publications made accessible in the public portal are retained by the authors and/or other copyright owners and it is a condition of accessing publications that users recognise and abide by the legal requirements associated with these

- Users may download and print one copy of any publication from the public portal for the purpose of private study or research.

- You may not further distribute the material or use it for any profit-making activity or commercial gain

If the publication is distributed under the terms of Article $25 \mathrm{fa}$ of the Dutch Copyright Act, indicated by the "Taverne" license above, 
The role of white noise speech

illusions in indicating risk for

psychotic disorders

Elaine Schepers 
ISBN: 978-94-6421-349-2

Cover design: Marloes Evers

Print: IpskampPrinting, Enschede

(C) 2021 Elaine Schepers

All rights reserved. No part of this publication may be reproduced or transmitted in any form or by any means, electronic or mechanical, including photocopy, recording, or any information storage or retrieval system, without written permission of the author. 


\title{
The role of white noise speech illusions in indicating risk for psychotic disorders
}

\begin{abstract}
PROEFSCHRIFT
ter verkrijging van de graad van doctor aan de Universiteit Maastricht, op gezag van de Rector Magnificus, Prof. dr. Rianne M. Letschert volgens het besluit van het College van Decanen, in het openbaar te verdedigen op donderdag 17 juni 2021 om 16.00 uur
\end{abstract}

door

Elaine Anne Willemijn Schepers 


\section{Promotor}

Prof. dr. J.J. van Os

\section{Co-promotor}

Dr. R. Lousberg

\section{Beoordelingscommissie}

Prof. dr. T.A.M.J. van Amelsvoort (voorzitter)

Prof. dr. W. Cahn (Universitair Medisch Centrum Utrecht)

Prof. dr. N.E. Jacobs (Open Universiteit Heerlen)

Prof. dr. K.R.J. Schruers

Prof. dr. J.J.M.H. Strik 


\section{Table of contents}

\section{Chapter 1}

General introduction

Chapter 2

Cortical processes of speech illusions in the general population

Chapter 3

Baseline alpha activity: a predictor of white noise speech illusions in the general population?

\section{Chapter 4}

White noise speech illusions in the general population: the association with psychosis expression and risk factors for psychosis

\section{Chapter 5}

White noise speech illusions: a trait-dependent risk marker for psychotic

disorder?

\section{Chapter 6}

General discussion

Chapter 7

Summary

\section{Chapter 8}

Samenvatting

Chapter 9

Valorisation 

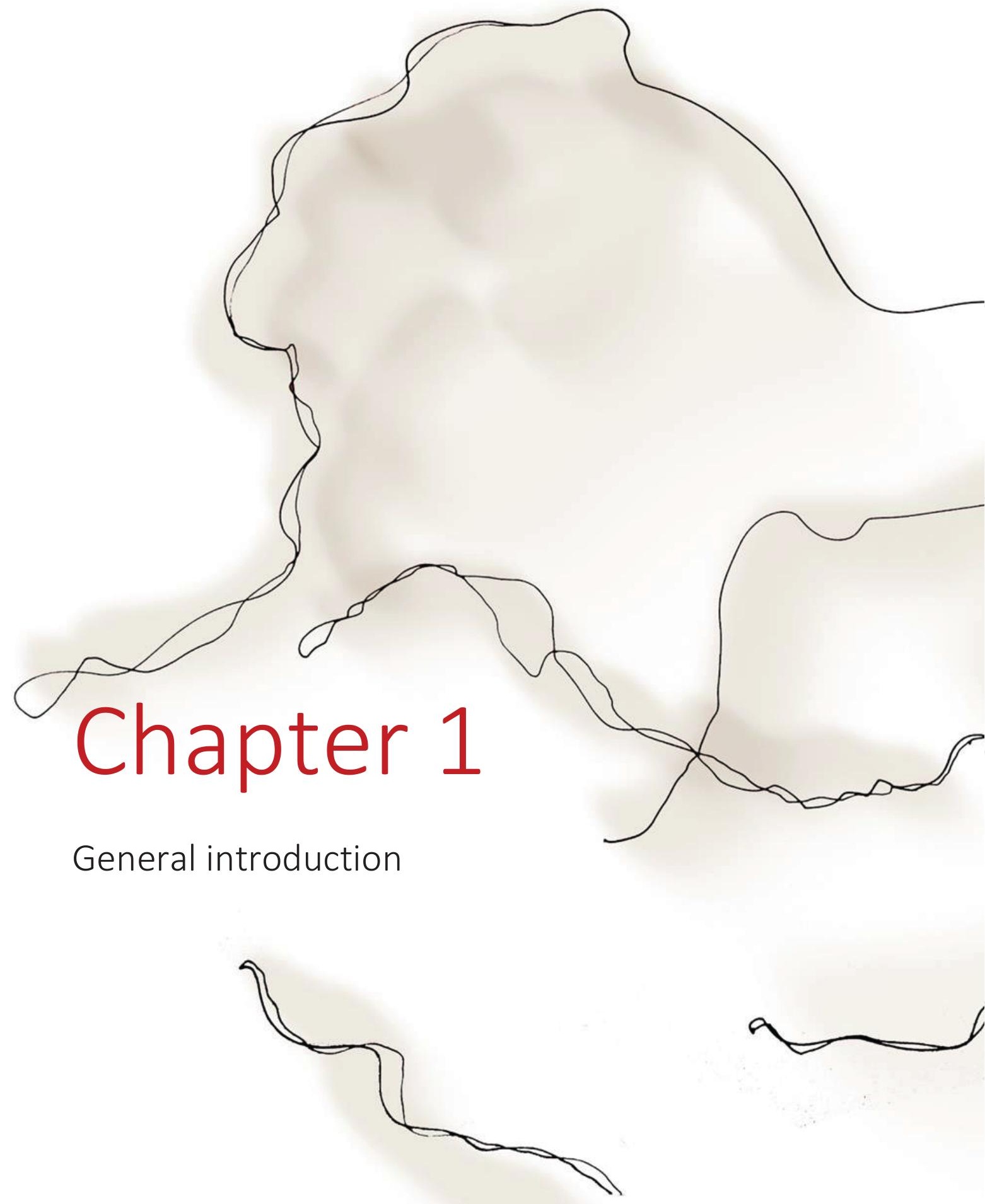


$$
=3
$$




\section{Psychotic disorders and the psychosis phenotype}

Psychotic disorder refers to a mental state characterised by severe distortion in the perception of reality and disruption of thought processes. Several psychotic disorders can be distinguished. The best known and most severe psychotic disorder is schizophrenia, with an estimated global lifetime prevalence of approximately 4.0/1,000 (2). For psychotic disorders in general (including non-affective and affective psychotic disorders, substance-induced psychotic disorders, and psychotic disorder due to general medication), the lifetime prevalence exceeds $3 \%$ (3). Symptoms of psychotic disorders can be divided into five main categories: the positive-symptom dimension, the negative-symptom dimension, cognitive symptoms, depressive symptoms and manic symptoms (4). The positive-symptom dimension includes hallucinations (i.e., sensory experiences without an external stimulus) and delusions. The negative symptom dimension is characterised by a lack of motivation and a reduction in spontaneous and social withdrawal. The cognitive dimension encompasses difficulties with memory, attention and executive functioning. Affective dysregulation gives rise to depressive and manic symptoms.

The syndrome-oriented categorical representation of psychotic disorders is generally thought to be dichotomous: a distinction is made between the presence or absence of symptoms. This may not be an accurate reflection of the psychosis phenotype in nature, however. Psychotic experiences - in the form of attenuated reality distortion, including perceptual abnormalities and persecutory ideas - can be found in the general population (5). The psychosis phenotype, therefore, may be seen as a dimensional phenomenon on a continuum with normality. 
Subclinical psychotic experiences are mostly transient in nature (6-8), but in some individuals, these experiences may be predictive of a psychotic disorder $(8,9)$.

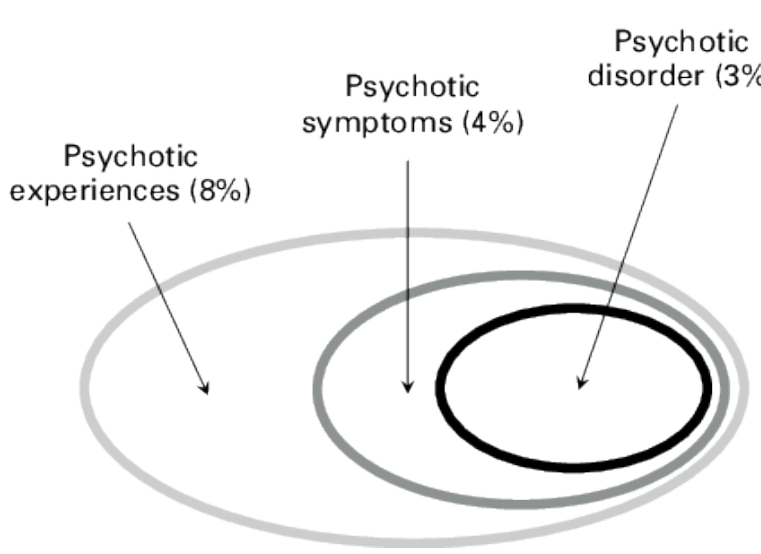

Psychosis: variation along a continuum (1)
According to the psychosis proneness-persistenceimpairment model (1), transitory developmental psychosis expression may become persistent and clinically relevant. This depends on developmental, environmental and psychopathological factors (1, 10). Furthermore, it has been

suggested that genetic $(11)$ and environmental risks $(12,13)$ for psychosis show etiological continuity across different levels of psychosis manifestation. The environment may influence symptoms of psychotic disorders, and symptoms affect one another in causal networks $(12,14,15)$. These interactions may lead to a psychopathological state characterised by severe psychotic experiences (12).

However, much additional research is required to fully comprehend these complex interactions between (unidimensional) mechanisms. In addition, the exact nature of the continuum assumption is still to be further elucidated. The main focus of the present thesis is the integration of known mechanisms of psychotic disorders (i.e., neurophysiological changes and genetic and environmental risk factors) within the expression of psychotic experiences (auditory illusions) along a continuum of expression.

\section{Neurophysiology}

Modern neuroimaging techniques have increased the understanding of brain alterations associated with psychotic disorders. Structural brain-image studies have 
found evidence for a decrease in grey and white matter and an enlargement of ventricular space in psychotic disorders (16). Associations have been found between auditory hallucinations and grey matter loss in the superior temporal regions (17) and the insula (18). Neurochemical studies have found some evidence for an association between psychotic disorders and dopamine dysregulation (19). It has been demonstrated that these alterations in brain structure and neurochemistry may lead to altered brain functioning, which can be observed with functional magnetic resonance imaging and electrophysiological techniques. Altered network responses in different regions (e.g., the prefrontal cortex, temporal lobe and subcortical regions) may be found in patients with psychotic disorders depending on the specific tasks (20). Studies into event-related potential suggest impairment of mismatch negativity in psychotic disorders (21). In addition, evidence has been found for significant reduction of the $P_{300}$ amplitude, a delayed latency of the $P_{300}$ and an altered $P_{50}$ suppression $(22,23)$. These findings indicate that patients tend to have a diminished brain response to new stimuli and a decreased ability to respond to repeated stimuli. Psychotic disorders, then, are probably associated with alterations in brain function.

In addition, neuropsychological alterations have also been reported in individuals with subclinical expression of psychosis. Although the research into subclinical psychosis is in its early stages, suggestions have been made that a decrease in grey matter integrity is already detectable in those with subclinical expression of psychosis (24). The dopamine hypothesis holds that psychosis is associated with an increased presynaptic dopamine availability and dopamine release. It has been suggested that dopamine dysregulation may also be present in individuals with subclinical expression who develop a psychotic illness (25). Furthermore, evidence has been found that relatives of patients with psychotic disorders may also exhibit deficits in $\mathrm{P}_{50}$ suppression, $\mathrm{P}_{300}$ amplitude, $\mathrm{P}_{300}$ latency and mismatch negativity (26). There may, however, be insufficient agreement among studies $(20,24,25)$. 


\section{Genetic variation}

Much research has been conducted with the aim of unravelling the genetic variation contributing to the risk of developing psychotic disorders. In this area of research, two methods can be distinguished: searching for indirect evidence of genetic influence using family, twin and adoption studies; and determining the chromosomal location of DNA risk variants using linkage and association studies. Strong evidence has been reported for familial influence, as siblings of patients have an increased risk (relative risk $=9.0$ ) of developing psychotic disorders (27). Moreover, adopted children whose biological parents were diagnosed with psychotic disorders also show an elevated risk (27). The reported clustering of clinical and subclinical psychosis expression in patients and relatives (resemblance in level of psychosis phenotype serving as an indicator of shared genetic risk) implies that there may be a degree of aetiological continuity of genetic risk across the spectrum of expression (1).

Twin studies suggest that the concordance rate for psychotic disorders for monozygotic twins is considerably higher $(\approx 45-50 \%)$ than for dizygotic twins $(\approx 5-10 \%)$ (28). However, the fact that around $50 \%$ of the monozygotic co-twins were unaffected, despite sharing $100 \%$ of the genes, indicates that non-inherited risk factors also play an important role. Estimated heritability for psychotic disorders is around $60-80 \%$ (27-29). On the basis of this indirect evidence of genetic risk, molecular genetic studies have attempted to localise DNA risk variants contributing to psychosis risk. Although genetic risk variance ranges from common to extremely rare, estimates suggest that a third of the genetic risk is indexed by common alleles genotyped through arrays in genome-wide association studies (30). Each marker, however, individually explains a small proportion of the genetic variation with insignificant predictive power. For this reason, researchers have developed polygenetic risk scores by summarising risk variants across many associated loci into quantitative scores (31). The Schizophrenia Working Group of the Psychiatric Genomics Consortium estimated that, despite the small effect of single loci, the cumulative effect of loci expressed a polygenic risk score explaining approximately 
$18 \%$ of the variance between patients with psychotic disorders and controls (30). As the estimated heritability of psychiatric disorders is much higher, however, a large proportion of the variance remains unaccounted for.

\section{Environment}

Although the heritability of psychotic disorders is high, the environment also appears to affect the risk of disorders. Environmental risk factors can be categorised as psychosocial, biological and physical, experienced from early life through childhood and maturation (32). There is some evidence that early-life factors play a role in shaping risk for later psychotic disorders, including obstetric complications (33), prenatal infection $(34)$, maternal stress $(35,36)$ and maternal malnutrition $(37)$. There is more evidence for postnatal environmental risk factors affecting psychosis risk. Thus, childhood adversity (38) and urbanicity (39) during childhood and adolescence are associated with psychosis. Other postnatal risk factors include belonging to a minority group or migrant group (40), cannabis use $(41,42)$ and adverse life events (43). In summary, risk factors for psychotic disorders may persist throughout the life course. However, these factors might not influence psychosis independently; indeed, it is plausible that they add to and interact with one another $(44,45)$. This thesis will focus on how adverse events experienced throughout the life course (during childhood and later life) may affect the risk for psychotic experiences.

\section{Childhood adversity}

Several studies have suggested that adverse childhood events are related to an increased risk of psychotic disorders (38, 46-49). Childhood adversity comprises physical, emotional and sexual abuse, physical and emotional neglect, bullying and parental death. The influence of childhood adversity is substantial: a meta-analytic summary odds ratio of 2.8 and a population-attributable risk of $30 \%$ has been reported (38). Evidence suggests a dose-response relationship between childhood adversity and psychotic disorders (50). In addition, there is evidence for a similar 
association with the subclinical phenotype. For example, in a sample of children reporting subclinical auditory hallucinations, $86 \%$ experienced traumatic and stressful events (51). Furthermore, it has been suggested that adverse events are associated with the persistence of psychotic experiences (52).

Several psychological and biological theories for the association between adverse events in childhood and psychosis have been proposed. At the psychological level, the focus has been on cognitive and attributional processes. Exposure to childhood trauma may lead to negative thoughts about the self, which can subsequently lead to distressing interpretations of daily events and possibly to psychotic experiences (53). Another theory is that abuse flashbacks are involved in the ontogenesis of delusions (54). Biological models focus on the neurodevelopmental effects of traumatic events, particularly damage to the stress-regulation mechanisms in the hypothalamicpituitary-adrenal (HPA) axis. Childhood trauma is associated with HPA-axis dysregulation (55) and structural brain changes such as hippocampal damage, cerebral atrophy, ventricular enlargement and reversed cerebral asymmetry (56). Furthermore, compared to children who have not experienced adversity, those who have tend to be related to stronger negative emotions and psychotic intensity in reaction to daily life stressors in adulthood (57). This is supported by the hypothesis that stress is associated with blunted cortical dopaminergic release, which reduces inhibition of mesostriatal dopamine release, resulting in an increased dopamine response to stress (58).

\section{Life events}

It has been suggested that childhood adversity makes an individual more likely to develop a psychotic disorder. In addition, during adolescence and adult life, an individual may experience various life events causing a substantial (positive or negative) impact on his or her life. These life events may increase or decrease the risk of developing a psychotic disorder, particularly by precipitating an existing developmental vulnerability towards the onset of symptoms (i.e., they may 'tip' 
subclinical psychopathology towards a clinical phenotype). However, while evidence has accumulated for the influence of childhood trauma on psychotic disorders, the relation to subsequent life events has received less attention. A meta-analysis showed an overall odds ratio of 3.2 for life events (43). Varying studies have been published regarding the length of time before of onset of psychotic disorders on which life events may exert their influence, ranging between 3 months (59) and 3.6 years (60). There are some indications that intrusive events may be particularly relevant for the development of psychosis $(61,62)$. In one study, associations with life events were also found in subclinical populations; individuals with psychotic experiences were more likely to report recent life events versus those without (43).

Theories of the mechanisms that may account for the association between life events and increased risk of psychotic disorders are similar to theories of childhood adversity: threatening and intrusive events may influence perceptions of the external world, resulting in a continuum from suspiciousness to paranoia to delusions; and stressinduced dysregulation of the HPA-axis may give rise to alterations in dopaminergic system signalling (43). Furthermore, evidence has been found for a possible correlation or interaction between childhood adversity and life events adversity in psychosis. Childhood events may influence psychosis expression by either increasing risk of exposure to later adverse events (correlation) and/or enhancing sensitivity to psychogenetic effects of later adversity (interaction) (60). Recently, evidence has been found for other possible relationships: psychotic experiences and childhood adversity may represent competing risk factors for adult adversity, and both childhood adversity and adult adversity are independently associated with increased risk of psychotic experiences (63). In conclusion, adverse events and psychotic disorders are probably interconnected throughout the life course.

\section{Gene-environment interaction}

As illustrated above, the aetiology of psychotic disorders is complex and multifactorial. Although high heritability estimates indicate a strong genetic influence, 
environmental risk factors also appear to play an important role. According to the vulnerability-stress model, genetic factors make individuals selectively vulnerable to environmental risks (64). It has been suggested that interactions have to be considered in a time-dependent model, with potentially different effects according to the developmental stage in the life course (13). Molecular studies suggest that environmental factors may also affect DNA sequence or DNA methylation. It may be hypothesised that the presence or absence of psychotic-disorder risk is a result of an overall effect that is grounded in epigenetic mechanisms: pre- and postnatal factors around birth and alterations due to internal and external environmental factors over the life course (65). There are a number of environmental factors associated with psychotic disorders for which a mechanism of gene-environment interaction is proposed (i.e., possibly interacting at the level of epigenetic mechanisms): obstetric complications, urbanicity, childhood trauma, cannabis use, migration and traumatic events later in life. It is possible that the effect of the environment and genes in isolation may be small compared to the effect mediated through gene-environment interactions (66).

Regarding the interaction between genes and childhood adversity, mixed results have been found. Tienari and colleagues found that the association between altered family communication and development of psychotic disorders is dependent on the level of genetic risk (67). Other 'patient-sibling studies' failed to demonstrate a significant interaction (68-71). Studies investigating molecular-genetic interaction with childhood trauma have found subtle evidence for an association with brain-derived neurotrophic factor (72), the serotonin transporter gene (73) and FKBP5 SNPs (74). The recent EUGEI study was the largest study to date investigating gene-environment interaction including childhood adversity (75). This study presented evidence of interaction between childhood adversity and polygenic molecular-genetic risk for schizophrenia $(76,77)$. Shakoor and colleagues investigated the interaction between genes and life events and found that the relationship between life events and psychotic symptoms was moderated by genetic risk (78). 


\section{Measures of psychotic experiences}

A psychosis continuum implies that the same symptoms can be measured in both healthy and ill individuals, shifting towards a more intense, more frequent or more clinical phenotype (1). In this regard, it has been argued that the development from subtle psychotic experiences (e.g., illusions) to clinically relevant psychotic symptoms (e.g., hallucinations) may originate from converging neurocognitive processes (79). It has been proposed that the altered meaning or emotional value of internal representations or external objects (80) is associated with alterations in top-down (perceptual expectation, prior knowledge and mental imagery) and bottom-up processing (external sensory input) (81). Neuropsychological theories argue that hallucinations (distorted perceptions in the absence of a stimulus) may result from giving top-down processing a higher priority at the expense of bottom-up information $(82,83)$. In this context, illusions (misinterpretations of an external stimulus) may be related to altered top-down processing of sensory information, presumably by increasing perceptual expectations (83). Psychotic experiences in the general population are thought to be transitory but nevertheless reflecting stable differences in the level of psychosis proneness, below the level of illness (84). It may be hypothesised that non-clinical differences in the expression of psychotic symptoms are associated with the tendency to express psychotic disorders and thus may represent a 'psychometric' (i.e., phenotypically measurable) indicator of psychosis liability. For example, several experimental assessments have been conducted in which meaning is assigned to a meaningless sound.

Hoffman and colleagues assessed the extraction of words from a multispeaker babble stimulus (85). An increase in the speech illusions score (counted as number of words) signals increased risk of psychotic disorders in individuals with prodromal signs of psychosis (82). A related variant is the speech-discrimination task in which participants must decide whether a spoken word is the same as the previously presented word embedded in noise (86). During the White Christmas task, participants listen to white noise and indicate whether they hear the White Christmas 
song, without this song actually being presented (87). Another approach is the experiment in which participants listen to music fragments embedded in noise that contains gaps of only pink noise. Individuals must indicate whether they hear the song during the gaps (88). Leske and colleagues have used the Zwicker tone illusion to investigate auditory afterimage. Participants are presented with fragments of notch-

filtered white noise, after which they must rate whether the noise is ongoing (89).

Galdos and colleagues developed an extended version of the assessments measuring 'false-positive meaning' assigned to a stimulus (90). The white noise task allows the testing of large samples and is not dependent on (working) memory or song familiarity. In addition, an attempt was made to increase the sensitivity of the task by using both pure white noise fragments and (both clearly and barely audible) words embedded in noise. Finally, a dimension for affective salience was incorporated. Experimental research of Holt and colleagues showed that patients diagnosed with schizophrenia and with presence of delusions were more likely to assign affective meaning to neutral stimuli than were non-delusional patients and healthy participants (91).

\section{The white noise task}

In the white noise task, designed by Galdos and colleagues, participants listen to three types of stimuli presented across 75 fragments in random order: white noise only; white noise mixed with barely audible speech; and white noise mixed with clearly audible speech with positive, negative or neutral content. The second and third stimuli are incorporated into the design to create a higher level of expectancy. After the ending of each fragment, participants are asked to respond by pushing one of five buttons describing what they heard: (i) clearly audible speech with positive content; (ii) clearly audible speech with negative content; (iii) clearly audible speech with neutral content; (iv) no speech; or (v) speech, but uncertain whether the content was positive, negative or neutral. Galdos and colleagues defined a speech illusion as a white noise fragment perceived as positive, negative or neutral speech (option 1, 2 or 
3). In this way, for each participant, the total number of speech illusions, varying from 0 to 25 , can be calculated. A dichotomised score is calculated of the occurrence of any (at least one) speech illusion.

Catalan and colleagues also used the white noise task to elicit speech illusions (92). However, they defined speech illusions as white noise in which any sound is heard (option 1, 2, 3, or 5). To exclude possible false positive results, they calculated a more conservative dichotomised score of the total number of speech illusions, which included two or more perceived white noise speech illusions.

A higher prevalence of white noise speech illusions was found in psychotic patients than in their relatives and the general population: $30 \%$ in patients with psychotic disorders, $14 \%$ in siblings of the patients and $9 \%$ in the general population (90), indicating that white noise speech illusions reflect individual differences in risk for psychotic disorders. Catalan and colleagues replicated the study and confirmed these findings at the level of case-control comparison (no siblings were included in the study) (92). However, the question remains whether the white noise task can be used to detect alterations in perception in the non-clinical population.

\section{Mechanisms of the white noise task}

\section{Electroencephalography}

Measurement of electroencephalography (EEG) activity may be useful to gain more insight into the neurocognitive processes underlying perceptual experiences and alterations associated with schizophrenia risk. Sensory input or other cognitive processes stimulate synaptic activity, generating a subtle electrical impulse referred to as a postsynaptic potential. The burst of a single neuron is hard to detect. However, the sum of synchronously active parallel-oriented neurons may lead to cortical field potentials strong enough to be detectable on scalp sites. Brain activity also occurs when the cortex is at rest. Once the cortex has a task to perform, the electrical activity desynchronises. After the task has been completed, the electrical activity returns to its 
resting state (93). To extract task-specific changes in the ongoing EEG, data need to be time-locked and averaged across several stimuli. Two features of the EEG are relevant in this regard: an event-related potential reflects EEG changes as a response to a specific event, and EEG changes can be extracted by averaging frequency bands. In the present thesis, the EEG frequency bands are analysed during the whole fragment.

Electroencephalography provides a non-invasive and painless method to measure neural activity. It is known that the spatial resolution of EEG is low, limiting a clear interpretation of the exact localisation of the origin of the cortical activity (except for 64-channel EEG). On the other hand, the strength of an EEG measurement is the high temporal resolution, enabling more insight to be gained into the temporal processing of a stimulus (94). Since the white noise task is a series of 75 consecutive sound fragments, EEG is a suitable method to gain more insight into speech illusions.

\section{CAPE scale}

Both the Community Assessment of Psychic Experiences (CAPE) and the Structured Interview for Schizotypy-Revised (SIS-R) are examples of instruments to measure subclinical psychotic experiences in the non-clinical population. There are several differences between these instruments. First, the CAPE is a self-report scale whereas the SIS-R is an interview-based measure. Second, the instruments differ in their approach to the measurement of psychotic experiences. Whereas the SIS-R is based on the assumption that experiences are presented in attenuated and slightly altered form in the subclinical population, the CAPE assumes that symptoms in the general population are basically comparable to those seen in clinical patients. Both the CAPE and the SIS-R are reliable and valid instruments, and their outcomes are strongly correlated. As the application of a self-report measure is more cost-effective than a structured interview (95), the CAPE was used in this thesis to observationally measure psychotic experiences. 


\section{Aims of this thesis}

White noise speech illusions reflect individual differences in risk of psychotic disorders $(90,92)$. Given that only $30 \%$ of patients with psychotic disorders show an elevated rate of speech illusions, the white noise task cannot be considered as a diagnostic tool. However, the question is whether speech illusions indicate increased risk of psychotic disorders. More insight is therefore necessary into the mechanisms underlying the white noise task. Evidence suggests that neurophysiological changes and genetic and environmental risk factors for psychotic disorders are present in individuals at increased risk. When white noise speech illusions indeed signal increased risk, it may be hypothesised that speech illusions lie on the causal pathway from psychosis risk factors to phenotypic expression.

The first aim of this thesis is to investigate the underlying neurophysiological mechanism of white noise speech illusions in the general population. Second, this thesis examines whether white noise speech illusions are associated with known risks for psychosis, such as childhood trauma and life events. Finally, it investigates whether experimentally elicited white noise speech illusions and self-reported psychotic experiences (measured with the CAPE positive scale) tap into the same dimensions of psychotic disorder.

In the second chapter, the cortical mechanisms of speech illusions are investigated in the general population. The goal is to examine whether cortical oscillations during the white noise fragment of speech illusions differ from a correctly judged white noise fragment. Following earlier findings that auditory illusions may be associated with reduced alpha activity $(88,89)$, the main focus is on changes in the alpha band.

The third chapter examines EEG oscillatory activity before white noise fragments. More specifically, it is investigated whether baseline alpha activity is associated with the interpretation of a noise fragment (i.e., speech illusion or correctly judged fragment). 
The fourth chapter investigates in the general population the association between experimentally elicited white noise speech illusions and self-reported psychotic experiences. Assuming that both measures tap into the same phenotypic dimension underlying psychotic disorders, a positive correlation between both measures is expected. In addition, this chapter examines to what degree both measures show the same pattern of association with risk factors for psychotic disorders. This thesis focuses on the exposure to adverse events over the life course (i.e., childhood adversity and life events).

In the fifth chapter, the rate of white noise speech illusions is investigated in patients with psychotic disorders, siblings of patients and the general population.

Furthermore, this chapter examines whether this rate is dependent on known environmental risks factors (i.e., childhood adversity and life events) and level of known endophenotypic dimensions of psychotic disorders (i.e., the CAPE positive scale and cognitive ability).

The sixth chapter provides a general critical retrospect of the studies discussed above. In addition, the clinical implications and recommendations for further research are provided. 


\section{References}

1. van Os J, Linscott RJ, Myin-Germeys I, Delespaul P, Krabbendam L. A systematic review and meta-analysis of the psychosis continuum: evidence for a psychosis pronenesspersistence-impairment model of psychotic disorder. Psychol Med. 2009;39(2):17995.

2. Saha S, Chant D, Welham J, McGrath J. A systematic review of the prevalence of schizophrenia. PLoS Med. 2005;2(5):e141.

3. Perala J, Suvisaari J, Saarni SI, Kuoppasalmi K, Isometsa E, Pirkola S, et al. Lifetime prevalence of psychotic and bipolar I disorders in a general population. Arch Gen Psychiatry. 2007;64(1):19-28.

4. van Os J, Kapur S. Schizophrenia. Lancet. 2009;374(9690):635-45.

5. Verdoux H, Van Os J. Psychotic symptoms in non-clinical populations and the continuum of psychosis. Schizophr Res. 2002;54(1-2):59-65.

6. Dhossche D, Ferdinand R, Van der Ende J, Hofstra MB, Verhulst F. Diagnostic outcome of self-reported hallucinations in a community sample of adolescents. Psychol Med. 2002;32(4):619-27.

7. Dominguez MD, Wichers M, Lieb R, Wittchen HU, van Os J. Evidence that onset of clinical psychosis is an outcome of progressively more persistent subclinical psychotic experiences: an 8-year cohort study. Schizophr Bull. 2011;37(1):84-93.

8. Wiles NJ, Zammit S, Bebbington P, Singleton N, Meltzer H, Lewis G. Self-reported psychotic symptoms in the general population: results from the longitudinal study of the British National Psychiatric Morbidity Survey. Br J Psychiatry. 2006;188:519-26.

9. Poulton R, Caspi A, Moffitt TE, Cannon M, Murray R, Harrington H. Children's selfreported psychotic symptoms and adult schizophreniform disorder: A 15-year longitudinal study. Arch Gen Psychiatry. 2000;57(11):1053-8.

10. Cougnard A, Marcelis M, Myin-Germeys I, De Graaf R, Vollebergh W, Krabbendam L, et al. Does normal developmental expression of psychosis combine with environmental risk to cause persistence of psychosis? A psychosis pronenesspersistence model. Psychol Med. 2007;37(4):513-27.

11. van Os J, van der Steen Y, Islam MA, Guloksuz S, Rutten BP, Simons CJ, et al. Evidence that polygenic risk for psychotic disorder is expressed in the domain of neurodevelopment, emotion regulation and attribution of salience. Psychol Med. 2017;47(14):2421-37.

12. Guloksuz S, van Nierop M, Lieb R, van Winkel R, Wittchen HU, van Os J. Evidence that the presence of psychosis in non-psychotic disorder is environment-dependent and mediated by severity of non-psychotic psychopathology. Psychol Med. 2015;45(11):2389-401.

13. van Os J, Kenis G, Rutten BP. The environment and schizophrenia. Nature. 2010;468(7321):203-12. 
14. Borsboom D, Cramer AO. Network analysis: an integrative approach to the structure of psychopathology. Annu Rev Clin Psychol. 2013;9:91-121.

15. van Os J. The dynamics of subthreshold psychopathology: implications for diagnosis and treatment. Am J Psychiatry. 2013;170(7):695-8.

16. Olabi B, Ellison-Wright I, McIntosh AM, Wood SJ, Bullmore E, Lawrie SM. Are there progressive brain changes in schizophrenia? A meta-analysis of structural magnetic resonance imaging studies. Biol Psychiatry. 2011;70(1):88-96.

17. Modinos G, Costafreda SG, van Tol MJ, McGuire PK, Aleman A, Allen P. Neuroanatomy of auditory verbal hallucinations in schizophrenia: a quantitative meta-analysis of voxel-based morphometry studies. Cortex. 2013;49(4):1046-55.

18. Palaniyappan L, Balain V, Radua J, Liddle PF. Structural correlates of auditory hallucinations in schizophrenia: a meta-analysis. Schizophr Res. 2012;137(1-3):169-73.

19. Howes OD, Kapur S. The dopamine hypothesis of schizophrenia: version III--the final common pathway. Schizophr Bull. 2009;35(3):549-62.

20. Fusar-Poli P, Perez J, Broome M, Borgwardt S, Placentino A, Caverzasi E, et al. Neurofunctional correlates of vulnerability to psychosis: a systematic review and meta-analysis. Neurosci Biobehav Rev. 2007;31(4):465-84.

21. Erickson MA, Ruffle A, Gold JM. A Meta-Analysis of Mismatch Negativity in Schizophrenia: From Clinical Risk to Disease Specificity and Progression. Biol Psychiatry. 2016;79(12):980-7.

22. Patterson JV, Hetrick WP, Boutros NN, Jin Y, Sandman C, Stern H, et al. P50 sensory gating ratios in schizophrenics and controls: a review and data analysis. Psychiatry Res. 2008;158(2):226-47.

23. Qiu YQ, Tang YX, Chan RC, Sun XY, He J. P300 aberration in first-episode schizophrenia patients: a meta-analysis. PLoS One. 2014;9(6):e97794.

24. Dietsche B, Kircher T, Falkenberg I. Structural brain changes in schizophrenia at different stages of the illness: A selective review of longitudinal magnetic resonance imaging studies. Aust N Z J Psychiatry. 2017;51(5):500-8.

25. Howes O, McCutcheon R, Stone J. Glutamate and dopamine in schizophrenia: an update for the 21st century. J Psychopharmacol. 2015;29(2):97-115.

26. Earls HA, Curran T, Mittal V. A Meta-analytic Review of Auditory Event-Related Potential Components as Endophenotypes for Schizophrenia: Perspectives From FirstDegree Relatives. Schizophr Bull. 2016;42(6):1504-16.

27. Lichtenstein P, Yip BH, Bjork C, Pawitan Y, Cannon TD, Sullivan PF, et al. Common genetic determinants of schizophrenia and bipolar disorder in Swedish families: a population-based study. Lancet. 2009;373(9659):234-9.

28. Cardno AG, Gottesman, II. Twin studies of schizophrenia: from bow-and-arrow concordances to star wars Mx and functional genomics. Am J Med Genet. 2000;97(1):12-7.

29. Sullivan PF, Kendler KS, Neale MC. Schizophrenia as a complex trait: evidence from a meta-analysis of twin studies. Arch Gen Psychiatry. 2003;60(12):1187-92. 
30. Schizophrenia Working Group of the Psychiatric Genomics C. Biological insights from 108 schizophrenia-associated genetic loci. Nature. 2014;511(7510):421-7.

31. Vassos E, Di Forti M, Coleman J, Iyegbe C, Prata D, Euesden J, et al. An Examination of Polygenic Score Risk Prediction in Individuals With First-Episode Psychosis. Biol Psychiatry. 2017;81(6):470-7.

32. Dean K, Murray RM. Environmental risk factors for psychosis. Dialogues Clin Neurosci. 2005; 7(1):69-80.

33. Cannon M, Jones PB, Murray RM. Obstetric complications and schizophrenia: historical and meta-analytic review. Am J Psychiatry. 2002;159(7):1080-92.

34. Brown AS, Derkits EJ. Prenatal infection and schizophrenia: a review of epidemiologic and translational studies. Am J Psychiatry. 2010;167(3):261-80.

35. Malaspina D, Corcoran C, Kleinhaus KR, Perrin MC, Fennig S, Nahon D, et al. Acute maternal stress in pregnancy and schizophrenia in offspring: a cohort prospective study. BMC Psychiatry. 2008;8:71.

36. van Os J, Selten JP. Prenatal exposure to maternal stress and subsequent schizophrenia. The May 1940 invasion of The Netherlands. Br J Psychiatry. 1998;172:324-6.

37. Brown AS, Susser ES. Prenatal nutritional deficiency and risk of adult schizophrenia. Schizophr Bull. 2008;34(6):1054-63.

38. Varese F, Smeets F, Drukker M, Lieverse R, Lataster T, Viechtbauer W, et al. Childhood adversities increase the risk of psychosis: a meta-analysis of patient-control, prospective- and cross-sectional cohort studies. Schizophr Bull. 2012;38(4):661-71.

39. Krabbendam L, van Os J. Schizophrenia and urbanicity: a major environmental influence--conditional on genetic risk. Schizophr Bull. 2005;31(4):795-9.

40. Cantor-Graae E, Selten JP. Schizophrenia and migration: a meta-analysis and review. Am J Psychiatry. 2005;162(1):12-24.

41. Hall W, Degenhardt L. Cannabis use and the risk of developing a psychotic disorder. World Psychiatry. 2008;7(2):68-71.

42. Moore TH, Zammit S, Lingford-Hughes A, Barnes TR, Jones PB, Burke M, et al. Cannabis use and risk of psychotic or affective mental health outcomes: a systematic review. Lancet. 2007;370(9584):319-28.

43. Beards S, Gayer-Anderson C, Borges S, Dewey ME, Fisher HL, Morgan C. Life events and psychosis: a review and meta-analysis. Schizophr Bull. 2013;39(4):740-7.

44. Guloksuz S, van Os J, Rutten BPF. The Exposome Paradigm and the Complexities of Environmental Research in Psychiatry. JAMA Psychiatry. 2018;75(10):985-6.

45. Pries LK, Lage-Castellanos A, Delespaul P, Kenis G, Luykx JJ, Lin BD, et al. Estimating Exposome Score for Schizophrenia Using Predictive Modeling Approach in Two Independent Samples: The Results From the EUGEI Study. Schizophr Bull. 2019;45(5):960-5.

46. Bebbington PE, Bhugra D, Brugha T, Singleton N, Farrell M, Jenkins R, et al. Psychosis, victimisation and childhood disadvantage: evidence from the second British National Survey of Psychiatric Morbidity. Br J Psychiatry. 2004;185:220-6. 
47. Heins M, Simons C, Lataster T, Pfeifer S, Versmissen D, Lardinois M, et al. Childhood trauma and psychosis: a case-control and case-sibling comparison across different levels of genetic liability, psychopathology, and type of trauma. Am J Psychiatry. 2011;168(12):1286-94.

48. Janssen I, Krabbendam L, Bak M, Hanssen M, Vollebergh W, de Graaf R, et al. Childhood abuse as a risk factor for psychotic experiences. Acta Psychiatr Scand. 2004;109(1):38-45.

49. Lataster T, van Os J, Drukker M, Henquet C, Feron F, Gunther N, et al. Childhood victimisation and developmental expression of non-clinical delusional ideation and hallucinatory experiences: victimisation and non-clinical psychotic experiences. Soc Psychiatry Psychiatr Epidemiol. 2006;41(6):423-8.

50. Read J, van Os J, Morrison AP, Ross CA. Childhood trauma, psychosis and schizophrenia: a literature review with theoretical and clinical implications. Acta Psychiatr Scand. 2005;112(5):330-50.

51. Escher S, Romme M, Buiks A, Delespaul P, Van Os J. Independent course of childhood auditory hallucinations: a sequential 3-year follow-up study. Br J Psychiatry Suppl. 2002;43:s10-8.

52. Trotta A, Murray RM, Fisher HL. The impact of childhood adversity on the persistence of psychotic symptoms: a systematic review and meta-analysis. Psychol Med. 2015;45(12):2481-98.

53. Larkin W, Read J. Childhood trauma and psychosis: evidence, pathways, and implications. J Postgrad Med. 2008;54(4):287-93.

54. Read J, Agar K, Argyle N, Aderhold V. Sexual and physical abuse during childhood and adulthood as predictors of hallucinations, delusions and thought disorder. Psychol Psychother. 2003;76(Pt 1):1-22.

55. Klaassens ER. Bouncing back - trauma and the HPA-axis in healthy adults. Eur J Psychotraumatol. 2010;1.

56. Read J, Perry BD, Moskowitz A, Connolly J. The contribution of early traumatic events to schizophrenia in some patients: a traumagenic neurodevelopmental model. Psychiatry. 2001;64(4):319-45.

57. Lardinois M, Lataster T, Mengelers R, Van Os J, Myin-Germeys I. Childhood trauma and increased stress sensitivity in psychosis. Acta Psychiatr Scand. 2011;123(1):28-35.

58. Howes OD, McCutcheon R, Owen MJ, Murray RM. The Role of Genes, Stress, and Dopamine in the Development of Schizophrenia. Biol Psychiatry. 2017;81(1):9-20.

59. Brown GW, Birley JL. Crises and life changes and the onset of schizophrenia. J Health Soc Behav. 1968;9(3):203-14.

60. Lataster J, Myin-Germeys I, Lieb R, Wittchen HU, van Os J. Adversity and psychosis: a 10-year prospective study investigating synergism between early and recent adversity in psychosis. Acta Psychiatr Scand. 2012;125(5):388-99.

61. Dohrenwend BP, Levav I, Shrout PE, Link BG, Skodol AE, Martin JL. Life stress and psychopathology: progress on research begun with Barbara Snell Dohrenwend. Am J Community Psychol. 1987;15(6):677-715. 
62. Raune D, Kuipers E, Bebbington P. Stressful and intrusive life events preceding first episode psychosis. Epidemiol Psichiatr Soc. 2009;18(3):221-8.

63. Honings S, Drukker M, Ten Have M, de Graaf R, van Dorsselaer S, van Os J. The interplay of psychosis and victimisation across the life course: a prospective study in the general population. Soc Psychiatry Psychiatr Epidemiol. 2017;52(11):1363-74.

64. Nuechterlein KH, Dawson ME. A heuristic vulnerability/stress model of schizophrenic episodes. Schizophr Bull. 1984;10(2):300-12.

65. Oh G, Petronis A. Environmental studies of schizophrenia through the prism of epigenetics. Schizophr Bull. 2008;34(6):1122-9.

66. van Os J, Rutten BP, Poulton R. Gene-environment interactions in schizophrenia: review of epidemiological findings and future directions. Schizophr Bull. 2008;34(6):1066-82.

67. Tienari P, Wynne LC, Sorri A, Lahti I, Laksy K, Moring J, et al. Genotype-environment interaction in schizophrenia-spectrum disorder. Long-term follow-up study of Finnish adoptees. Br J Psychiatry. 2004;184:216-22.

68. Arseneault L, Cannon M, Fisher HL, Polanczyk G, Moffitt TE, Caspi A. Childhood trauma and children's emerging psychotic symptoms: A genetically sensitive longitudinal cohort study. Am J Psychiatry. 2011;168(1):65-72.

69. Fisher HL, McGuffin P, Boydell J, Fearon P, Craig TK, Dazzan P, et al. Interplay between childhood physical abuse and familial risk in the onset of psychotic disorders. Schizophr Bull. 2014;40(6):1443-51.

70. Trotta A, Di Forti M, lyegbe C, Green P, Dazzan P, Mondelli V, et al. Familial risk and childhood adversity interplay in the onset of psychosis. BJPsych Open. 2015;1(1):6-13.

71. Wigman JT, van Winkel R, Ormel J, Verhulst FC, van Os J, Vollebergh WA. Early trauma and familial risk in the development of the extended psychosis phenotype in adolescence. Acta Psychiatr Scand. 2012;126(4):266-73.

72. Alemany S, Arias B, Aguilera M, Villa H, Moya J, Ibanez MI, et al. Childhood abuse, the BDNF-Val66Met polymorphism and adult psychotic-like experiences. Br J Psychiatry. 2011;199(1):38-42.

73. Aas M, Djurovic S, Athanasiu L, Steen NE, Agartz I, Lorentzen S, et al. Serotonin transporter gene polymorphism, childhood trauma, and cognition in patients with psychotic disorders. Schizophr Bull. 2012;38(1):15-22.

74. Collip D, Myin-Germeys I, Wichers M, Jacobs N, Derom C, Thiery E, et al. FKBP5 as a possible moderator of the psychosis-inducing effects of childhood trauma. $\mathrm{Br} J$ Psychiatry. 2013;202(4):261-8.

75. European Network of National Networks studying Gene-Environment Interactions in Schizophrenia, van Os J, Rutten BP, Myin-Germeys I, Delespaul P, Viechtbauer W, et al. Identifying gene-environment interactions in schizophrenia: contemporary challenges for integrated, large-scale investigations. Schizophr Bull. 2014;40(4):72936.

76. Guloksuz S, Pries LK, Delespaul P, Kenis G, Luykx JJ, Lin BD, et al. Examining the independent and joint effects of molecular genetic liability and environmental 
exposures in schizophrenia: results from the EUGEI study. World Psychiatry. 2019;18(2):173-82.

77. van Os J, Pries L, Delespaul P, Kenis G, Luyx J, Lin B, et al. Evidence that endophenotypic expression of schizophrenia polygenic risk is greater in healthy siblings of patients compared to controls, suggesting gene-environment interaction, and that the association between polygenic risk and cognition may represent prognostic confounding. The EUGEI study. submitted manuscript. 2019.

78. Shakoor S, Zavos HM, Haworth CM, McGuire P, Cardno AG, Freeman D, et al. Association between stressful life events and psychotic experiences in adolescence: evidence for gene-environment correlations. Br J Psychiatry. 2016;208(6):532-8.

79. Pries LK, Guloksuz S, Menne-Lothmann C, Decoster J, van Winkel R, Collip D, et al. White noise speech illusion and psychosis expression: An experimental investigation of psychosis liability. PLoS One. 2017;12(8):e0183695.

80. Kapur S. Psychosis as a state of aberrant salience: a framework linking biology, phenomenology, and pharmacology in schizophrenia. Am J Psychiatry. 2003;160(1):13-23.

81. Aleman A, Bocker KB, Hijman R, de Haan EH, Kahn RS. Cognitive basis of hallucinations in schizophrenia: role of top-down information processing. Schizophr Res. 2003;64(23):175-85.

82. Hoffman RE, Woods SW, Hawkins KA, Pittman B, Tohen M, Preda A, et al. Extracting spurious messages from noise and risk of schizophrenia-spectrum disorders in a prodromal population. Br J Psychiatry. 2007;191:355-6.

83. Hugdahl K. "Hearing voices": auditory hallucinations as failure of top-down control of bottom-up perceptual processes. Scand J Psychol. 2009;50(6):553-60.

84. Collip D, Myin-Germeys I, Van Os J. Does the concept of "sensitization" provide a plausible mechanism for the putative link between the environment and schizophrenia? Schizophr Bull. 2008;34(2):220-5.

85. Hoffman RE. New methods for studying hallucinated 'voices' in schizophrenia. Acta Psychiatr Scand Suppl. 1999;395:89-94.

86. Vercammen A, de Haan EH, Aleman A. Hearing a voice in the noise: auditory hallucinations and speech perception. Psychol Med. 2008;38(8):1177-84.

87. Merckelbach $\mathrm{H}$, van de Ven V. Another White Christmas: fantasy proneness and reports of 'hallucinatory experiences' in undergraduate students. J Behav Ther Exp Psychiatry. 2001;32(3):137-44.

88. Muller N, Keil J, Obleser J, Schulz H, Grunwald T, Bernays RL, et al. You can't stop the music: reduced auditory alpha power and coupling between auditory and memory regions facilitate the illusory perception of music during noise. Neuroimage. 2013;79:383-93.

89. Leske S, Tse A, Oosterhof NN, Hartmann T, Muller N, Keil J, et al. The strength of alpha and beta oscillations parametrically scale with the strength of an illusory auditory percept. Neuroimage. 2014;88:69-78. 
90. Galdos M, Simons C, Fernandez-Rivas A, Wichers M, Peralta C, Lataster T, et al. Affectively salient meaning in random noise: a task sensitive to psychosis liability. Schizophr Bull. 2011;37(6):1179-86.

91. Holt DJ, Titone D, Long LS, Goff DC, Cather C, Rauch SL, et al. The misattribution of salience in delusional patients with schizophrenia. Schizophr Res. 2006;83(2-3):24756.

92. Catalan A, Simons CJ, Bustamante S, Drukker M, Madrazo A, de Artaza MG, et al. Novel evidence that attributing affectively salient signal to random noise is associated with psychosis. PLoS One. 2014;9(7):e102520.

93. Britton JW, Frey LC, Hopp JL, Korb P, Koubeissi MZ, Lievens WE, et al. In: St. Louis EK, Frey LC, editors. Electroencephalography (EEG): An Introductory Text and Atlas of Normal and Abnormal Findings in Adults, Children, and Infants. Chicago2016.

94. Teplan M. Fundamentals of EEG measurement. Measurement science review. 2002;2(2):1-11.

95. Konings M, Bak M, Hanssen M, van Os J, Krabbendam L. Validity and reliability of the CAPE: a self-report instrument for the measurement of psychotic experiences in the general population. Acta Psychiatr Scand. 2006;114(1):55-61. 


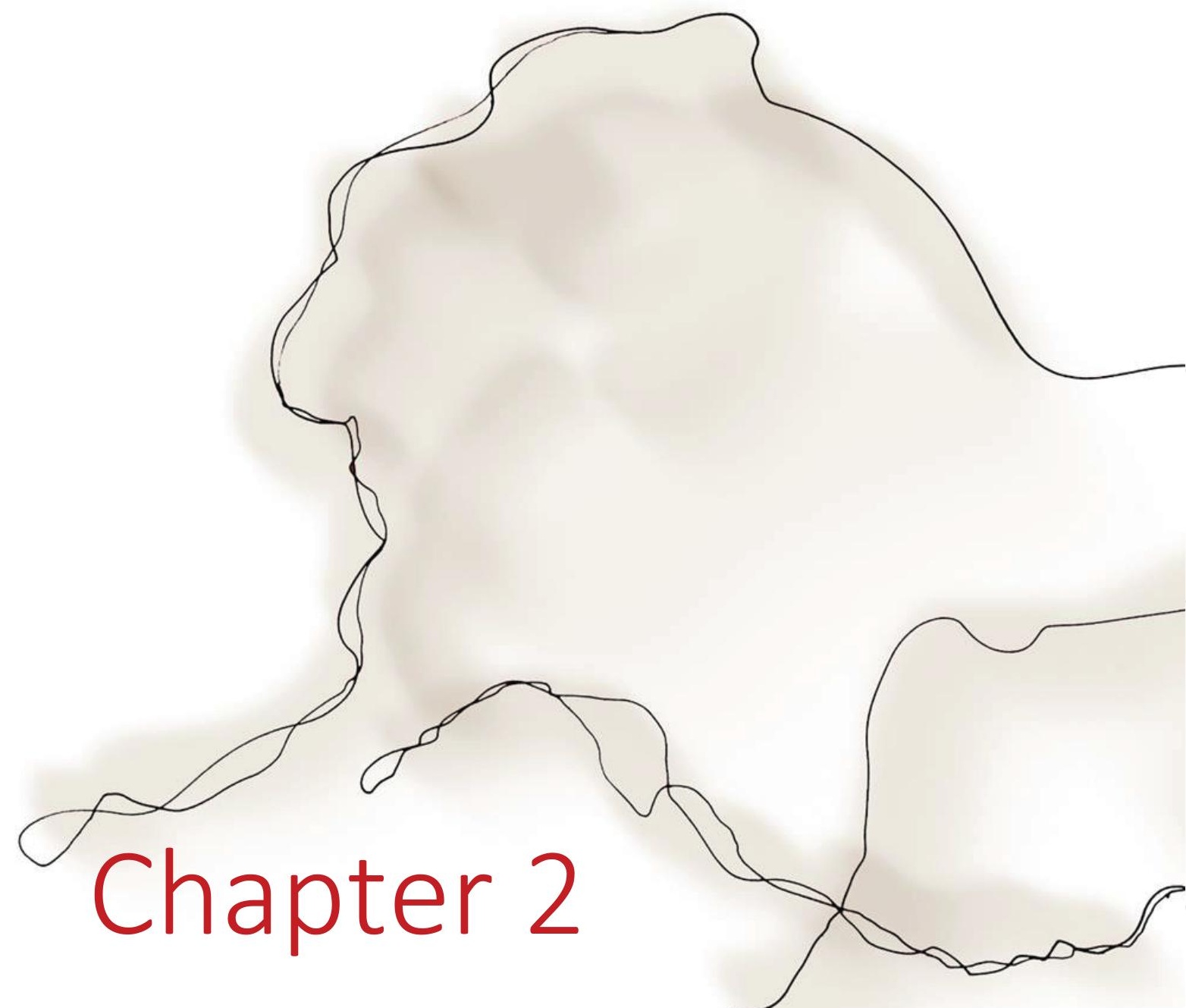

Cortical processes of speech illusions in the general population
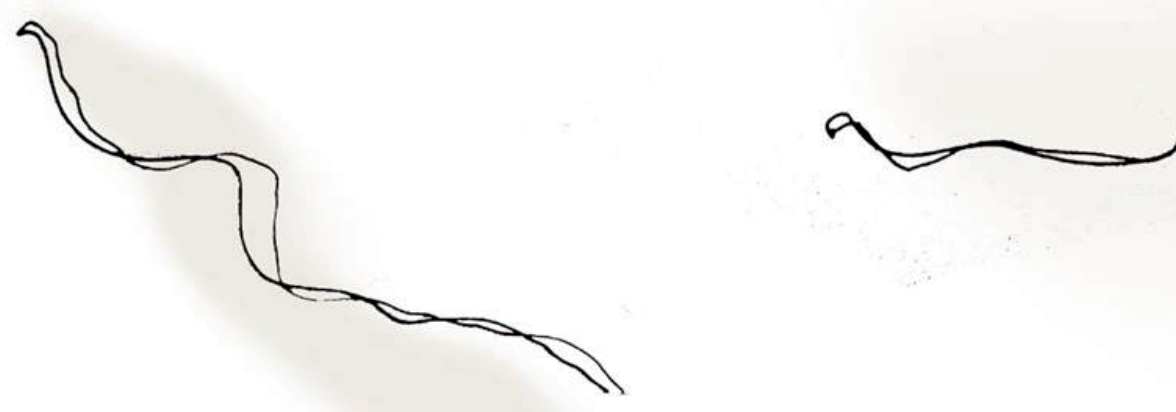


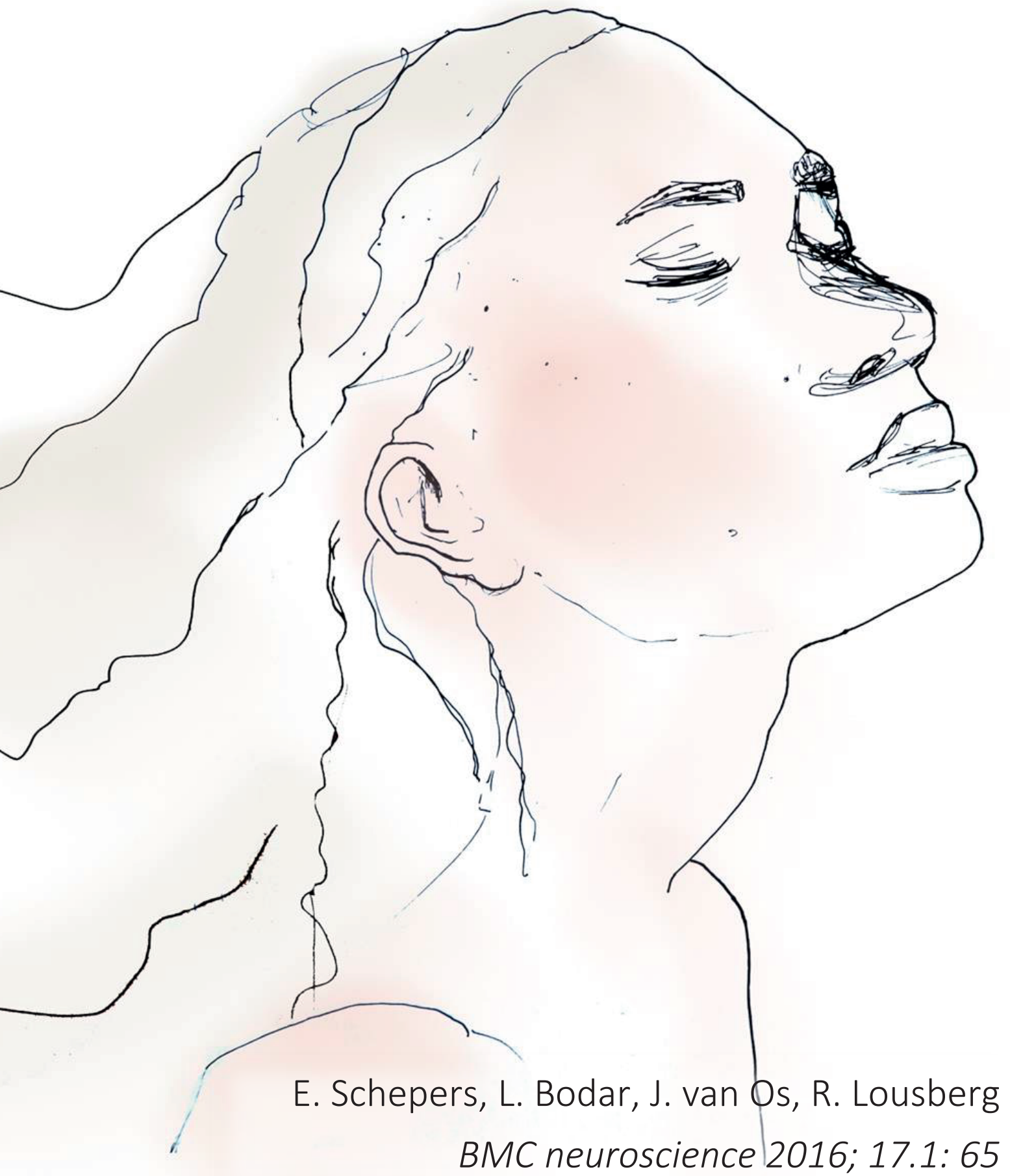




\section{Abstract}

Introduction There is evidence that experimentally elicited auditory illusions in the general population index risk for psychotic symptoms. As little is known about underlying cortical mechanisms of auditory illusions, an experiment was conducted to analyze processing of auditory illusions in a general population sample.

Methods In a follow-up design with two measurement moments (baseline and 6 months), participants ( $n=83$ ) underwent the White Noise task under simultaneous recording with a 14-lead EEG. An auditory illusion was defined as hearing any speech in a sound fragment containing white noise.

Results A total number of 256 speech illusions (SI) were observed over the two measurements, with a high degree of stability of SI over time. There were 7 main effects of speech illusion on the EEG alpha band-the most significant indicating a decrease in activity at T3 $(\mathrm{t}=-4.05)$. Other EEG frequency bands (slow beta, fast beta, gamma, delta, theta) showed no significant associations with SI.

Conclusion SIs are characterized by reduced alpha activity in non-clinical populations. Given the association of SIs with psychosis, follow-up research is required to examine the possibility of reduced alpha activity mediating SIs in high risk and symptomatic populations. 


\section{Introduction}

Cognitive and neuroimaging studies (in both clinical and general populations) have focussed on the phenomenology and neurophysiological correlates of hallucinations in clinical and non-clinical populations. Theoretical accounts of the cognitive basis of hallucinations have focused on the hypothesis of a distorted balance between imagery and perception (1). Alterations in information processing, in which the system assigns an increased influence to top-down factors (perceptual expectation through mental imagery), at the expense of bottom-up information (incoming sensory information), may contribute to the beginning of hallucinations. The hypothesized increased top-down influence of imagery on perception is supported by the finding that the hallucinatory severity correlates positively with the influence of mental imagery on auditory tone detection (2). Functional neuroimaging has frequently been used to measure neural activity during hallucinations, as well as to assess associations with brain change (3-5). For example, it has been reported that more intense hallucinations are associated with smaller left anterior superior temporal gyrus volumes. This suggests that the dysfunction underlying the production of auditory hallucinations affects brain regions subserving language processing (3). Woodruff et al. (5) suggest that auditory hallucinations involve activation of brain areas associated with the perception of external speech, in addition to misperception of internal speech. In a study conducted by Shergill et al. (4), it was observed that 6-9 s before the onset of hallucinatory activity, the left inferior frontal and right middle temporal gyri were triggered. In another study, the left insula and bilateral temporal gyri were activated during the perception of a hallucination. In combination, these studies provide evidence for cortical brain changes during or even before the occurrence of hallucinations.

Unlike hallucinations, illusions are distorted interpretations of a 'real' external stimulus. Illusions are believed to be precursors of hallucinations in the early stages of psychosis (6). However, illusions are more common than hallucinations and illusions do not necessarily lead to hallucinations. Hoffman and colleagues reported that 
speech illusions may signal an increased risk for transition to psychotic disorder in a prodromal population (7). Galdos and colleagues described an experimental speech illusion task, designed to prime and elicit auditory illusions. In this task, participants are presented with three different categories of sound fragments: fragments containing 'pure' white noise; fragments of white noise mixed with a barely audible speech in the background and fragments with white noise mixed with clearly audible speech. After hearing fragments, participants (controls, patients with psychotic disorder and their siblings) were asked to indicate whether they heard a sentence with positive, negative or neutral content, or heard a voice but were uncertain whether the content was positive, negative or neutral, or heard no voice at all. A speech illusion (SI) was defined as a white noise fragment in which any speech was heard. In the control group, there were $9 \%$ speech illusions, in the group of patients with psychotic disorder this was $30 \%$. Therefore, although the rate of speech illusions in the patient group was much higher than in control participants, speech illusions were also relatively common in the non-psychotic population. In addition, siblings of patients had higher rates of speech illusions (14 \%) than controls, suggesting speech illusions index risk for psychosis (8).

Studies investigating the role of cortical mechanisms of illusory perceptions are primarily conducted in the visual domain (9-12), and to a lesser extent in the auditory domain. According to recent literature, the power of alpha oscillations is associated with perception and cognitive processes $(13,14)$. Romei et al. $(13)$ suggested that the activity of alpha oscillations in the visual cortex mediates whether stimuli are perceived or not, showing that low alpha power (high excitability) may facilitate visual perception and high alpha power may inhibit perception of stimuli. Comparable effects are reported in studies investigating the cortical oscillations during auditory perception. Weisz et al. (15) studied the role of alpha oscillations in tinnitus. They found a significant decrease in the power of ongoing alpha activity for the tinnitus group compared to normal hearing controls. The reduction was predominantly found in the bilateral temporal regions of the auditory cortex. Similar findings of an 
association between alpha activity and auditory perceptions were reported in a study of Müller et al. (16). These authors recorded brain activity while participants listened to familiar as well as unknown music that was partly replaced by sections of noise. During the noise fragments, participants reported a stronger illusory music perception for familiar songs as compared to unfamiliar songs. Leske et al. (17) investigated oscillatory activity during a Zwicker Tone illusion with different notch widths. In this paradigm, a notch-filtered auditory noise induces an 'auditory afterimage'.

Participants reported a stronger auditory perception with increasing notch widths. The increasing notch widths were associated with decreased alpha power, showing an inverse relation between 'auditory afterimage' and alpha power. Reported associations between altered alpha activity and illusionary phenomena in these studies suggest it may be productive to examine the hypothesis of alterations in oscillatory activity during a pure white noise fragment reported as a speech illusion.

We wished to examine the auditory speech illusion experiment, reported by Galdos et al. (8), and replicated by Catalan et al. (18), using a repeated measure paradigm (baseline and 6 months) in a general population sample. The main objective was to demonstrate that cortical processing of a speech illusion (SI) would differ from a correctly judged white noise fragment. Based on the findings of previous research, our main hypothesis focussed on changes on the alpha band. However, we planned to analyse the complete frequency spectrum, ranging from delta to gamma. Age and sex impact EEG activity, and were included as confounding variables in the statistical models.

\section{Materials and method}

\section{Participants}

Eighty-three persons participated, of which 66 took part both at baseline and at follow-up. Participants were recruited from the population of Maastricht (population: $120,000)$ using flyers at public places. Exclusion criteria were the use of antipsychotic, anti-epileptic, antidepressant or anxiolytic medications during the past year or 
structural use of more than 5 units of alcohol per day. Participants were asked to avoid the use of alcohol the day before the experimental session. They were also asked not to use caffeine-containing beverages $3 \mathrm{~h}$ before the experiment. Participants with hearing problems were excluded. Participants reported on the presence of a first- or second-degree relative diagnosed with a psychotic disorder. Compensation for participating in the two measurements was $50 €$.

\section{Ethics statement}

The study was conducted according to the principles of the Declaration of Helsinki and the medical ethics committee at Maastricht University Medical Centre approved the study. Participants gave written informed consent before the start of the experiment.

\section{Design and procedure}

The study design included two measurements, at baseline and at 6 months. On both occasions, the white noise task was administered in a psychophysiological laboratory. Each participant was exposed to 75 sound fragments, equally divided over three subgroups: 25 fragments containing 'pure' white noise; 25 fragments of white noise mixed with barely audible speech in the background; 25 fragments with white noise mixed with a clearly audible speech. The affective context of the sentence of the clearly audible speech fragments was either positive, negative or neutral. For example: 'Sport is good for health', 'I think it is going to rain today' or 'Madrid is the capital of Spain'. Each fragment had a duration of $4.3 \mathrm{~s}$; the spoken sentence was constructed to last as close as possible to $4.3 \mathrm{~s}$. The 75 fragments were presented in random order. After each fragment, participants were asked to press a button on a keyboard (just in front of them) to characterize the fragment: 1: endorsed hearing speech with positive content, 2: endorsed hearing speech with negative content, 3 : endorsed hearing speech with neutral content, 4: no speech heard, and 5: endorsed hearing speech but uncertain whether it was positive, negative or neutral. As stated above, a speech illusion was defined as a white noise fragment in which any speech was heard (thus either option 1, 2, 3 or 5). The sound fragments were binaurally 
presented through headphones (Plantronics) and making use of a Soundmax integrated digital HD audiodriver sound card. The protocol was guided by the software package 'Presentation' (Version 13.0, Neurobehavioral Systems, Inc.). Markers were placed in a separate EEG marker-channel to indicate the start and the end of a fragment as well as at the moment the participant pressed the 'answerbutton'. During the fragment, the word "listen!" was displayed on the computer screen (placed in front of the participant). Immediately after a fragment, the five answer options were shown and participants were asked to rate the fragment. A new fragment was started $1 \mathrm{~s}$ after an answer was given. Response time was calculated as the time (measured in ms) between the end of a fragment and the button push. The total duration of the task was variable, since the response times varied per participant. The average task duration was $8.8 \mathrm{~min}$ (SD =0.88, range: $7.3-11.9$ ).

\section{EEG measurement}

$\mathrm{Ag} / \mathrm{AgCl}$ electrodes were attached to the participant's head at the following locations: $\mathrm{Fz}, \mathrm{F} 3, \mathrm{~F} 4, \mathrm{Cz}, \mathrm{C3}, \mathrm{C4}, \mathrm{Pz}, \mathrm{P3}, \mathrm{P} 4, \mathrm{T3}, \mathrm{T4}, \mathrm{Oz}, \mathrm{O} 1$ and O2, using the international 10-20 system (19). Electro-oculogram electrodes were placed $1 \mathrm{~cm}$ under the midline of both eyes to measure ocular activity. A reference electrode was placed on each ear lobe. The two reference electrodes were linked to each other. A ground electrode was placed at the forehead. To reduce resistance, Nuprep scub gel was used. Conductive gel (Ten20 conductive) was used to fill the electrodes. Impedances were kept below $5 \mathrm{k} \Omega$. BrainAmp Research Amplifier (Brain Products, resolution $0.1 \mu \mathrm{V}$ ) was used for all recordings. EEG was sampled with $1000 \mathrm{~Hz}$.

\section{EEG offline data processing}

Offline data processing was performed with BrainVision Analyser 2.0 (Brain Products, München, Germany). In a first step, data was offline filtered (band pass $0.5-50 \mathrm{~Hz}$ ). The data were divided into 4096 ms segments, marked by the onset and end of the fragment. For each segment, a FFT transformation was applied after which the frequency bands delta $(1-3 \mathrm{~Hz})$, theta $(3-7.5 \mathrm{~Hz})$, alpha $(7.5-13 \mathrm{~Hz})$, slow beta $(13-$ 
$20 \mathrm{~Hz})$, fast beta $(20-30 \mathrm{~Hz})$ and gamma $(30-48 \mathrm{~Hz})$ were computed. Because of skewed non-normal distributions of the EEG band data, a log-transformation on each EEG band was carried out. The log-transformed EEG variables were normally distributed.

\section{Statistical analysis}

Given the hierarchical structure of the EEG dataset, consisting of 25 white noise fragments (level 1) clustered within individuals (level 2), clustered within two experimental sessions (level 3), multilevel random regression analyses were performed (20). In order to test which covariance structure yielded the best fit, various covariance structures were tested. The covariance structure which best fitted the data was an autoregressive (AR1) structure. All models were tested with a random intercept and random slope for the number of fragments. The EEG frequency bands of each location were the dependent variables. The following variables served as covariates: EOG (left and right activity), age (in years) and sex (male $=0$, female $=1$ ). A dummy variable 'speech illusion' (SI: yes or no) was used as the independent variable of main interest. In addition, the independent variables response time, fragment number, 1/fragment number (as a non-linear fragment effect) and measurement were incorporated in the model. All statistical analyses were performed with SPSS version 21.0. $p$-values $\leq 0.05$ were considered as statistically significant.

\section{Results}

\section{Participant characteristics}

Eighty-three (Age: $\mu=37.2$ (SD = 17.8); sex: 30 men, 53 women) participated at baseline, sixty-six (Age: $\mu=38.1$ (SD = 17.9); sex: 26 men, 40 women) were seen at 6month follow-up. Analyses were performed to check whether there was selective attrition, which revealed no large or significant differences with regard to rate of SI $(p=0.26)$, age $(p=0.38)$ and sex $(p=0.23)$. Two participants indicated they had a 
relative with a psychotic disorder, 4 participants did not know and the remainder did not have a relative with a psychotic disorder.

\section{Rate of speech illusions}

Each participant listened to 75 fragments per measurement occasion, of which 25 were pure white noise fragments. Thus, a maximum of 25 Sls could occur per measurement occasion. At baseline, 83 participants generated a total of $148 \mathrm{SIs}$ (7.1 \% = $148 \mathrm{SI} /[83$ participants * 25 noise fragments]). The total number of SIs made by the $n=66$ participants at follow-up was 108 or $6.5 \%$.

The number of SIs was divided into three categories: 3 or more during a measurement occasion, 1-2 during a measurement occasion and zero SIs. The frequency of these three categories over the two measurements can be observed in Table $\underline{1}$. The Chi square test of this table was significant $\left(\chi^{2}=20.5 ; d f=4 ; p<0.001\right)$, indicating relative stability over the two sessions. Twenty participants consistently had no SI at baseline and follow-up, 9 persons generated 3 or more SIs at both measurements. In the latter group, no one had a family member with a psychotic disorder.

Table 1. Rate of SI (number of participants) over both measurements

\begin{tabular}{|c|c|c|c|c|c|}
\hline & \multicolumn{3}{|c|}{ Measurement 2} & \multirow[b]{2}{*}{ Total } \\
\hline & & $S I=0$ & $1 \leq S I \leq 2$ & $S I \geq 3$ & \\
\hline \multirow{4}{*}{ Measurement 1} & $S I=0$ & 20 & 9 & 4 & 33 \\
\hline & $1 \leq S I \leq 2$ & 11 & 7 & 2 & 20 \\
\hline & $S I \geq 3$ & 2 & 2 & 9 & 13 \\
\hline & Total & 33 & 18 & 15 & 66 \\
\hline
\end{tabular}

\section{Response time}

Although no instruction was given to judge the fragments as quickly as possible, analysis of the response time is important in order to better understand the (cortical) 
decision process underlying Sls. The response time was defined as the time between the end of the stimulus and the push on the button. An inspection of the frequency distribution of the response times (the dependent variable) showed that there were some extreme (outlying) values. It was decided to remove all response times above $10000 \mathrm{~ms}$ ( $0.6 \%$ of the data). Figure 1 gives an illustration of how response times decrease during the series of 75 fragments. The curve is indicative for a non-linear (inverse) decreasing effect, the largest decrease being observed during the first twenty fragments. Both the linear effect as well as the inverse (1/fragment) effect was associated with the response time $\left(p^{\prime} s<0.001\right)$. In addition, it can be observed that the mean response time of the fragments at baseline (1745 ms) was longer compared to follow-up (1563 ms; $p<0.001)$. Further analyses revealed that increasing age was accompanied by longer response times $(p=0.001)$. SI was not associated with response time $(p=0.78)$.

Figure 1. Response time per fragment

\section{Response time per fragment}

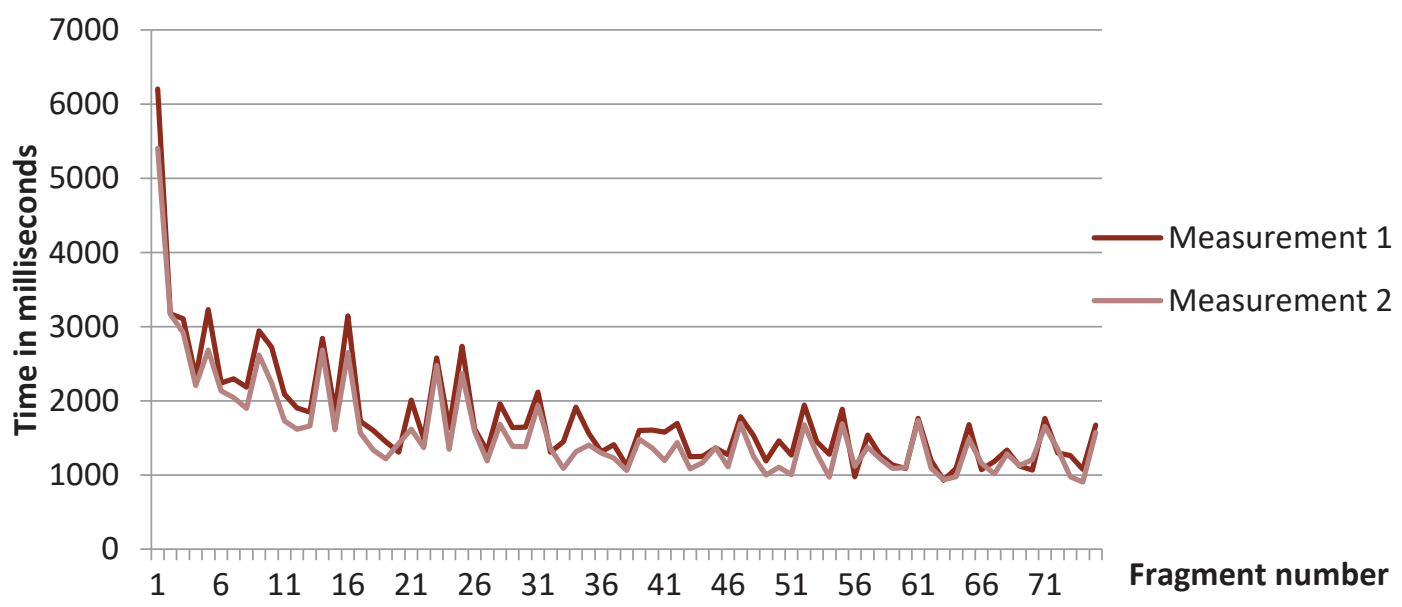




\section{EEG during SI}

The recorded EEG of one participant did not fulfil the resistance criterion (all electrodes $>5 \mathrm{k} \Omega$ ). Consequently, this person was excluded from the EEG analyses. In Fig. 2 the raw, untransformed alpha power of SI versus no SI are displayed for all 14 locations. At all locations, alpha power during a speech illusion was reduced. Significant main effects of SI were observed at locations C3, Pz, P3, O1, O2, T3 and T4. Correcting for the multiple testing (applying the Bonferroni criterion), p-values less than $0.0035(0.05 / 14)$ were considered significant. This is conservative, given that Bonferroni correction may result in diminished power to detect differentiation among pairs of sample collections (21). After applying Bonferroni correction, 4 cortical locations: C3, P3, T3 and T4 remained significant. Table $\underline{2}$ shows the log transformed alpha band power with the corresponding t-values at all electrodes. The most significant main effect was at T3 alpha $(t=-4.05)$. Finally, a series of interaction models was run to test whether there were speech illusion * measurement interaction effects. No significant interaction effects were found. At all other EEG frequency bands no significant main and interaction ( $\mathrm{SI}$ *measurement) effects were apparent. 
Figure 2. Alpha power of SI versus no SI

\section{Alpha power of SI versus no SI}

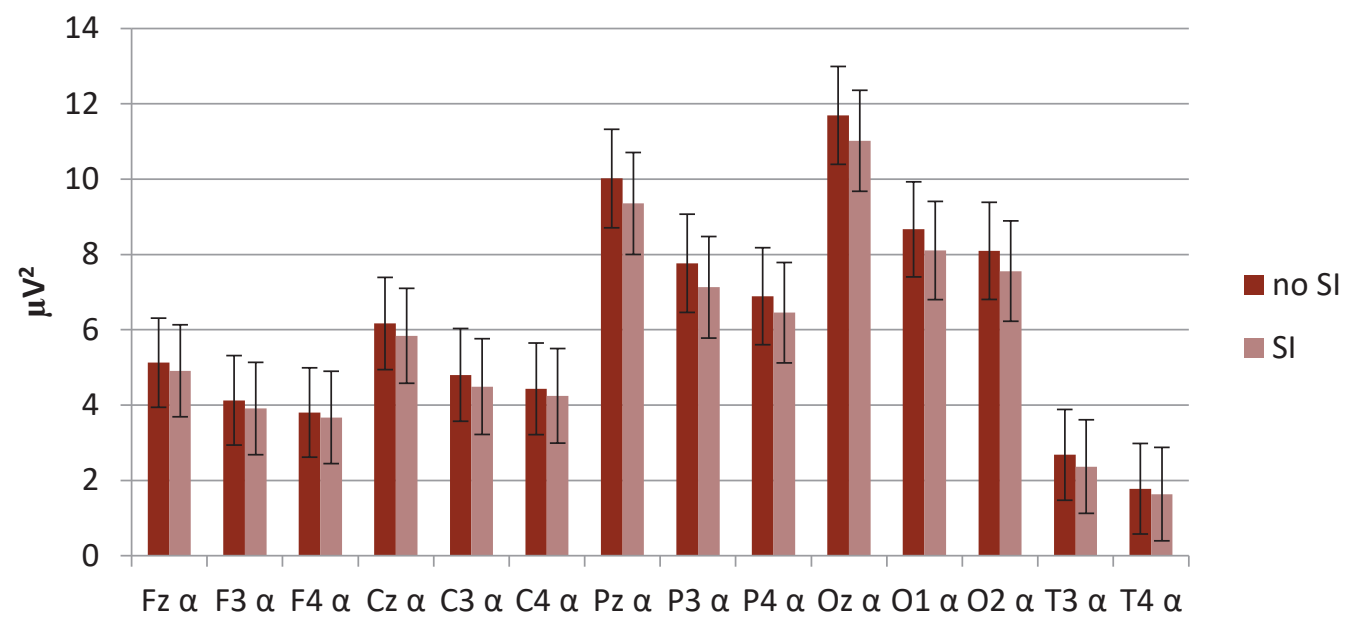


Table 2. Estimates of the log power of the alpha band during SI versus no SI with corresponding t-and $p$-values

\begin{tabular}{|c|c|c|c|c|}
\hline & Estimate no SI & Estimate SI & t-value & $p$-value \\
\hline $\log F z \alpha$ & 0.710 & 0.691 & -1.359 & 0.174 \\
\hline $\log$ F3 $\alpha$ & 0.616 & 0.592 & -1.696 & 0.090 \\
\hline $\log F 4 \alpha$ & 0.580 & 0.565 & -1.063 & 0.288 \\
\hline $\log C z \alpha$ & 0.790 & 0.766 & -1.865 & 0.062 \\
\hline $\log C 3 \alpha$ & 0.681 & 0.652 & $\underline{-2.120}$ & 0.034 \\
\hline $\log C 4 \alpha$ & 0.646 & 0.628 & -1.349 & 0.177 \\
\hline $\log P z \alpha$ & 1.001 & 0.971 & $\underline{-1.972}$ & $\underline{0.049}$ \\
\hline $\log$ P3 $\alpha$ & 0.890 & 0.853 & $\underline{-2.542}$ & $\underline{0.011}$ \\
\hline $\log P 4 \alpha$ & 0.838 & 0.810 & -1.907 & 0.057 \\
\hline $\log \mathrm{Oz} \alpha$ & 1.068 & 1.042 & -1.879 & 0.060 \\
\hline $\log 01 \alpha$ & 0.938 & 0.909 & $\underline{-2.074}$ & $\underline{0.038}$ \\
\hline $\log 02 \alpha$ & 0.908 & 0.878 & $\underline{-2.075}$ & $\underline{0.038}$ \\
\hline $\log$ T3 $\alpha$ & 0.428 & 0.374 & $\underline{-4.045}$ & $\leq 0.001$ \\
\hline $\log$ T4 $\alpha$ & 0.250 & 0.214 & $\underline{-2.670}$ & $\underline{0.008}$ \\
\hline
\end{tabular}




\section{Discussion}

\section{Protocol validation}

In this study, an attempt was made to link speech illusions to cortical activity in a general population sample using a specific protocol. The results of the analyses of the response time can be regarded as a validation of the protocol, as both the decreasing non-linear response times over fragments as well as the mean decreased response time in measurement 2 have face validity: participants learned to perform the task faster and participated twice in the same experiment. Also, the finding that older people displayed longer response times is in line with expectation.

At baseline, there were 13 participants who reported three or more SIs. Six months later, almost $70 \%$ (9 out of 13) again displayed three or more SIs. This observation suggests substantial stability of SI over time. In addition, no significant EEG activity * measurement interactions were observed for any dependent variable.

\section{Main findings}

The main finding of this experiment was that speech illusions can be characterized by significant changes in cortical activity in the EEG alpha band across different cortical locations.

Seven SI main effects were observed on the alpha band, the most significant at temporal locations. The decrease of alpha oscillations during an auditory illusion supports findings of earlier studies. The perception of a sound is associated with decreased alpha activity, indicating high excitability. As described earlier, the most significant reduction in alpha oscillations was found at the temporal region, a result also reported by Müller and Weisz. Higher excitably of the temporal lobes is conform expectation given that the auditory cortex is located within the temporal lobe, and the same area is involved in hallucinations. As mentioned in the introduction, research has shown that activity in the left temporal lobe is altered during hallucinatory states 
(4). More specifically, just before a hallucination, the left inferior frontal and right middle temporal gyri are recruited, and during the (hallucinatory) perception, the left insula and bilateral temporal gyri are activated (4). Significantly reduced alpha activity, however, was not only observed at the temporal regions. It is possible that other regions than the temporal regions are also involved in alpha reduction during an illusion.

The fact that SIs were reported in a sample of the general population without a psychotic disorder supports the idea of phenomenological continuity of psychosis across clinical and non-ill populations (22). Phenomenological continuity relates to the notion that psychotic experiences can occur outside psychotic disorder and reflect the psychometric liability to psychosis as distributed in the population (22).

\section{Methodological issues}

A number of participants were lost to follow-up, i.e. did not participate in follow-up measurement at 6 months. However, analyses suggested little potential for differential attrition. A second limitation is that from a 14-leads EEG no inferences can be made on which cortical sources are active. Future studies may combine EEG measurements with $\mathrm{fMRI}$ in order to pinpoint source location.

Future efforts may focus on cortical processing of SI in healthy controls as compared to patients with a psychotic disorder. Two opposing hypotheses may be tested. On the one hand, a stronger and more pronounced cortical activity underlying SIs may be expected in patients; on the other hand, involvement of other cortical mechanisms may differentiate patients from controls. In addition, the cortical relationship between illusions and hallucinations may be explored in a prodromal population in order to understand the process of transition to psychotic disorder as reflected by cortical activity underlying psychotic symptoms. 


\section{References}

1. Aleman A, de Haan EH, Bocker KB, Hijman R, Kahn RS. Hallucinations in schizophrenia: imbalance between imagery and perception? Schizophr Res. 2002;57(2-3):315-6.

2. Aleman A, Bocker KB, Hijman R, de Haan EH, Kahn RS. Cognitive basis of hallucinations in schizophrenia: role of top-down information processing. Schizophr Res. 2003;64(2-3):175-85.

3. Levitan C, Ward PB, Catts SV. Superior temporal gyral volumes and laterality correlates of auditory hallucinations in schizophrenia. Biol Psychiatry. 1999;46(7):955-62.

4. Shergill SS, Brammer MJ, Amaro E, Williams SC, Murray RM, McGuire PK. Temporal course of auditory hallucinations. Br J Psychiatry. 2004;185:516-7.

5. Woodruff $P$, Brammer M, Mellers J, Wright I, Bullmore E, Williams S. Auditory hallucinations and perception of external speech. Lancet. 1995;346(8981):1035.

6. Corlett PR, Honey GD, Krystal JH, Fletcher PC. Glutamatergic model psychoses: prediction error, learning, and inference. Neuropsychopharmacology. 2011;36(1):294-315.

7. Hoffman RE, Woods SW, Hawkins KA, Pittman B, Tohen M, Preda A, et al. Extracting spurious messages from noise and risk of schizophrenia-spectrum disorders in a prodromal population. Br J Psychiatry. 2007;191:355-6.

8. Galdos M, Simons C, Fernandez-Rivas A, Wichers M, Peralta C, Lataster T, et al. Affectively salient meaning in random noise: a task sensitive to psychosis liability. Schizophr Bull. 2011;37(6):1179-86.

9. Romei V, Brodbeck V, Michel C, Amedi A, Pascual-Leone A, Thut G. Spontaneous fluctuations in posterior alpha-band EEG activity reflect variability in excitability of human visual areas. Cereb Cortex. 2008;18(9):2010-8.

10. Romei V, Rihs T, Brodbeck V, Thut G. Resting electroencephalogram alpha-power over posterior sites indexes baseline visual cortex excitability. Neuroreport. 2008;19(2):203-8.

11. Sokoliuk R, VanRullen R. The flickering wheel illusion: when alpha rhythms make a static wheel flicker. J Neurosci. 2013;33(33):13498-504.

12. VanRullen R, Reddy L, Koch C. The continuous wagon wheel illusion is associated with changes in electroencephalogram power at approximately $13 \mathrm{~Hz}$. J Neurosci. 2006;26(2):502-7.

13. Romei V, Gross J, Thut G. On the role of prestimulus alpha rhythms over occipitoparietal areas in visual input regulation: correlation or causation? J Neurosci. 2010;30(25):8692-7.

14. Weisz N, Hartmann T, Muller N, Lorenz I, Obleser J. Alpha rhythms in audition: cognitive and clinical perspectives. Front Psychol. 2011;2:73. 
15. Weisz N, Moratti S, Meinzer M, Dohrmann K, Elbert T. Tinnitus perception and distress is related to abnormal spontaneous brain activity as measured by magnetoencephalography. PLoS Med. 2005;2(6):e153.

16. Muller N, Keil J, Obleser J, Schulz H, Grunwald T, Bernays RL, et al. You can't stop the music: reduced auditory alpha power and coupling between auditory and memory regions facilitate the illusory perception of music during noise. Neuroimage. 2013;79:383-93.

17. Leske S, Tse A, Oosterhof NN, Hartmann T, Muller N, Keil J, et al. The strength of alpha and beta oscillations parametrically scale with the strength of an illusory auditory percept. Neuroimage. 2014;88:69-78.

18. Catalan A, Simons CJ, Bustamante S, Drukker M, Madrazo A, de Artaza MG, et al. Novel evidence that attributing affectively salient signal to random noise is associated with psychosis. PLoS One. 2014;9(7):e102520.

19. Klem GH, Luders HO, Jasper HH, Elger C. The ten-twenty electrode system of the International Federation. The International Federation of Clinical Neurophysiology. Electroencephalogr Clin Neurophysiol Suppl. 1999;52:3-6.

20. Snijders T A B. BRJ. Multilevel Analysis: An Introduction to Basic and Advanced Multilevel Modeling. London: Sage Publications; 1999.

21. Narum SR. Beyond Bonferroni: less conservative analyses for conservation genetics. Conservation Genetics. 2006;7(5):811-.

22. Linscott RJ, van Os J. An updated and conservative systematic review and metaanalysis of epidemiological evidence on psychotic experiences in children and adults: on the pathway from proneness to persistence to dimensional expression across mental disorders. Psychol Med. 2013;43(6):1133-49. 


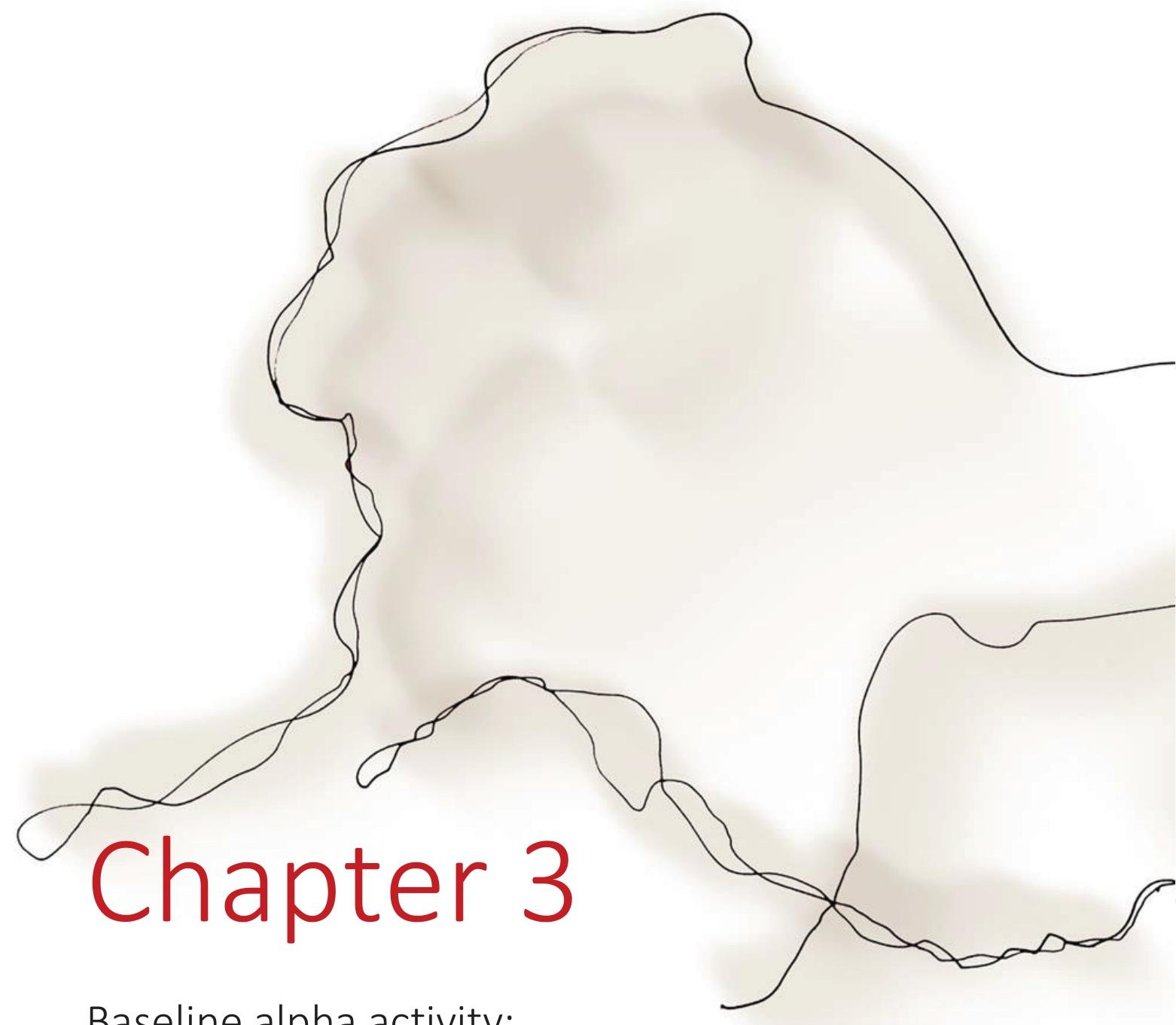

Baseline alpha activity:

a predictor of white noise speech illusions in the general population?
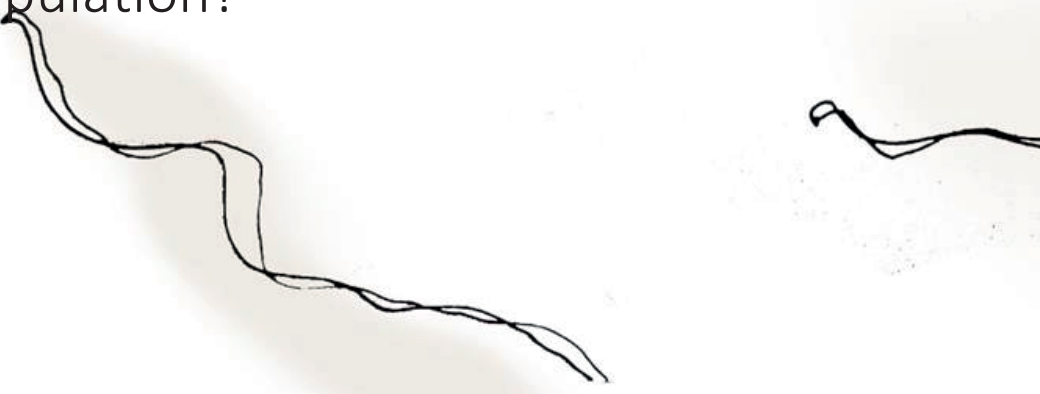


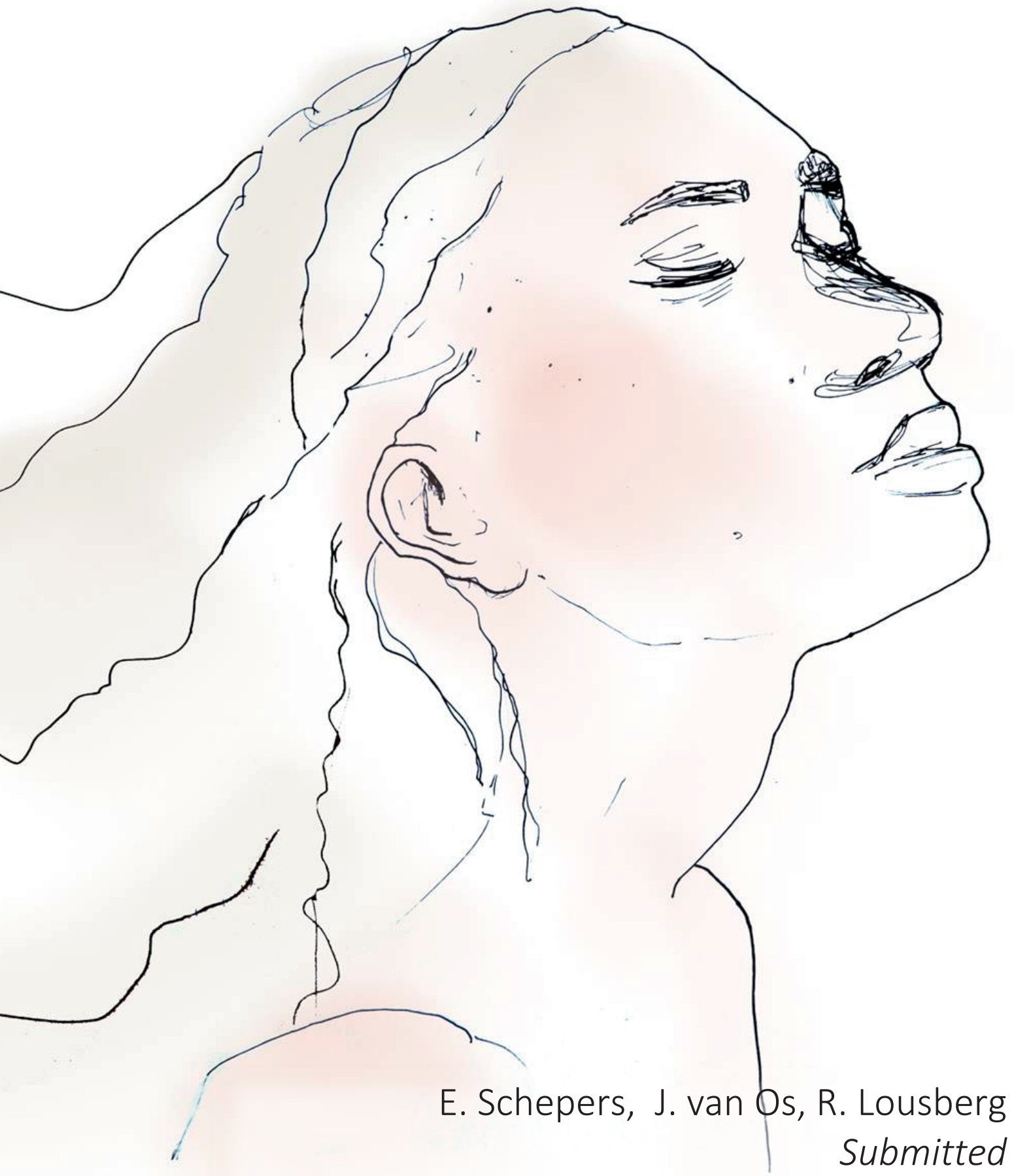




\section{Abstract}

Introduction White noise speech illusions are associated with reduced alpha activity during a white noise fragment. It has been suggested that alpha activity before stimulus onset may moderate illusory perception. The aim of this study is to investigate whether the interpretation of a white noise fragment is predicted by alpha activity $500 \mathrm{~ms}$ before the onset of a fragment.

Methods In a follow-up design (baseline and 6 months), 83 participants sampled from the general population underwent the white noise task under simultaneous recording with a 14-lead EEG.

Results No significant association was found between baseline alpha activity and speech illusions for any location.

Conclusion While some studies have found evidence that pre-stimulus alpha oscillations are involved in the shaping of cortical networks for upcoming stimuli, baseline alpha activity does not predict perception of white noise speech illusions. 


\section{Introduction}

It has been suggested that the experience of altered meaning assigned to internal representations or external stimuli (1) is rooted in a distorted balance between topdown and bottom-up processes (2). Hallucinations (perceptions in the absence of a stimulus) may result from an increased influence of top-down processing (perceptual expectation, prior knowledge and mental imagery), at the expense of bottom-up information (external sensory information) $(3,4)$. Research focusing on brain structure and function may be used to examine aspects of this hypothesis but has not yielded consistent results.

Functional neuroimaging has been used to examine associations of hallucinations with cortical activity and structural brain changes, with some evidence for a possible reduction of the grey matter volume in the superior temporal gyri and insula $(5,6)$. Shergill and colleagues found that 6 to 9 seconds before the onset of a hallucination, the left inferior frontal and right middle temporal gyri are activated. During a hallucination, associations were found with activation in the bilateral temporal gyri and the left insula (7). Electroencephalography and magnetoencephalography studies have reported inconsistent findings regarding the frequency bands involved, which may be related to small sample sizes. Thus, the theta $(8)$, alpha $(9)$, beta $(10,11)$ and gamma bands $(12,13)$ have all been reported as associated with hallucinations.

Psychotic phenomena are present not only in patients with psychotic disorders; in an attenuated form, psychotic experiences are also reported in the general population (14). Subclinical psychotic experiences are mostly transient in nature (15-17) and are thought to reflect stable differences in psychosis proneness below the level of illness (4). In some individuals, psychotic experiences may be predictive of the development of psychotic disorders $(17,18)$. It may be hypothesised that the tendency to extract spurious meaning from external stimuli is an indicator of psychosis liability. Hoffman and colleagues tested a paradigm to elicit auditory illusions and found evidence that 
such illusions may signal increased risk of psychotic disorders in a prodromal population $(3,19)$.

Subsequent research suggests that exposure to white noise induces perception of speech illusions, possibly through a mechanism of altered top-down processing. A higher prevalence of white noise speech illusions was found in psychotic patients than in their relatives and the general population: $30 \%$ in patients with psychotic disorders, $14 \%$ in siblings of the patients and $9 \%$ in the general population $(20,21)$. Given these findings, it may be hypothesised that white noise speech illusions signal increased risk of psychotic disorders and that more insight into the neurophysiological mechanism underlying white noise illusions may help to understand the occurrence of speech illusions in the general population.

Studies investigating the oscillatory activity during illusions have mainly focused on visual misperceptions and suggest that alpha oscillations are associated with perception (22). Several studies have investigated the role of alpha activity in auditory illusions (23-25). Individuals with tinnitus have decreased power of alpha activity compared to normal-hearing individuals (25). Müller and colleagues recorded brain activity while participants listened to music fragments partly replaced by pink noise. Illusory perception of music during pink noise was associated with reduction of alpha activity, indicating increased excitability (24). Similar findings were reported by Leske and colleagues (23). Stronger perceptions of a Zwicker Tone illusion (auditory afterimage induced by notch-filtered noise) were accompanied by reduced alpha power. Previously, we reported that alterations in alpha activity are also associated with white noise illusions in the general population. During a white noise fragment, alpha activity during a speech illusion was lower than for a correctly judged fragment (26).

Although these findings point to a possible mechanism of mediation, it remains to be established to what degree alpha oscillations play a role in mediating the process of 
altered perception. There is evidence that alpha activity before stimulus onset moderates (visual) illusory perception (22). This suggests that baseline alpha oscillations may be involved in shaping cortical networks for upcoming stimuli. It may be hypothesised, therefore, that interpretation of white noise is predicted by alpha activity before the onset of a fragment.

The aim of this article is to investigate whether a speech illusion is characterised not only by a reduction in alpha activity during a white noise fragment, as shown before, but also by changes in alpha activity during a 500 ms segment immediately before the onset of a fragment. An a priori negative association between alpha activity and white noise speech illusions is hypothesised.

\section{Materials and method}

\section{Participants}

In this article, we present novel analyses of the same sample used in the earlier study by Schepers and colleagues (26). The sample consists of 83 participants, of whom 66 attended a follow-up assessment 6 months later. Participants were recruited by distributing flyers at public places in Maastricht (population: 120,000). Exclusion criteria were use of antipsychotic, anti-epileptic, antidepressant or anxiolytic drugs during the past year and structural use of more than 5 units of alcohol per day. Participants were asked to avoid the use of alcohol the day before the experiment and caffeine-containing beverages 3 hours before the experiment. Participants with hearing problems were excluded. Participants received $€ 50$ for participating in the two measurements.

\section{Ethics statement}

The study was conducted according to the principles of the Declaration of Helsinki. The medical ethics committee at Maastricht University Medical Centre approved the 
study (NL40284.068.12/METC 12-3-015). Participants gave written informed consent before the start of the experiment.

\section{Design and procedure}

The study design included a baseline and a 6-month follow-up measurement. Several demographic variables of participants were collected (age, sex and highest educational level). A dichotomised educational-level variable was used: 0 indicating a low-to-average educational level, and 1 indicating a high educational level. The white noise task was administered on both occasions. Participants were exposed to three types of stimuli presented across 75 fragments in random order: white noise only; white noise mixed with barely audible speech; and white noise mixed with clearly audible speech with positive, negative or neutral content. Fragments were binaurally presented through headphones, and each had a duration of 4.3 seconds. After each fragment, participants were asked to respond by pushing one of five buttons to describe what they heard: (i) speech with positive content; (ii) speech with negative content; (iii) speech with neutral content; (iv) no speech; and (v) speech, but uncertain whether it was positive, negative or neutral. The protocol was guided by the software package Presentation (version 13.0, Neurobehavioral Systems, Inc.).

During each fragment, the word 'Listen!' was displayed on the computer screen in front of the participant. The five buttons were shown immediately after each fragment. A new fragment started 1 second after a button had been pushed. Via a separate marker EEG-channel, the moment of the start and end of each fragment and the button push were marked. Since the time between the end of a fragment and a button push (response time) varied, the total duration of the task was variable. The average duration was 8.8 minutes $(S D=0.88$, range: $7.3-11.9)$. In line with the definition proposed by Catalan and colleagues (20), a speech illusion (SI) was defined as a white noise fragment in which any speech was heard (options 1,2,3 or 5). As participants were exposed to 75 fragments, of which 25 were white noise only, the maximum number of speech illusions per measurement was 25 . 


\section{EEG measurement}

$\mathrm{Ag} / \mathrm{AgCl}$ electrodes were attached to the participant's head at 14 locations (Fz, F3, F4, $\mathrm{Cz}, \mathrm{C} 3, \mathrm{C} 4, \mathrm{Pz}, \mathrm{P} 3, \mathrm{P} 4, \mathrm{~T} 3, \mathrm{~T} 4, \mathrm{Oz}, \mathrm{O} 1$ and O2) using the international 10-20 system (27). Impedances were kept below $5 \mathrm{k} \Omega$. Electrooculogram electrodes were placed $1 \mathrm{~cm}$ under the midline of each eye to control for eye movements. Reference electrodes were placed on each ear lobe and linked to each other. A ground electrode was placed on the forehead. Ten20 conductive gel was used to fix the electrodes. A BrainVision BrainAmp Research Amplifier (Brain Products: sampling rate 1,000 Hz, resolution $0.1 \mu \mathrm{V}$ ) was used for EEG recording.

\section{EEG offline data processing}

Offline data processing was performed with BrainVision Analyser 2.0 (Brain Products, München Germany). First, the data were offline filtered $(0.5-50 \mathrm{~Hz})$. So-called baseline segments, $512 \mathrm{~ms}$ before the start of each fragment, and sound segments, 4,096 ms after the onset of each fragment, were extracted. A fast Fourier transformation was applied to each segment after which the frequency bands delta (1-3 Hz), theta $(3-7.5 \mathrm{~Hz})$, alpha $(7.5-13 \mathrm{~Hz})$, slow beta $(13-20 \mathrm{~Hz})$, fast beta (20-30 $\mathrm{Hz}$ ) and gamma (30--48 Hz) were computed. A log-transformation was carried out because of the skewed distribution of each EEG band.

\section{Statistical analyses}

Binary logistic mixed-effect regression models were run with speech illusion (<2 SI: 0 , $\geq 2 \mathrm{SI}: 1$ ) as the dependent variable. As the data had a hierarchical structure (25 noise fragments within individuals, clustered within two measurements), random intercepts for individuals were added to the models. The baseline alpha activity was the predictor of main interest. For each of the 14 EEG locations, the association with speech illusion was calculated in a separate model. All 14 models were then re-run with an interaction term between the trial number and baseline alpha activity. Finally, models were re-run with an interaction term between the alpha activity during the 
previous fragment and during baseline for each location. Before the analyses were carried out, the EEG predictor variables were visually inspected for outliers. In no case did the number of excluded outlying observations exceed $1 \%$ of the total. A two-sided p-value $<0.05$ was considered statistically significant. All analyses were corrected for measurement, trial number, electrooculogram-activity, age, sex and educational level. All statistical analyses were performed with SPSS version 24.0.

\section{Results}

\section{Participants}

Eighty-three persons (age: $\mu=37.2$ [SD = 17.8]; sex: 30 men, 53 women) participated at baseline, of which 66 (age: $\mu=38.1$ [SD = 17.9]; sex: 26 men, 40 women) attended the 6-month follow-up. The total number of speech illusions generated by the participants was $148(7 \%)$ at baseline and 108 (7\%) at follow-up. At baseline, 29 of the 83 participants (35\%) generated two or more speech illusions. At the 6-month followup measurement, this was the case for 20 of the 66 participants (30\%). Ten participants had two or more speech illusions on both measurement occasions.

\section{Baseline}

Two participants were excluded from the analyses due to incomplete baseline EEG data and elevated resistance (all electrodes $>5 \mathrm{k} \Omega$ ). Table 1 shows associations between speech illusion and the log-transformed alpha band power at all electrodes. No significant main effect was demonstrated at any location. Furthermore, neither interactions between baseline alpha activity and trial number nor interactions between baseline alpha activity and alpha activity during the previous fragment were significant for any location ( $p$-values $\geq 0.086$ ). 
Table 1. Association between baseline alpha activity and speech illusion

\begin{tabular}{|c|c|c|}
\hline & t-value & p-value \\
\hline $\log$ Fz $\alpha$ & -0.149 & 0.882 \\
\hline${ }^{*}$ Trial number & 0.691 & 0.490 \\
\hline *Previous fragment Fz $\alpha$ & 1.118 & 0.263 \\
\hline $\log$ F3 $\alpha$ & -0.083 & 0.934 \\
\hline${ }^{*}$ Trial number & 0.536 & 0.592 \\
\hline${ }^{*}$ Previous fragment F3 $\alpha$ & -0.470 & 0.683 \\
\hline $\log$ F4 $\alpha$ & -0.094 & 0.925 \\
\hline *Trial number & 1.262 & 0.207 \\
\hline${ }^{*}$ Previous fragment F4 $\alpha$ & -0.137 & 0.891 \\
\hline $\log \mathrm{Cz} \alpha$ & 0.282 & 0.778 \\
\hline *Trial number & 0.016 & 0.987 \\
\hline${ }^{*}$ Previous fragment $\mathrm{Cz} \alpha$ & 0.104 & 0.917 \\
\hline $\log C 3 \alpha$ & -0.794 & 0.427 \\
\hline *Trial number & 0.320 & 0.749 \\
\hline * Previous fragment C3 $\alpha$ & -0.148 & 0.882 \\
\hline $\log C 4 \alpha$ & -0.304 & 0.761 \\
\hline *Trial number & 0.815 & 0.415 \\
\hline${ }^{*}$ Previous fragment C4 $\alpha$ & -0.920 & 0.357 \\
\hline $\log P z \alpha$ & -0.275 & 0.783 \\
\hline *Trial number & 0.232 & 0.817 \\
\hline${ }^{*}$ Previous fragment Pz $\alpha$ & -1.351 & 0.177 \\
\hline $\log P 3 \alpha$ & -1.071 & 0.284 \\
\hline *Trial number & 0.025 & 0.980 \\
\hline *Previous fragment P3 $\alpha$ & -1.030 & 0.303 \\
\hline $\log$ P4 $\alpha$ & -0.398 & 0.691 \\
\hline *Trial number & 0.218 & 0.828 \\
\hline *Previous fragment P4 $\alpha$ & -1.220 & 0.223 \\
\hline $\log \mathrm{Oz} \alpha$ & 0.293 & 0.770 \\
\hline${ }^{*}$ Trial number & 0.534 & 0.593 \\
\hline *Previous fragment $\mathrm{Oz} \alpha$ & -0.009 & 0.993 \\
\hline $\log 01 \alpha$ & -0.336 & 0.737 \\
\hline *Trial number & 1.063 & 0.288 \\
\hline *Previous fragment $01 \alpha$ & -0.868 & 0.385 \\
\hline $\log 02 \alpha$ & 0.441 & 0.660 \\
\hline${ }^{*}$ Trial number & 0.978 & 0.328 \\
\hline * Previous fragment $02 \alpha$ & -0.437 & 0.662 \\
\hline $\log$ T3 $\alpha$ & -0.119 & 0.905 \\
\hline *Trial number & 0.299 & 0.765 \\
\hline *Previous fragment T3 $\alpha$ & 0.974 & 0.330 \\
\hline $\log$ T4 $\alpha$ & 0.211 & 0.833 \\
\hline *Trial number & 1.718 & 0.086 \\
\hline *Previous fragment T4 $\alpha$ & 1.431 & 0.152 \\
\hline
\end{tabular}




\section{Discussion}

This study investigated the association between baseline alpha activity and speech illusions. More specifically, it tested whether baseline alpha oscillations, immediately before a white noise fragment, could predict the interpretation of the fragment. The results were not in line with the hypothesis, however. No significant association between baseline alpha activity and speech illusions was demonstrated for any location.

Previously, we presented evidence that a speech illusion was accompanied by reduced alpha activity during a noise fragment (26). While some studies have found evidence for the involvement of baseline alpha oscillations in the shaping of cortical networks for upcoming stimuli (22), pre-stimulus alpha activity of white noise speech illusions did not predict perception. The methodological difference between paradigms may explain the discrepancy in the findings. In the paradigms that demonstrated an association between perception and baseline activity (28-30), participants were presented with identical stimuli (e.g., transcranial magnetic stimuli) and had to indicate whether they perceived a stimulus. During the white noise task, participants are exposed to three types of stimuli. Furthermore, participants in the white noise task are not asked whether an auditory stimulus is present but are asked to judge the content of a fragment. A speech illusion can occur only during a white noise fragment, as the fragments with (clearly and barely) audible speech are added to the paradigm only to create a higher level of expectancy (21). Cortical mechanisms may differ between interpreting a stimulus and determining the presence of a stimulus. Cortical changes may therefore be illusion-dependent.

In the current study, the white noise task was carried out in a sample of the general population. White noise speech illusions are thought to reflect individual differences in risk of psychotic disorders $(20,21)$. It can be questioned, however, whether similar mechanisms are at play in patients with a psychotic disorder and in the subclinical population. With respect to a clinical population, it has been proposed that 
hallucinations may result from an increased influence of top-down processing. In the general population, however, evidence has been found that alterations in top-down processing during the white noise task (i.e., speech illusions) are unrelated to selfreported psychotic experiences (31). This may suggest that the underlying mechanisms of white noise speech illusions differ between the clinical and subclinical populations. Such differences may also extend to cortical oscillations during the white noise task. To obtain more insight into altered perceptions, it may be productive to directly compare the (pre-) stimulus alpha activity between clinical and subclinical populations.

\section{Methodological issues}

Baseline activity was defined as the alpha power $512 \mathrm{~ms}$ before the start of a white noise fragment. It cannot be ruled out that the pre-stimulus segment (treated as a 'baseline' measure) still contained effects of the previous fragment. In the paradigm, a new fragment starts 1 second after a button push (i.e., judgement of the previous fragment). Even though the second half of this 'baseline-second' was used as a predictor in the analyses, contamination of the baseline fragment cannot be eliminated. On the other hand, the association between baseline alpha activity and white noise speech illusion appeared not to be influenced by alpha activity during the previous fragment, which argues against the contamination of baseline alpha activity. In future studies, broadening the inter-stimulus interval may be considered.

In conclusion, in a sample of the general population, no association was found between baseline alpha activity and the interpretation of a white noise fragment. This topic may be studied further, taking into account other measures of psychosis proneness in addition to speech illusions and additional measures of risk stratification, such as familial risk of psychotic disorders and exposure to childhood trauma. 


\section{References}

1. Kapur S. Psychosis as a state of aberrant salience: a framework linking biology, phenomenology, and pharmacology in schizophrenia. Am J Psychiatry. 2003;160(1):13-23.

2. Aleman A, Bocker KB, Hijman R, de Haan EH, Kahn RS. Cognitive basis of hallucinations in schizophrenia: role of top-down information processing. Schizophr Res. 2003;64(2-3):175-85.

3. Hoffman RE, Woods SW, Hawkins KA, Pittman B, Tohen M, Preda A, et al. Extracting spurious messages from noise and risk of schizophrenia-spectrum disorders in a prodromal population. Br J Psychiatry. 2007;191:355-6.

4. Hugdahl K. "Hearing voices": auditory hallucinations as failure of top-down control of bottom-up perceptual processes. Scand J Psychol. 2009;50(6):553-60.

5. Modinos G, Costafreda SG, van Tol MJ, McGuire PK, Aleman A, Allen P. Neuroanatomy of auditory verbal hallucinations in schizophrenia: a quantitative meta-analysis of voxel-based morphometry studies. Cortex. 2013;49(4):1046-55.

6. Palaniyappan L, Balain V, Radua J, Liddle PF. Structural correlates of auditory hallucinations in schizophrenia: a meta-analysis. Schizophr Res. 2012;137(1-3):16973.

7. Shergill SS, Brammer MJ, Amaro E, Williams SC, Murray RM, McGuire PK. Temporal course of auditory hallucinations. Br J Psychiatry. 2004;185:516-7.

8. Ishii R, Shinosaki K, Ikejiri Y, Ukai S, Yamashita K, Iwase M, et al. Theta rhythm increases in left superior temporal cortex during auditory hallucinations in schizophrenia: a case report. Neuroreport. 2000;11(14):3283-7.

9. Sritharan A, Line P, Sergejew A, Silberstein R, Egan G, Copolov D. EEG coherence measures during auditory hallucinations in schizophrenia. Psychiatry Res. 2005;136(2-3):189-200.

10. Nathou C, Etard O, Simon G, Dollfus S. How do high- and low-frequency repetitive transcranial magnetic stimulations modulate the temporal cortex. Psychophysiology. 2015;52(2):192-8.

11. Ropohl A, Sperling W, Elstner S, Tomandl B, Reulbach U, Kaltenhauser M, et al. Cortical activity associated with auditory hallucinations. Neuroreport. 2004;15(3):523-6.

12. Spencer KM, Niznikiewicz MA, Nestor PG, Shenton ME, McCarley RW. Left auditory cortex gamma synchronization and auditory hallucination symptoms in schizophrenia. BMC Neurosci. 2009;10:85.

13. Steinmann S, Leicht G, Andreou C, Polomac N, Mulert C. Auditory verbal hallucinations related to altered long-range synchrony of gamma-band oscillations. Sci Rep. 2017;7(1):8401.

14. Verdoux $\mathrm{H}$, van Os J. Psychotic symptoms in non-clinical populations and the continuum of psychosis. Schizophr Res. 2002;54(1-2):59-65. 
15. Dhossche D, Ferdinand R, Van der Ende J, Hofstra MB, Verhulst F. Diagnostic outcome of self-reported hallucinations in a community sample of adolescents. Psychol Med. 2002;32(4):619-27.

16. Dominguez MD, Wichers M, Lieb R, Wittchen HU, van Os J. Evidence that onset of clinical psychosis is an outcome of progressively more persistent subclinical psychotic experiences: an 8-year cohort study. Schizophr Bull. 2011;37(1):84-93.

17. Wiles NJ, Zammit S, Bebbington P, Singleton N, Meltzer H, Lewis G. Self-reported psychotic symptoms in the general population: results from the longitudinal study of the British National Psychiatric Morbidity Survey. Br J Psychiatry. 2006;188:51926.

18. Poulton R, Caspi A, Moffitt TE, Cannon M, Murray R, Harrington H. Children's selfreported psychotic symptoms and adult schizophreniform disorder: a 15-year longitudinal study. Arch Gen Psychiatry. 2000;57(11):1053-8.

19. Hoffman RE. New methods for studying hallucinated 'voices' in schizophrenia. Acta Psychiatr Scand Suppl. 1999;395:89-94.

20. Catalan A, Simons CJ, Bustamante S, Drukker M, Madrazo A, de Artaza MG, et al. Novel evidence that attributing affectively salient signal to random noise is associated with psychosis. PLoS One. 2014;9(7):e102520.

21. Galdos M, Simons C, Fernandez-Rivas A, Wichers M, Peralta C, Lataster T, et al. Affectively salient meaning in random noise: a task sensitive to psychosis liability. Schizophr Bull. 2011;37(6):1179-86.

22. Lange J, Keil J, Schnitzler A, van Dijk H, Weisz N. The role of alpha oscillations for illusory perception. Behav Brain Res. 2014;271:294-301.

23. Leske S, Tse A, Oosterhof NN, Hartmann T, Muller N, Keil J, et al. The strength of alpha and beta oscillations parametrically scale with the strength of an illusory auditory percept. Neuroimage. 2014;88:69-78.

24. Muller N, Keil J, Obleser J, Schulz H, Grunwald T, Bernays RL, et al. You can't stop the music: reduced auditory alpha power and coupling between auditory and memory regions facilitate the illusory perception of music during noise. Neuroimage. 2013;79:383-93.

25. Weisz N, Moratti S, Meinzer M, Dohrmann K, Elbert T. Tinnitus perception and distress is related to abnormal spontaneous brain activity as measured by magnetoencephalography. PLoS Med. 2005;2(6):e153.

26. Schepers E, Bodar L, van Os J, Lousberg R. Cortical processes of speech illusions in the general population. BMC Neurosci. 2016;17(1):65.

27. Klem GH, Luders HO, Jasper HH, Elger C. The ten-twenty electrode system of the International Federation. The International Federation of Clinical Neurophysiology. Electroencephalogr Clin Neurophysiol Suppl. 1999;52:3-6.

28. Dugue L, Marque $P$, VanRullen R. The phase of ongoing oscillations mediates the causal relation between brain excitation and visual perception. J Neurosci.

2011;31(33):11889-93. 
29. Lange J, Oostenveld R, Fries P. Reduced occipital alpha power indexes enhanced excitability rather than improved visual perception. J Neurosci. 2013;33(7):321220.

30. Romei V, Brodbeck V, Michel C, Amedi A, Pascual-Leone A, Thut G. Spontaneous fluctuations in posterior alpha-band EEG activity reflect variability in excitability of human visual areas. Cereb Cortex. 2008;18(9):2010-8.

31. Pries LK, Guloksuz S, Menne-Lothmann C, Decoster J, van Winkel R, Collip D, et al. White noise speech illusion and psychosis expression: An experimental investigation of psychosis liability. PLoS One. 2017;12(8):e0183695. 
Baseline alpha activity: a predictor of white noise speech illusions in the general population? | 63 


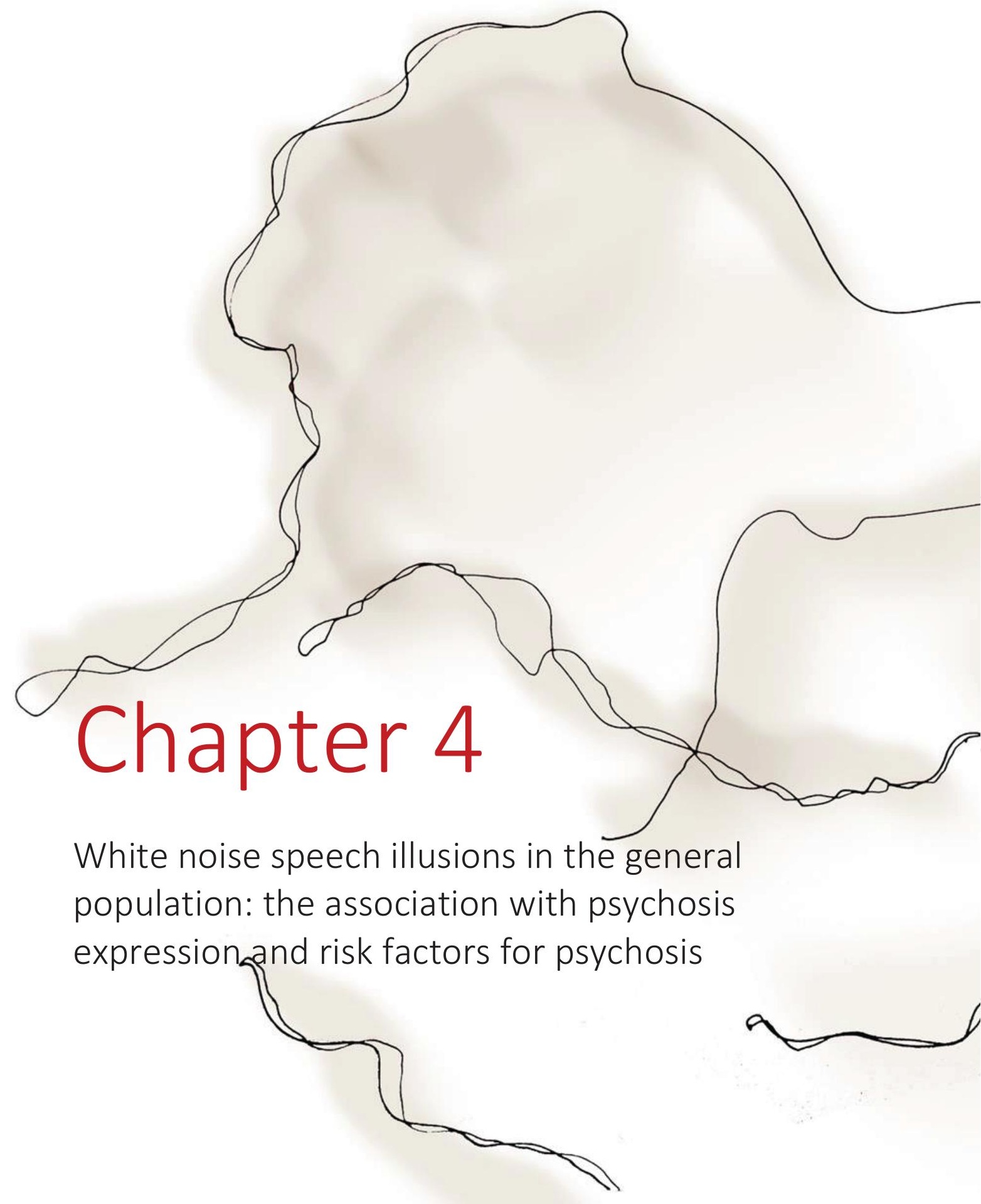




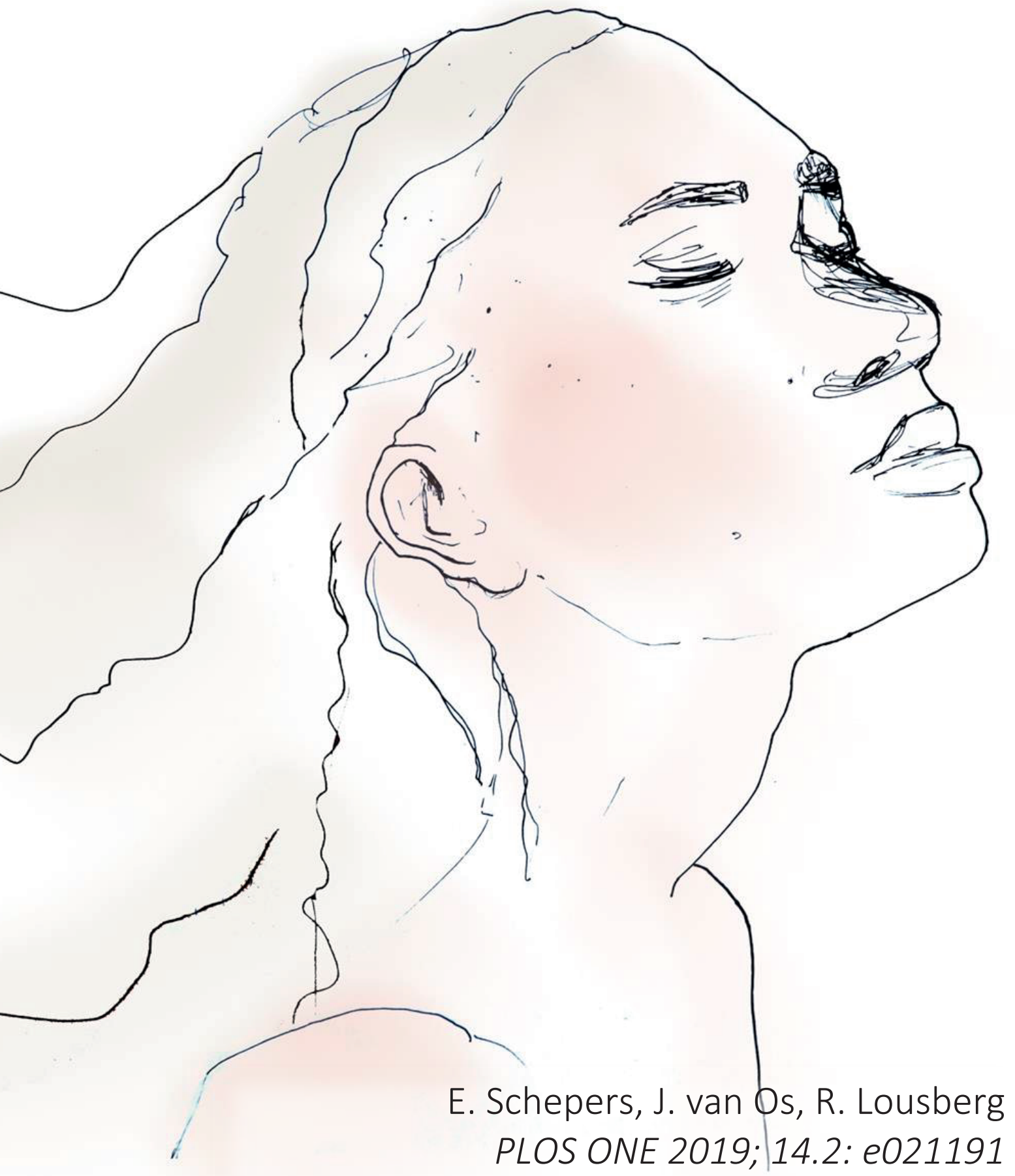




\section{Abstract}

Introduction Positive psychotic experiences are associated with increased rate of white noise speech illusions in patients and their relatives. However, findings have been conflicting to what degree speech illusions are associated with subclinical expression of psychosis in the general population. The aim of this study was to investigate the link between speech illusions and positive psychotic experiences in a general population sample. In addition, the hypothesis that speech illusions are on the pathway from known risk factors for psychosis (childhood adversity and recent life events) to subthreshold expression of psychosis, was examined.

Methods In a follow-up design (baseline and 6 months) the association between the number of white noise speech illusions and self-reported psychotic experiences, assessed with the Community Assessment of Psychic Experiences (CAPE), was investigated in a general population sample $(n=112)$. In addition, associations between speech illusions and childhood adversity and life events, using the Childhood Experiences of Care and Abuse questionnaire and the Social Readjustment Rating Scale, were investigated.

Results No association was found between the CAPE positive scale and the number of white noise speech illusions. The CAPE positive scale was significantly associated with childhood adversity between 12 and 16 years $(B=0.980 p=0.001)$ and life events ( $B=0.488 p=0.044)$. The number of speech illusions showed no association with either life events or childhood adversity.

Conclusion In the nonclinical population, the pathway from risk factors to expression of subclinical psychotic experiences does not involve white noise speech illusions as an intermediate outcome. 


\section{Introduction}

Psychotic experiences- in the form of attenuated reality distortion, such as bizarre experiences, perceptual abnormalities and persecutory ideas, as observed in psychotic disorders, are also prevalent in the general population (1). Psychotic experiences cooccur with other domains of subthreshold psychopathology particularly affective dysregulation (2) and the domain of motivational and cognitive alterations $(3,4)$. These findings suggest the existence of a multidimensional 'extended psychosis phenotype', encompassing a spectrum of severity $(3,4)$. Psychotic experiences show phenomenological continuity, in the same psychopathological domains, with psychotic disorder (5), and display transitions in severity over time (temporal continuity) (6-8). The so-called 'psychosis-proneness-persistence-impairment model' suggests that developmental expression of psychosis may become abnormally persistent, and clinically relevant, depending on the degree of environmental exposure interacting with genetic risk (1). In addition, it has been suggested that psychosis represents a transdiagnostic spectrum, with manifestation in psychotic disorders, emotional disorders, individuals considered at 'clinical high-risk' and the general population (4).

The aetiology of altered perceptions and ideation in the context of psychosis remains largely unknown. Theoretical accounts of the cognitive mechanism of hallucinations suggest that normal perception can be viewed as (sensory) bottom-up information combined with top-down information originating from prior knowledge based on previous experience (9-11). A relatively higher priority to top-down factors compared to bottom-up factors may contribute to the formation of hallucinations $(9,12)$.

Unlike hallucinations, illusions are distorted interpretations of a 'real' existing stimulus (13). A number of experimental illusion studies have used an experimental paradigm to examine the tendency to hear voices in white noise (defined as speech illusions), which may operate on top-down processing. The results suggest that the number of 
speech illusions reflects individual differences in psychosis liability. Thus, Hoffman and colleagues suggested that speech illusions signal an increased risk for transition to a psychotic disorder in a prodromal population (14). Subsequent research suggested that a White Noise experiment, first reported by Galdos et al. (15) and replicated by Catalan and colleagues (16), can be used to prime and elicit auditory illusions as an index of psychosis liability.

However, there is inconsistency to what degree subclinical expression of psychosis in the general population may be associated with speech illusions generated in the White Noise Task. Both the Structured Interview for Schizotypy-Revised (SIS-R) (17) and the self-report Community Assessment of Psychic Experiences (CAPE) $(18,19)$ are designed to measure positive psychotic experiences in the general population. Whereas Galdos and colleagues found evidence for an association between any speech illusion and SIS-R positive schizotypy in well controls (odds ratio 2.4) (15), Catalan and colleagues failed to demonstrate an association between speech illusions and either SIS-R positive schizotypy (OR 1.1) or the CAPE positive scale (OR 1.4) (16). Recently, novel analyses of the expanded sample of the study of Catalan and colleagues showed a significant association between positive schizotypy and speech illusions (OR 4.1). However, after adjusting for age, sex and WAIS-III, the association was no longer significant and appeared to be mediated to a large extent by cognitive ability (20). Pries et al. replicated the various statistical methodologies of Catalan and Galdos in a general population twin sample. The results revealed that perception of white noise speech illusion was not associated with either schizotypy (positive or negative) or CAPE score, independent of the methodological strategy used (21). In a general population cohort of pre-adolescent children, speech illusions were only associated with hallucinations (last month) and negative affect (last month and lifetime) when focussing on affectively salient speech illusions (22).

Given these inconclusive findings, we decided to conduct a new study, not only to reinvestigate the relationship between the number of speech illusions and the CAPE 
positive scale, but also to examine to what degree experimental (white noise task) and observational measures (CAPE positive scale) of psychosis showed the same pattern of association with known risk factors for psychosis such as childhood trauma $(23,24)$ and life events $(25)$, which would be compatible with the hypothesis of speech illusions lying on the causal pathway between psychosis risk factors, such as childhood trauma, and psychosis outcome. Alternatively, childhood trauma and life events may have a moderating influence, strengthening the association between speech illusions and psychotic experiences. We thus hypothesized i) a positive association between CAPE and speech illusions; ii) a stronger association between the CAPE positive scale and white noise speech illusions if there was additional evidence for childhood adversity or life events; iii) significant associations between speech illusions and psychosis risk factors of childhood trauma and life events; and iv) positive associations between CAPE and psychosis risk factors.

\section{Materials and method}

\section{Participants}

One-hundred and twelve persons participated, of whom 95 attended the 6-month follow up assessment. Recruitment of participants was carried out by distributing flyers at public places in Maastricht (population: 120.000). Persons, willing to participate in scientific research about development of (mental) health problems in the general population, were asked to contact the research assistant. Exclusion criteria were the use of antipsychotic, anti-epileptic, antidepressant or anxiolytic medications during the past year and structural excessive use of alcohol (more than 5 units per day). Participants were asked to avoid the use of alcohol the day before the experiment as well as caffeine-containing beverages three hours before the experiment. Participants with hearing problems were excluded. Compensation for participating in both assessments was $50 €$. 


\section{Ethics statement}

The study was conducted according to the principles of the Declaration of Helsinki. The medical ethics committee at Maastricht University Medical Centre approved the study (NL40284.068.12/METC 12-3-015). Written informed consent was given by the participants before the start of the experiment.

\section{Instruments}

\section{CAPE}

The Community Assessment of Psychic Experiences $(18,19)$ was used to measure subclinical positive, negative and depressive symptoms. Participants rated both frequency $(0=$ never to $3=$ nearly always $)$ and distress $(0=$ not distressed to $3=$ very distressed) of psychotic experiences. The sum of the frequency scale and the mean of the distress scale was calculated for each domain of psychotic experiences (positive, negative and depressive). In theanalysis, only the frequency measure of the positive symptom domain was used. The CAPE has been shown to possess good reliability and validity in general population samples (18).

\section{Social Readjustment Rating Scale}

A shortened version (14 life events) of the Social Readjustment Rating Scale was used to measure stressful life events (26). At baseline, individuals rated the presence of life events experienced during the past year. Six months later, at follow up, participants were asked whether they had experienced new events over the follow-up period. The sum of life events rated at baseline and at follow up were calculated. The internal consistency was adequate (Cronbach's $\alpha=0.622$ ).

\section{Childhood adversity}

Childhood Adversity (CA) was measured with a questionnaire developed within the context of the FP7 EU-GEI project (European network of national schizophrenia networks studying Gene-Environment Interactions) (27). Participants were asked to fill in the Childhood Experiences of Care and Abuse questionnaire during baseline 
assessment. The questionnaire consists of 15 questions on adverse childhood events like presence of financial problems, occurrence of sexual abuse and divorce of parents. Two categories were distinguished: adverse life events between 0 and 11 years (early childhood), and events between 12 and 16 years (adolescence). The sum score of each category was calculated, ranging from 0 to 15 . Cronbach's $\alpha$ was 0.690 for childhood adversity between 0 and 11 years and 0.642 for childhood adversity between 12 and 16 years.

\section{Educational level}

Highest educational level was assessed and classified according to the Dutch school system ( 1 = primary education, 2 = pre-vocational secondary education, 3 = senior secondary vocational education and training, 4 = senior general secondary education, $5=$ pre-university secondary education, 6 = higher professional education and $7=$ university). A dichotomized 0-1 dummy-variable was calculated, 0 indicating low to average educational level (category 1 to 3 ), and 1 indicating higher educational level (category 4 to 7 ).

The white noise task

The experiment was conducted at baseline and at 6-month follow-up. The white noise task was administered on both occasions and was carried out, for each individual separately, by a master-level research assistant with 5 years of experience. Before the start of the experiment, participants were instructed to listen to sound fragments and to rate the content of the fragments. If there were uncertainties about the instructions, participants could discuss their questions with the research assistant. During the task, each participant was exposed to 75 sound fragments: 25 fragments containing white noise; 25 fragments of white noise mixed with barely audible speech and 25 fragments of white noise mixed with clearly audible speech with a positive, negative or neutral affective context. For example: 'Sport is good for health', 'I think it is going to rain today' or 'Madrid is the capital of Spain'. The presentation of the 75 fragments was in random order and the (clearly and barely audible) sentences were of 
the same male voice. The fragments were binaurally presented through a wire headset (Plantronics) and the task was carried out in a soundproof room. After the ending of each fragment, participants were asked to press a button on a keyboard in front of them indicating five options: 1: endorsed hearing speech with positive content, 2: endorsed hearing speech with negative content, 3: endorsed hearing speech with neutral content, 4: no speech heard, and 5: endorsed hearing speech but uncertain whether it was positive, negative or neutral. The protocol was guided by the software package 'Presentation' (Version 13.0, Neurobehavioral Systems, Inc.). The word "Listen!" was displayed on the computer screen in front of the participant during the fragment. After a fragment, the five answering options were shown. A new fragment started after an option had been selected by a push on the button. Response time was calculated as the time (in $\mathrm{ms}$ ) between the end of a fragment and a button push. The total duration of the task varied, since the response time varied per participant per sound fragment. The average duration of the task was 8.9 minutes. In line with the definition proposed by Catalan and colleagues (16), a speech illusion was defined as a white noise only fragment in which any speech was heard (option $1,2,3$ or 5). As participants were exposed to 75 fragments, of which 25 contained 'pure' white noise, the maximum number of speech illusions per measurement occasion was 25.

\section{Statistical analyses}

First, the association between the CAPE positive scale and speech illusions was investigated. Number of speech illusions as dependent variable was treated both as continuous and dichotomized variable. The dichotomized score was defined in two ways: as a cut-off value of $\geq 1$, conform the methodology proposed by Galdos et al (15), as well as a cut-off value of $\geq 2$, as proposed by Catalan and colleagues (16). Poisson mixed-effects regression models were applied to the non-normally distributed count variable, and binary logistic mixed-effects regression models for the dichotomous variables. As the data were hierarchically organised (measurement occasions nested within individuals), random intercepts for individuals were added to 
the models. First, models were run with the CAPE positive scale as the predictor of main interest. Second, separate models were executed with speech illusion explained by the interaction between the CAPE positive scale and (i) childhood adversity between 0 and 11 years, (ii) childhood adversity between 12 and 16 years and (iii) life events one year before baseline. Analyses were corrected for age, sex and educational level. Similarly, the Poisson mixed-effects regression model and binary logistic mixedeffect regression models were run with respectively continuous and dichotomised speech illusion as the dependent variable, explained by 4 predictor variables: (i) childhood adversity between 0 and 11 years; (ii) childhood adversity between 12 and 16 years; (iii) life events experienced one year before baseline and (iv) life events between baseline and follow-up. All models were corrected for age, sex and educational level. Finally, linear regression models were run with the CAPE positive scale as dependent variable explained by childhood adversity (between 0 and 11 and between 12 and 16 years) and life events. Since the CAPE positive scale was administered once (at baseline), only life events experienced 1 year before baseline were incorporated in the model, corrected for age sex and educational level. Associations were significant when two-sided p-value was $<0.05$. SPSS-version 24 was used as the statistical software package.

\section{Results}

\section{Participants}

One-hundred and twelve participants (age: mean $=39.4 ; \mathrm{SD}=17.5$; sex: 39 men, 73 women) were included at baseline. At 6-month follow up, 95 participants (age: mean = 40.8; SD = 17.3; sex: 34 men, 61 women) were assessed again. Loss-to-follow up analyses were carried out to check for differential attrition. There was no evidence for differential attrition with respect to the rate of speech illusions $(p=0.239)$, age $(p=$ $0.053)$ and sex $(p=0.611)$. Table 1 reports the overview of the demographic variables for baseline and six month follow-up. The median of number of speech illusions at both baseline and follow-up was 1 (Table 2). In total, 461 speech illusions were 
observed at both measurements. Only two speech illusions (0.4\%) were judged as having an affective connotation (one positive and one negative).

Table 1. Summary of selected demographic variables and covariates

\begin{tabular}{|c|c|c|}
\hline & $\begin{array}{l}\text { Baseline ( } n=112 \text { ) } \\
\text { mean (SD) }\end{array}$ & $\begin{array}{l}\text { Follow-up }(n=95) \\
\text { mean (SD) }\end{array}$ \\
\hline Age & $39.4(17.5)$ & $40.8(17.3)$ \\
\hline Female & $65.2 \%(n=73)$ & $64.2 \%(n=61)$ \\
\hline Male & $34.8 \%(n=39)$ & $35.8 \%(n=34)$ \\
\hline \multicolumn{3}{|l|}{ Educational level } \\
\hline Level 1 & $5.4 \%(n=6)$ & $4.2 \%(n=4)$ \\
\hline Level 2 & $8.9 \%(n=10)$ & $9.5 \%(n=9)$ \\
\hline Level 3 & $17.9 \%(n=20)$ & $17.9 \%(n=17)$ \\
\hline Level 4 & $5.4 \%(n=6)$ & $5.3 \%(n=5)$ \\
\hline Level 5 & $28.6 \%(n=32)$ & $27.4 \%(n=26)$ \\
\hline Level 6 & $18.8 \%(n=21)$ & $20.0 \%(n=19)$ \\
\hline Level 7 & $15.2 \%(n=17)$ & $15.8 \%(n=15)$ \\
\hline \multicolumn{3}{|l|}{ CAPE scale } \\
\hline Positive dimension & $4.6(4.1)$ & $4.8(4.1)$ \\
\hline Negative dimension & $8.0(5.4)$ & $8.2(5.7)$ \\
\hline Depressive dimension & $4.9(3.2)$ & $5.0(3.4)$ \\
\hline Total number of life events & $2.0(1.5)$ & $1.9(1.6)$ \\
\hline \multicolumn{3}{|l|}{ Childhood adversity } \\
\hline Between 0 and 11 & $1.7(1.9)$ & $1.6(1.8)$ \\
\hline Between 11 and 18 & $1.6(1.8)$ & $1.6(1.8)$ \\
\hline
\end{tabular}


Table 2. White noise speech illusions during baseline and follow-up.

\begin{tabular}{|l|l|l|}
\hline & Baseline $(n=112)$ & Follow-up $(n=95)$ \\
\hline Total number of SIs & 249 & 212 \\
\hline Percentage of SIs & 8.9 & 8.9 \\
\hline Median number of SIs per participant & 1 & 1 \\
\hline
\end{tabular}

$\mathrm{SI}=$ speech illusion

\section{Prediction models of speech illusions}

No association between the CAPE-positive scale and white noise speech illusions could be demonstrated, neither with speech illusions as a continuous variable $(B=0.011$, $95 \% \mathrm{Cl}-0.053-0.074, \mathrm{p}=0.742$ ); nor with a dichotomized variable (cut-off $\geq 1 \mathrm{~B}=$ 0.030, 95\% Cl -0.049-0.109, p = 0.454, cut-off $\geq 2$ B $=0.018,95 \% \mathrm{Cl}-0.067-0.104, p=$ 0.671). There was no evidence that the association between the CAPE-positive scale and white noise speech illusions was moderated by childhood adversity or life events (Table 3). In addition, white noise speech illusions (both as a continuous and as dichotomized variable) were not associated with either childhood adversity or life events (Table 4). 
Table 3. Interaction between CAPE positive scale and childhood trauma or life events.

\begin{tabular}{|c|c|c|c|c|c|c|}
\hline \multirow{2}{*}{$\begin{array}{l}\text { Dependent } \\
\text { variables }\end{array}$} & \multicolumn{2}{|l|}{ SI; continuous } & \multicolumn{2}{|l|}{ SI; cut-off $\geq 2$} & \multicolumn{2}{|l|}{ SI; cut-off $\geq 1$} \\
\hline & $\begin{array}{l}\text { B-coefficient } \\
(95 \% \mathrm{Cl})\end{array}$ & $p$ & $\begin{array}{l}\text { B-coefficient } \\
(95 \% \mathrm{Cl})\end{array}$ & $\mathrm{p}$ & $\begin{array}{l}\text { B-coefficient } \\
(95 \% \mathrm{Cl})\end{array}$ & $\mathrm{p}$ \\
\hline $\begin{array}{l}\text { CAPE } x \\
\text { Child abuse } \\
0 \text { and } 11 \\
\text { years }\end{array}$ & $\begin{array}{l}0.012 \\
(-0.022-0.046)\end{array}$ & 0.483 & $\begin{array}{l}0.012 \\
(-0.033-0.056)\end{array}$ & 0.606 & $\begin{array}{l}0.025 \\
(-0.019-0.068)\end{array}$ & 0.265 \\
\hline $\begin{array}{l}\text { CAPE } x \\
\text { Child abuse } \\
12 \text { and } 16 \\
\text { years }\end{array}$ & $\begin{array}{l}0.006 \\
(-0.023-0.036)\end{array}$ & 0.662 & $\begin{array}{l}0.006 \\
(-0.035-0.046)\end{array}$ & 0.781 & $\begin{array}{l}0.011 \\
(-0.028-0.050)\end{array}$ & 0.592 \\
\hline $\begin{array}{l}\text { CAPE } x \text { Life } \\
\text { events } \\
\text { before } \\
\text { baseline }\end{array}$ & $\begin{array}{l}-0.015 \\
(-0.060-0.029)\end{array}$ & 0.493 & $\begin{array}{l}-0.029 \\
(-0.089-0.031)\end{array}$ & 0.346 & $\begin{array}{l}-0.002 \\
(-0.056-0.052)\end{array}$ & 0.941 \\
\hline
\end{tabular}

$\mathrm{SI}=$ speech illusion

B-coefficient= non-standardized regression coefficient

$95 \% \mathrm{Cl}=95 \%$ confidence interval

$p=p$-value 
Table 4. Main effect of childhood trauma and life events on white noise speech illusions.

\begin{tabular}{|c|c|c|c|c|c|c|}
\hline \multirow{2}{*}{$\begin{array}{l}\text { Dependent } \\
\text { variables }\end{array}$} & \multicolumn{2}{|l|}{ SI; continuous } & \multicolumn{2}{|l|}{ SI; cut-off $\geq 2$} & \multicolumn{2}{|l|}{ SI; cut-off $\geq 1$} \\
\hline & $\begin{array}{l}\text { B-coefficient } \\
(95 \% \mathrm{Cl})\end{array}$ & $p$ & $\begin{array}{l}\text { B-coefficient } \\
(95 \% \mathrm{Cl})\end{array}$ & $p$ & $\begin{array}{l}\text { B-coefficient } \\
(95 \% \mathrm{Cl})\end{array}$ & $\mathrm{p}$ \\
\hline $\begin{array}{l}\text { Child abuse } \\
0 \text { and } 11 \\
\text { years }\end{array}$ & $\begin{array}{l}-0.078 \\
(-0.333-0.178)\end{array}$ & 0.547 & $\begin{array}{l}-0.117 \\
(-0.493-0.259)\end{array}$ & 0.537 & $\begin{array}{l}-0.125 \\
(-0.505-0.255)\end{array}$ & 0.515 \\
\hline $\begin{array}{l}\text { Child abuse } \\
12 \text { and } 16 \\
\text { years }\end{array}$ & $\begin{array}{l}0.092 \\
(-0.156-0.340)\end{array}$ & 0.463 & $\begin{array}{l}0.209 \\
(-0.156-0.573)\end{array}$ & 0.258 & $\begin{array}{l}0.319 \\
(-0.084-0.721)\end{array}$ & 0.119 \\
\hline $\begin{array}{l}\text { Life events } \\
\text { before } \\
\text { baseline }\end{array}$ & $\begin{array}{l}0.078 \\
(-0.130-0.287)\end{array}$ & 0.458 & $\begin{array}{l}0.098 \\
(-0.202-0.399)\end{array}$ & 0.518 & $\begin{array}{l}0.010 \\
(-0.290-0.310)\end{array}$ & 0.946 \\
\hline $\begin{array}{l}\text { Life events } \\
\text { before } \\
\text { follow up }\end{array}$ & $\begin{array}{l}0.141 \\
(-0.229-0.512)\end{array}$ & 0.450 & $\begin{array}{l}0.272 \\
(-0.291-0.834)\end{array}$ & 0.339 & $\begin{array}{l}-0.063 \\
(-0.632-0.506)\end{array}$ & 0.826 \\
\hline
\end{tabular}

$\mathrm{SI}=$ speech illusion

B-coefficient= non-standardized regression coefficient

$95 \% \mathrm{Cl}=95 \%$ confidence interval

$p=p$-value

\section{Prediction models of the CAPE-positive scale}

In the linear regression model correcting for age sex and educational level (R-square 0.217), an association was found between the CAPE-positive scale and childhood adversity between 12 and 16 years $(B=0.980,95 \% \mathrm{Cl} 0.389-1.562, \mathrm{p}=0.001)$ and life events one year before baseline $(B=0.488,95 \% \mathrm{Cl} 0.013-0.963, p=0.044)$. There was no association with childhood adversity between 0 and 11 years $(B=-0.210,95 \% \mathrm{Cl}-$ $0.764-0.343 p=0.453)$. 


\section{Discussion}

This study investigated hypothesized associations between white noise speech illusions, psychosis expression and risk factors for psychosis. The initial hypotheses could not be confirmed by the results of the present study. Thus, the analyses demonstrated that: (i) speech illusions were not associated with the CAPE positive scale; (ii) the association between speech illusions and the CAPE positive scale was not moderated by childhood adversity or life events; (iii) speech illusions were not associated with childhood adversity or life events and (iv) the CAPE positive scale was associated with childhood adversity and life events. These findings therefore are not compatible with the hypothesis that early risk factors impact on psychosis expression via speech illusions, or that environmental risks moderate the association between speech illusions and psychotic experiences.

Previous research is inconclusive with respect to the association between speech illusions and observational measures for psychotic experiences (CAPE positive scale and the SIS-R) $(15,16,21,22)$. In line with the results of Catalan and colleagues and Pries et al., the current study showed no significant association between the CAPE positive scale and the number of speech illusions. This finding might be explained by the theory that observational measures of psychosis and the white noise task focus on different mechanisms underlying psychosis liability in the nonclinical population. The CAPE positive scale mainly indexes alterations in psychosis ideation, whereas the white noise task focusses on alterations in perception. Also, the CAPE positive scale may reflect trait psychosis proneness whereas speech illusions may reflect state variation.

Importantly, the present study focussed on the association between the white noise task and subclinical expression of positive psychotic experiences in the nonclinical population. In the clinical population, imbalance between top-down and bottom-up processing may mediate psychotic symptoms. However, the current findings suggest that in the nonclinical population, altered processing of sensory information is 
unrelated to the expression of subclinical symptoms. In other words, alteration in perception will not always induce alteration in ideation. Clinical psychosis may reflect the state where alterations in perceptions give rise to delusional explanations (28). Further research is required to support this theory.

This study is not without shortcomings. Earlier research showed that the association between speech illusions and interview-based measures of positive schizotypy appeared to be mediated by other variables including cognitive ability. Therefore, analyses were corrected for educational level. It might have been more precise, however, to examine cognitive ability with neuropsychological testing. Given the nullfinding, however, this lack of sensitivity of the cognitive measure is unlikely to have biased the findings. A second point is related to the choice to include a non-clinical sample. A comparison of effects with a clinical population would have been helpful to better understand possible mediating mechanisms associated with speech illusion on the pathway form risk to psychosis expression. Further study is required to examine this issue.

Finally, no association between white noise speech illusions and expression of subclinical psychotic experiences could be demonstrated in the non-clinical population, suggesting this association is a marker of illness rather than risk. Further research is required, particularly research focussing in non-clinical but at-risk populations such as siblings of patients with a psychotic disorder, who may have higher levels of speech illusions (15). 


\section{References}

1. van Os J, Linscott RJ, Myin-Germeys I, Delespaul P, Krabbendam L. A systematic review and meta-analysis of the psychosis continuum: evidence for a psychosis proneness-persistence-impairment model of psychotic disorder. Psychol Med. 2009;39(2):179-95.

2. van Rossum I, Dominguez MD, Lieb R, Wittchen HU, van Os J. Affective dysregulation and reality distortion: a 10-year prospective study of their association and clinical relevance. Schizophr Bull. 2011;37(3):561-71.

3. Linscott RJ, van Os J. An updated and conservative systematic review and metaanalysis of epidemiological evidence on psychotic experiences in children and adults: on the pathway from proneness to persistence to dimensional expression across mental disorders. Psychol Med. 2013;43(6):1133-49.

4. van Os J, Reininghaus U. Psychosis as a transdiagnostic and extended phenotype in the general population. World Psychiatry. 2016;15(2):118-24.

5. Dominguez MD, Saka MC, Lieb R, Wittchen HU, van Os J. Early expression of negative/disorganized symptoms predicting psychotic experiences and subsequent clinical psychosis: a 10-year study. Am J Psychiatry. 2010;167(9):1075-82.

6. Debbane M, Eliez S, Badoud D, Conus P, Fluckiger R, Schultze-Lutter F. Developing psychosis and its risk states through the lens of schizotypy. Schizophr Bull. 2015;41 Suppl 2:S396-407.

7. Fonseca Pedrero E, Debbane M. Schizotypal traits and psychotic-like experiences during adolescence: An update. Psicothema. 2017;29(1):5-17.

8. Kaymaz N, Drukker M, Lieb R, Wittchen HU, Werbeloff N, Weiser M, et al. Do subthreshold psychotic experiences predict clinical outcomes in unselected nonhelp-seeking population-based samples? A systematic review and meta-analysis, enriched with new results. Psychol Med. 2012;42(11):2239-53.

9. Aleman A, Bocker KB, Hijman R, de Haan EH, Kahn RS. Cognitive basis of hallucinations in schizophrenia: role of top-down information processing. Schizophr Res. 2003;64(2-3):175-85.

10. Behrendt RP. Underconstrained perception: a theoretical approach to the nature and function of verbal hallucinations. Compr Psychiatry. 1998;39(4):236-48.

11. Daalman K, Verkooijen S, Derks EM, Aleman A, Sommer IE. The influence of semantic top-down processing in auditory verbal hallucinations. Schizophr Res. 2012;139(1-3):82-6.

12. Hugdahl K. "Hearing voices": auditory hallucinations as failure of top-down control of bottom-up perceptual processes. Scand J Psychol. 2009;50(6):553-60.

13. Collip D, Myin-Germeys I, Van Os J. Does the concept of "sensitization" provide a plausible mechanism for the putative link between the environment and schizophrenia? Schizophr Bull. 2008;34(2):220-5. 
14. Hoffman RE, Woods SW, Hawkins KA, Pittman B, Tohen M, Preda A, et al. Extracting spurious messages from noise and risk of schizophrenia-spectrum disorders in a prodromal population. Br J Psychiatry. 2007;191:355-6.

15. Galdos M, Simons C, Fernandez-Rivas A, Wichers M, Peralta C, Lataster T, et al. Affectively salient meaning in random noise: a task sensitive to psychosis liability. Schizophr Bull. 2011;37(6):1179-86.

16. Catalan A, Simons CJ, Bustamante S, Drukker M, Madrazo A, de Artaza MG, et al. Novel evidence that attributing affectively salient signal to random noise is associated with psychosis. PLoS One. 2014;9(7):e102520.

17. Vollema MG, Ormel J. The reliability of the structured interview for schizotypyrevised. Schizophr Bull. 2000;26(3):619-29.

18. Konings $M$, Bak M, Hanssen M, van Os J, Krabbendam L. Validity and reliability of the CAPE: a self-report instrument for the measurement of psychotic experiences in the general population. Acta Psychiatr Scand. 2006;114(1):55-61.

19. Mossaheb N, Becker J, Schaefer MR, Klier CM, Schloegelhofer M, Papageorgiou K, et al. The Community Assessment of Psychic Experience (CAPE) questionnaire as a screening-instrument in the detection of individuals at ultra-high risk for psychosis. Schizophr Res. 2012;141(2-3):210-4.

20. Gonzalez de Artaza M, Catalan A, Angosto V, Valverde C, Bilbao A, van Os J, et al. Can an experimental white noise task assess psychosis vulnerability in adult healthy controls? PLoS One. 2018;13(2):e0192373.

21. Pries LK, Guloksuz S, Menne-Lothmann C, Decoster J, van Winkel R, Collip D, et al. White noise speech illusion and psychosis expression: An experimental investigation of psychosis liability. PLoS One. 2017;12(8):e0183695.

22. Rimvall MK, Clemmensen L, Munkholm A, Rask CU, Larsen JT, Skovgaard AM, et al. Introducing the White Noise task in childhood: associations between speech illusions and psychosis vulnerability. Psychol Med. 2016;46(13):2731-40.

23. Read J, van Os J, Morrison AP, Ross CA. Childhood trauma, psychosis and schizophrenia: a literature review with theoretical and clinical implications. Acta Psychiatr Scand. 2005;112(5):330-50.

24. Varese F, Smeets F, Drukker M, Lieverse R, Lataster T, Viechtbauer W, et al. Childhood adversities increase the risk of psychosis: a meta-analysis of patientcontrol, prospective- and cross-sectional cohort studies. Schizophr Bull. 2012;38(4):661-71.

25. Beards S, Gayer-Anderson C, Borges S, Dewey ME, Fisher HL, Morgan C. Life events and psychosis: a review and meta-analysis. Schizophr Bull. 2013;39(4):740-7.

26. Holmes TH, Rahe RH. The Social Readjustment Rating Scale. J Psychosom Res. 1967;11(2):213-8.

27. European Network of National Networks studying Gene-Environment Interactions in S, van Os J, Rutten BP, Myin-Germeys I, Delespaul P, Viechtbauer W, et al. Identifying gene-environment interactions in schizophrenia: contemporary 
challenges for integrated, large-scale investigations. Schizophr Bull. 2014;40(4):729-36.

28. Smeets F, Lataster $T$, van Winkel $R$, de Graaf $R$, Ten Have $M$, van Os J. Testing the hypothesis that psychotic illness begins when subthreshold hallucinations combine with delusional ideation. Acta Psychiatr Scand. 2013;127(1):34-47. 
White noise speech illusions in the general population: the association with psychosis expression and risk factors for psychosis | 83 


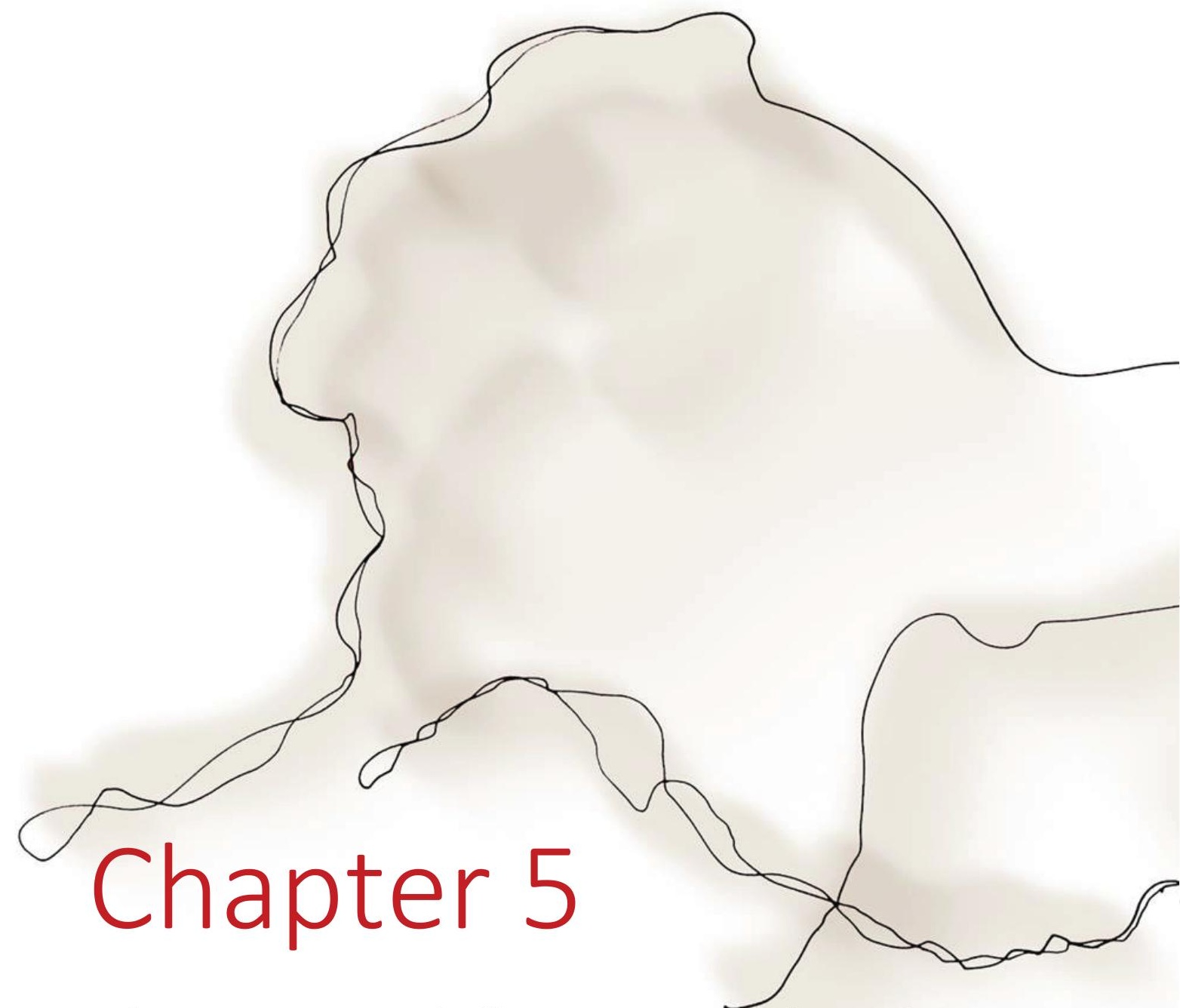

White noise speech illusions: a trait-dependent risk marker for psychotic disorder?

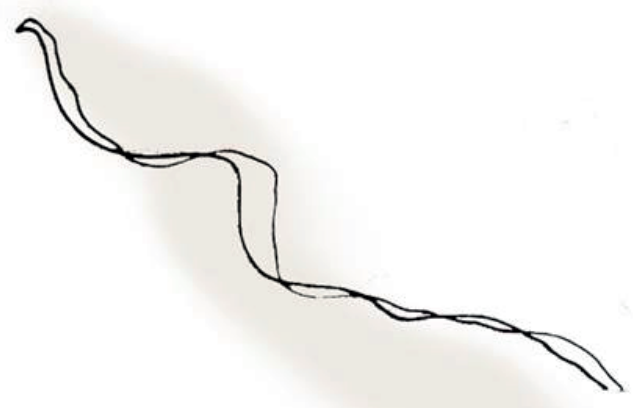




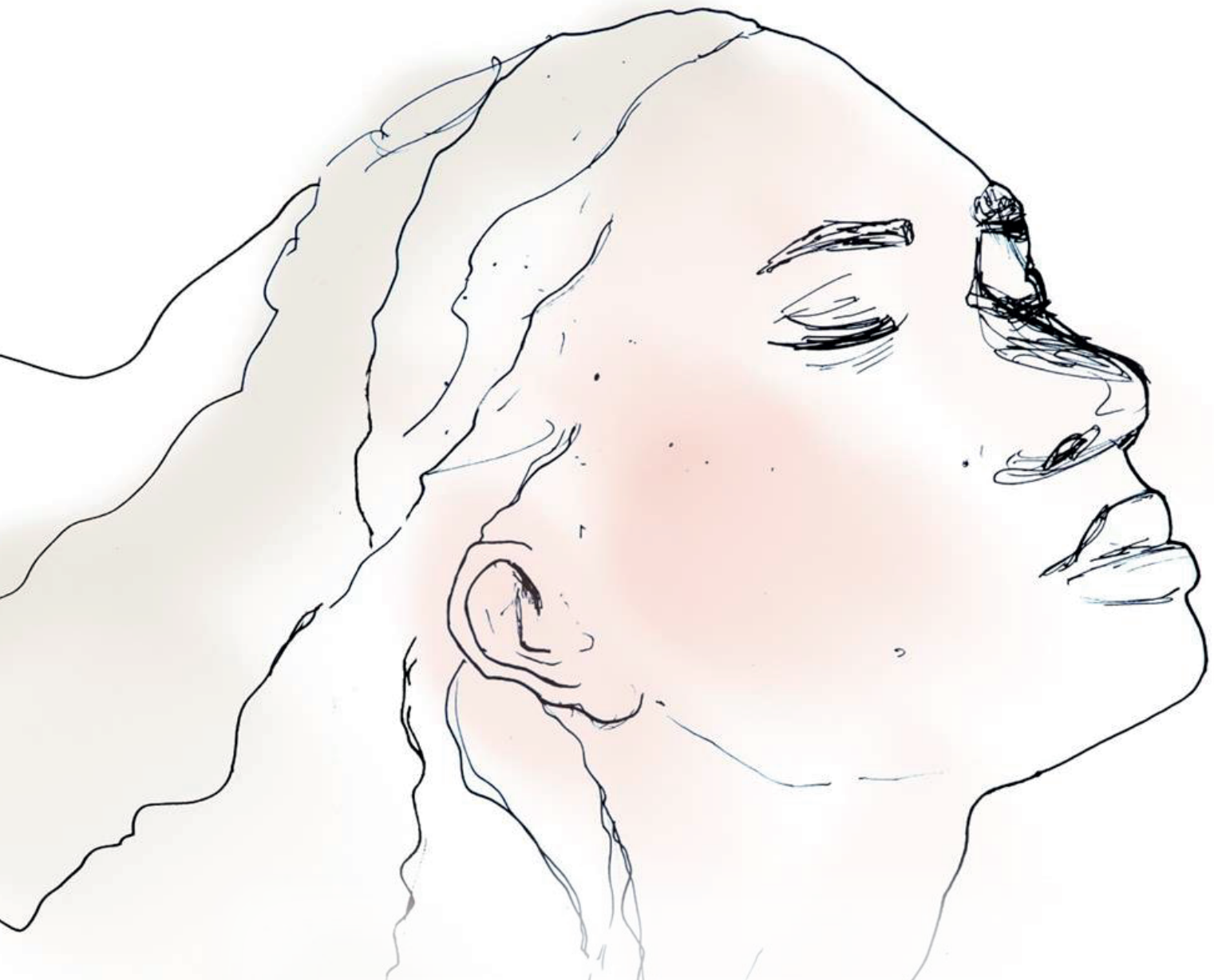

Elaine Schepers, Richel Lousberg, Sinan Guloksuz, Lotta-Katrin Pries, Philippe Delespaul, Gunter Kenis, Jurjen J. Luykx, Bochao D. Lin, Alexander L. Richards, Berna Akdede, Tolga Binbay, Vesile Altınyazar, Berna Yalınçetin, Güvem Gümüş-Akay, B Irçin Cihan, Haldun Soygür, Halis Ulaş, Eylem Şahin Cankurtaran, Semra Ulusoy Kaymak, Marina M. Mihaljevic, Sanja Andric Petrovic, Tijana Mirjanic, Miguel Bernard, Bibiana Cabrera, Julio Bobes, Pilar A. Saiz, María Paz García-Portilla, Julio Sanjuan, Eduardo J. Aguilar, José Luis Santos, Estela Jiménez-López, Manuel Arrojo, Angel Carracedo, Gonzalo López, Javier González-Peñas, Mara Parellada, Nadja P. Maric, Cem Atbaşoğlu, Alp Ucok, Köksal Alptekin, Meram Can Saka, Celso Arango, Bart P.F. Rutten, Jim van Os Frontiers in Psychiatry 2019; 10: 676 


\section{Abstract}

Introduction White noise speech illusions index liability for psychotic disorder in case-control comparisons. In the current study, we examined (i) the rate of white noise speech illusions in siblings of patients with psychotic disorder, and (ii) to what degree this rate would be contingent on exposure to known environmental risk factors (childhood adversity and recent life events) and level of known endophenotypic dimensions of psychotic disorder (psychotic experiences assessed with the Community Assessment of Psychic Experiences (CAPE) scale and cognitive ability).

Methods The White Noise task was used as an experimental paradigm to elicit and measure speech illusions in 1014 patients with psychotic disorders, 1157 siblings and 1507 healthy participants. We examined associations between speech illusions and increasing familial risk (control -> sibling -> patient), modelled both as a linear and a categorical effect, and associations between speech illusions and level of childhood adversities and life events as well as with CAPE scores and cognitive ability scores.

Results While a positive association was found between white noise speech illusions across hypothesized increasing levels of familial risk (controls -> siblings -> patients): OR linear $1.11,95 \% \mathrm{Cl} 1.02-1.21, p=0.019)$, there was no evidence for a categorical association with sibling status (OR 0.93, 95\% $\mathrm{Cl} 0.79-1.09, p=0.360$ ). The association between speech illusions and linear familial risk was greater if scores on the CAPE positive scale were higher $(p$ interaction $=0.003$; OR Iow CAPE positive scale $0.96,95 \% \mathrm{Cl} 0.85$ 1.07; ORhigh CAPE positive scale 1.26, $95 \% \mathrm{Cl} 1.09-1.46)$, cognitive ability was lower ( $p$ interaction $<0.001 ; O R_{\text {high cognitive ability }}=0.94,95 \% \mathrm{Cl}$ 0.84-1.05; OR $\mathrm{R}_{\text {low }}$ cognitive ability $=1.43$, 95\% Cl 1.23-1.68) and exposure to childhood adversity was higher ( $p$ interaction $<0.001$; ORlow adversity $0.92,95 \% \mathrm{Cl} 0.82-1.04$; ORhigh adversity $1.31,95 \% \mathrm{Cl} 1.13-1.52$ ). A similar, although less marked, pattern was seen for categorical patient-control and 
sibling-control comparisons. Exposure to recent life events did not modify the association between white noise and familial risk ( $p$ interaction=0.232).

Conclusion The association between white noise speech illusions and familial risk is contingent on additional evidence of endophenotypic expression and of exposure to childhood adversity. Therefore, speech illusions may represent a trait-dependent risk marker. 


\section{Introduction}

The positive symptoms of psychotic disorder are characterized by altered attribution of meaning to internal or external stimuli. It is thought that psychosis may occur across a spectrum of severity, representing a dimension of human variation extending into the general population $(1,2)$. Research has demonstrated that psychotic experiences - in the form of attenuated reality distortion including perceptual abnormalities and persecutory ideas - can be demonstrated in the general population (2) across the world (3). Subthreshold psychotic experiences in the general population are mostly transient in nature (4-6), but in some individuals, persistent psychotic experiences may be predictive of psychotic disorder $(6,7)$. According to the psychosisproneness-persistence-impairment model, psychosis expression may become persistent and clinically relevant, depending on developmental, environmental and cognitive factors $(1,8)$. Furthermore, it has been suggested that the two ends of the psychosis spectrum, from subthreshold mental variation to severe impairment, show a degree of etiological continuity. This refers to the notion that genetic (9) and environmental risk factors $(10,11)$ for psychotic disorder also drive variation at the level of subtle psychotic experiences in the non-ill population.

Theoretical accounts of the cognitive mechanism of hallucinations (perceptions in the absence of a stimulus) suggest that abnormal perception originates from an imbalance in top-down and bottom-up processing (12). Altered perceptions may arise when a higher priority is given to top-down processing (perceptual expectation, prior knowledge and mental imagery), at the expense of bottom-up information (sensory input) $(13,14)$. In this context, illusions (misinterpretations of an external stimulus) may originate from perceptual expectations associated with top-down processing (14).

Experimental illusion studies have been designed around the paradigm of hearing voices in white noise, giving rise to a speech illusion representing the tendency to attribute meaning to neutral sensory input. Hoffman and colleagues, studying a 
population of individuals at psychometric risk of psychotic disorder, suggested that speech illusions may signal an increased risk of psychotic disorder (13). Galdos and colleagues reported on the White Noise task, showing differences between individuals with psychotic disorders and healthy participants (15), later replicated by Catalan and colleagues (16). There was a suggestion that white noise speech illusions may represent an intermediate phenotype in that a prevalence of $30 \%$ was found in patients with psychotic disorder, $14 \%$ in siblings of patients, and $9 \%$ in the general population. Hypothetically, when self-reported psychotic experiences (e.g. Community Assessment of Psychic Experiences (CAPE) positive scale) and white noise speech illusions tap into the same dimension of psychotic disorder, a positive association is expected. However, in the general population, no clear association has been observed, indicating that variations of speech illusions in the general population may not signal increased risk to develop disorder $(17,18)$. A finding supporting this notion is that while risk factors for subclinical psychosis expression generally correspond with risk factors for psychotic disorder $(10,11)$, white noise speech illusions were not associated with either childhood adversity nor life events in the general population (18). In conclusion, underlying mechanisms of white noise speech illusions may be different in patients and the general population. However, in non-ill individuals with a higher than average genetic risk for psychotic disorder, such as siblings of patients, white noise speech illusions may be associated with psychotic experiences as an expression of genetic risk, which may be even stronger if there is additional evidence of environmental exposure under a model of gene-environment interaction $(11,19)$. Furthermore, the subclass of affectively salient speech illusions (speech illusions with emotional impact) may be more strongly associated with psychotic experiences and psychosis risk. Thus, in a sample of healthy children, hallucinations during the last month were associated with white noise speech illusions that were affectively salient but not white noise speech illusions that were not affectively salient (20). Similarly, in the case-sibling-healthy participant study by Galdos and colleagues, stronger associations were apparent with affective speech illusions (15). It has been suggested that affective salience might characterize speech 
illusions in individuals at risk for clinical outcomes $(20,21)$ and may be mediated in part by cognitive alterations (22) although another study did not find evidence for this (15). Therefore, further research is required to evaluate differences in psychopathology, cognition and affective valence of speech illusions in patients, siblings and healthy participants.

In this report, the following hypotheses were examined. First, speech illusions were expected to be more prevalent in patients and to a lesser degree in siblings of patients, compared to healthy participants, indicating that speech illusions may represent a familial marker for psychosis liability. Second, we hypothesized that the association between speech illusions and patient/sibling status would be traitdependent, i.e. more pronounced in patients and relatives with greater levels of expression of known endophenotypic dimensions associated with psychosis. These included positive psychotic experiences and alterations in cognition. In addition, we hypothesized that the association between speech illusions and patient/relative status would be stronger if there was additional evidence of early environmental exposure (childhood adversity) or late environmental exposure (recent life events). Finally, investigating differences in underlying mechanisms of non-affective and affective speech illusions, we expected to find the most pronounced differences with affective speech illusions.

\section{Materials and method}

The current sample was derived from Workpackage 6 of the international EU-GEI (European Network of National Schizophrenia Networks Studying Gene-Environment Interactions) project, a collaborative network studying genetic and environmental influences on the development, severity and course of psychotic disorders (23). Workpackage 6 (GxE Vulnerability \& Severity) focussed on the expression of genetic and environmental liability in siblings of patients, who are thought to be at higher risk to develop psychotic disorders compared to healthy participants. In Workpackage 6, participants were collected in Spain (5 centres), Turkey (3 centres) and Serbia (1 
centre). The sample consisted of 1525 healthy comparison participants, 1261 patients with diagnosis of psychotic spectrum disorder (the great majority medicated patients with a diagnosis of schizophrenia or schizoaffective disorder) and 1282 siblings of the patients. Patients were diagnosed with schizophrenia spectrum disorder according to the DSM-IV-TR. This diagnosis was confirmed by the Operational Criteria Checklist for Psychotic and Affective Illness (24). Participants with a diagnosis of psychotic disorder due to another medical condition, a history of head injury with loss of consciousness and an intelligence quotient $<70$ were excluded. The current analyses were restricted to the participants who underwent the white noise task, leaving 1507 healthy participants, 1014 patients and 1157 siblings.

In order to achieve high quality and homogeneity in clinical, experimental, and environmental assessments, standardized instruments were administered by psychiatrists, psychologists, or trained research assistants who completed mandatory on-country training sessions and online training modules including interactive interview videos and self-assessment tools $(23,25)$. Both on-country and online training sessions were repeated annually to maintain high inter-rater reliability throughout the 2010-2015 study enrolment period.

The EU-GEI project was approved by the Medical Ethics Committees of all participating countries and conducted in accordance with the Declaration of Helsinki. All participants provided written informed consent.

\section{Cognitive ability}

A short version of the Wechsler Adult Intelligence Scale-III (WAISIII) was used to measure cognitive ability, consisting of the Digit Symbol Coding subtest, uneven items of the Arithmetic subtest, uneven items of the Block Design subtest and every third item of the Information subtest (26-28). The Z- score was calculated separately for each country and sex, for each test. The score for cognitive ability was calculated as the mean of the Z-scores of the different tests, expressed as a T-score (shifted and 
scaled to have a mean of 50 and a standard deviation of 10). In the interaction analyses, cognitive score was modelled as a binary variable, calculated around the $20^{\text {th }}$ percentile of the healthy participant group.

\section{CAPE scale}

The Community Assessment of Psychic Experiences (CAPE) $(29,30)$ is a questionnaire designed to rate self-reports of positive, negative and depressive psychotic experiences. The questionnaire consists of 42 items: 20 items on positive psychotic experiences; 14 items on negative psychotic experiences and 8 items on depressive feelings. Participants rated both frequency $(0=$ never to $4=$ nearly always $)$ and distress ( $1=$ not distressed to $4=$ very distressed) of psychotic experiences. The mean score of the frequency and distress scale was calculated for each domain. In the analyses, the frequency measure of the positive psychotic experiences was used. In the interaction analyses, CAPE score was modelled as a binary variable, calculated around the $80^{\text {th }}$ percentile of the healthy participant group, separately for each country.

\section{Childhood adversity}

Childhood adversity was assessed using the Childhood Trauma Questionnaire Short Form (CTQ) that consists of 28 items rated on a 5-point Likert scale measuring five domains of maltreatment (emotional and physical neglect along with emotional, physical, and sexual abuse) (31). The psychometric characteristics of the translated versions (Spanish, Turkish, Dutch, and Serbian) of the CTQ have been comprehensively studied (32-35). Consistent with previous work in similar samples, CTQ score was modelled as a binary variable, calculated around the $80^{\text {th }}$ percentile of the mean score of the healthy participant group, separately for each country (36).

\section{Life Events}

Life events were measured with an expanded version (20 items) of the Brugha list of threatening experiences $(37,38)$. Participants rated the presence of an event during the 12-month period before onset (for patients) or before the interview (for healthy 
participants and siblings). The sum of life events was calculated and used as a continuous measure in the analyses.

\section{The white noise task}

During the white noise task, participants are exposed to three types of stimuli randomly presented across 75 fragments: 25 fragments of white noise only; 25 fragments containing white noise mixed with barely audible speech and 25 fragments of white noise mixed with clearly audible speech. The clearly audible speech fragments had a positive negative or neutral affective content. For example: 'Sport is good for health', 'I think it is going to rain today' or 'Madrid is the capital of Spain'. Speech was adapted to each country's native language. Each fragment had a duration of 4.3 seconds; the spoken sentence lasted as close as possible to 4.3 seconds. Sound fragments were binaurally presented through headphones. After the ending of each fragment, participants were asked to indicate what they heard by pressing on a button on the keyboard in front of them: 1: endorsed hearing speech with positive content, 2: endorsed hearing speech with negative content, 3: endorsed hearing speech with neutral content, 4: no speech heard, and 5: endorsed hearing speech but uncertain whether it was positive, negative or neutral. The protocol was guided by the software system E-prime 1.1 (Psychology Software Tools, Pittsburgh, Pennsylvania) and took approximately 15 minutes. In line with the definition proposed by Catalan and colleagues (16), a speech illusion was defined broadly as a white noise fragment in which any speech was heard (option 1,2,3 or 5). As participants were exposed to 75 fragments, of which 25 contained white noise only, the maximum number of speech illusions was 25 . First, a dichotomous speech illusion variable was calculated, with two or more speech illusions as cut-off, as defined by Catalan and colleagues (16). Second, in order to examine the effect of affective valence, a categorical affective speech illusion variable was calculated $(0=$ less than two non-affective/affective speech illusions, 1= two or more non-affective speech illusions and 2= two or more affective speech illusions). 


\section{Statistical analyses}

Binary logistic regression models were applied to the dichotomous speech illusion variable. As the data were hierarchically organised (individuals nested within families), familial clustering was taken into account. A first model was run with group (healthy participants $=0$, siblings $=1$ and patients $=2$ ), modelled both as linear effect and as dummy variables, as the independent variable of main interest, corrected for age, sex, cognitive ability and country of data collection. Second, a model was run with the interaction between group and the CAPE positive scale as endophenotypic moderator. Similarly, a model was run with the interaction between group and cognitive ability as endophenotypic moderator. Finally, two models were executed with speech illusions explained by the interaction between group and (i) childhood adversity and (ii) life events, respectively, in order to test for environmental effect modification. Interaction models were followed by calculation of stratified effects, using linear combination of terms in the model with the interaction, using the Stata lincom routine. The latter models were adjusted for the CAPE positive scale, age, sex, cognitive ability and country of data collection.

Multinomial logistic regression models, yielding odds ratio's, were applied to the three-level categorical affective speech illusion variable described above. The models described above for the dichotomous speech illusions variable, were run again, using multinomial logistic regression with the three-level categorical affective speech illusion variable. Associations were considered 'significant' when the two-sided pvalue was $<0.05$, a p-value between 0.05 and 0.1 was referred to as trend. STATAversion 13 was used (39).

\section{Results}

\section{Participants}

An overview of selected demographic variables, familial risk and white noise speech illusions is provided in table 1. Of the 3678 participants 1526 (41.5\%) reported two or 
more speech illusions. Patients had a higher rate of speech illusions (47.2\%) compared to healthy participants (41.0\%) and siblings (37.1\%). Inspection rates in table 1 suggests differences between countries in the rate of speech illusions however the within-country pattern of differences between groups was similar. The rate of two or more speech illusions with affective content was $14.6 \%$ in healthy participants, $8.2 \%$ in siblings and $18.4 \%$ in patients.

\section{Associations between speech illusion and group}

In models adjusted for age, sex, country, cognitive ability and familial clustering of observations, a positive association was observed with white noise speech illusions across increasing level of familial risk (OR linear trend 1.11, 95\% Cl 1.02-1.21, $p$ $=0.019$ ), modelled as a linear variable. Modelling group as two dummy variables revealed that the association with white noise speech illusions was 0.93 for siblings (95\% Cl 0.79-1.09, $p=0.360$ ) and 1.27 for patients (95\% Cl 1.07-1.51, $p=0.007)$.

\section{Psychoticism-dependence of association between group and white noise speech illusions}

White noise speech illusions were differentially associated with the dichotomous CAPE positive scale as a function of group (OR interaction: 1.32, 95\% Cl 1.10-1.58, $p$ $=0.003)$. Calculation of stratified effect sizes revealed an intermediate albeit nonsignificant association between speech illusions and sibling status in the high CAPE positive group (OR 1.07, 95\% $\mathrm{Cl} 0.75-1.52, p=0.713$ ) and a larger association between speech illusions and patient status in the high CAPE positive group (OR $1.56,95 \% \mathrm{Cl}$ 1.17-2.08, $p=0.003$ ) (table 2). There were no significant positive associations between speech illusions and either sibling or patients in the low CAPE positive group (table 2).

\section{Cognition-dependence of association between group and white noise} speech illusions

The association between white noise speech illusions and group was significantly 
influenced by dichotomous cognitive ability (OR interaction: 1.53, 95\% Cl 1.27-1.84, $p$ $<0.001)$. Stratified analyses revealed a significant association between speech illusions and sibling status in the low cognition group (OR 2.03, 95\% $\mathrm{Cl} 1.41-2.93, p<0.001$ ) as well between speech illusions and patient status in the low cognition group (OR 2.16, $95 \% \mathrm{Cl}$ 1.57-2.97, $p<0.001$ ) (table 2). There was a significant negative association between speech illusions and sibling status in the high cognition group (OR 0.77, 95\% $\mathrm{Cl} 0.64-0.92, p=0.004)$ and no significant association between speech illusions and patients in the high cognition group (OR 0.95, 95\% Cl 0.76-1.18, $p=0.651$ ) (table 2).

\section{Environmental moderation of association between group and white noise speech illusion}

The association between group and white noise speech illusion was modified by dichotomously defined childhood adversity (OR interaction: 1.42, 95\% Cl 1.19-1.70, $p$ $<0.001)$. Stratified analyses showed a positive albeit non-significant association between speech illusions and sibling status in the group exposed to childhood adversity (OR 1.19, 95\% Cl 0.87-1.64, $p=0.272)$ and a larger association between speech illusions and patient status in the exposed group (OR 1.71, 95\% $\mathrm{Cl} 1.27-2.30, p$ $<0.001$ ) (table 2). There were no significant positive associations between speech illusions and either sibling or patient status in the low childhood adversity group (table 2). There was no interaction between life events in the previous 12 months and group risk in the model of speech illusions (OR 1.03, 95\% $\mathrm{Cl}$ 0.98-1.09, $p=0.232$ ).

\section{Difference between non-affective and affective speech illusions}

A suggestive difference was found for the association between group and nonaffective white noise speech illusions (OR linear trend: 1.10, 95\% Cl 0.99-1.21, $p=0.064)$, and a significant association was found between group and affective white noise speech illusions (OR 1.14 linear trend, 95\% Cl 1.00-1.29, $p=0.046$ ) (table 3). The interaction between group and CAPE positive scale was significant for both nonaffective (OR 1.23, 95\% Cl 1.00-1.51, $p=0.048$ ) and affective (OR 1.57, 95\% Cl 1.192.08, $p=0.002$ ) speech illusions. A significant interaction between group and cognitive 
ability was found in the model of affective speech illusions (OR interaction: $2.44,95 \%$ $\mathrm{Cl} 1.85-3.21, p<0.001)$, but only at trend level in the model of non-affective speech illusions (OR interaction 1.21, 95\% Cl 0.99-1.49, $p=0.069$ ). For both non-affective (OR interaction $1.42,95 \% \mathrm{Cl} 1.16-1.74, p=0.001$ ) and affective (OR interaction $1.48,95 \%$ $\mathrm{Cl} 1.13-1.93, p=0.005$ ) speech illusions, a significant interaction was found with childhood adversity (table 4). No interaction was found between group and life events for either non-affective (OR interaction 1.03, 95\% $\mathrm{Cl} 0.98-1.09, p=0.261$ ) or affective (OR interaction 1.05, 95\% $\mathrm{Cl}$ 0.95-1.15, $p=0.353$ ) speech illusions.

Associations between speech illusions and sibling status were found for non-affective speech illusions in the low cognition group and the high childhood adversity group, and for affective hallucinations in the high (negative association) and low cognition (positive association) group, as well as a negative association in the low childhood adversity group and the low CAPE positive group. 


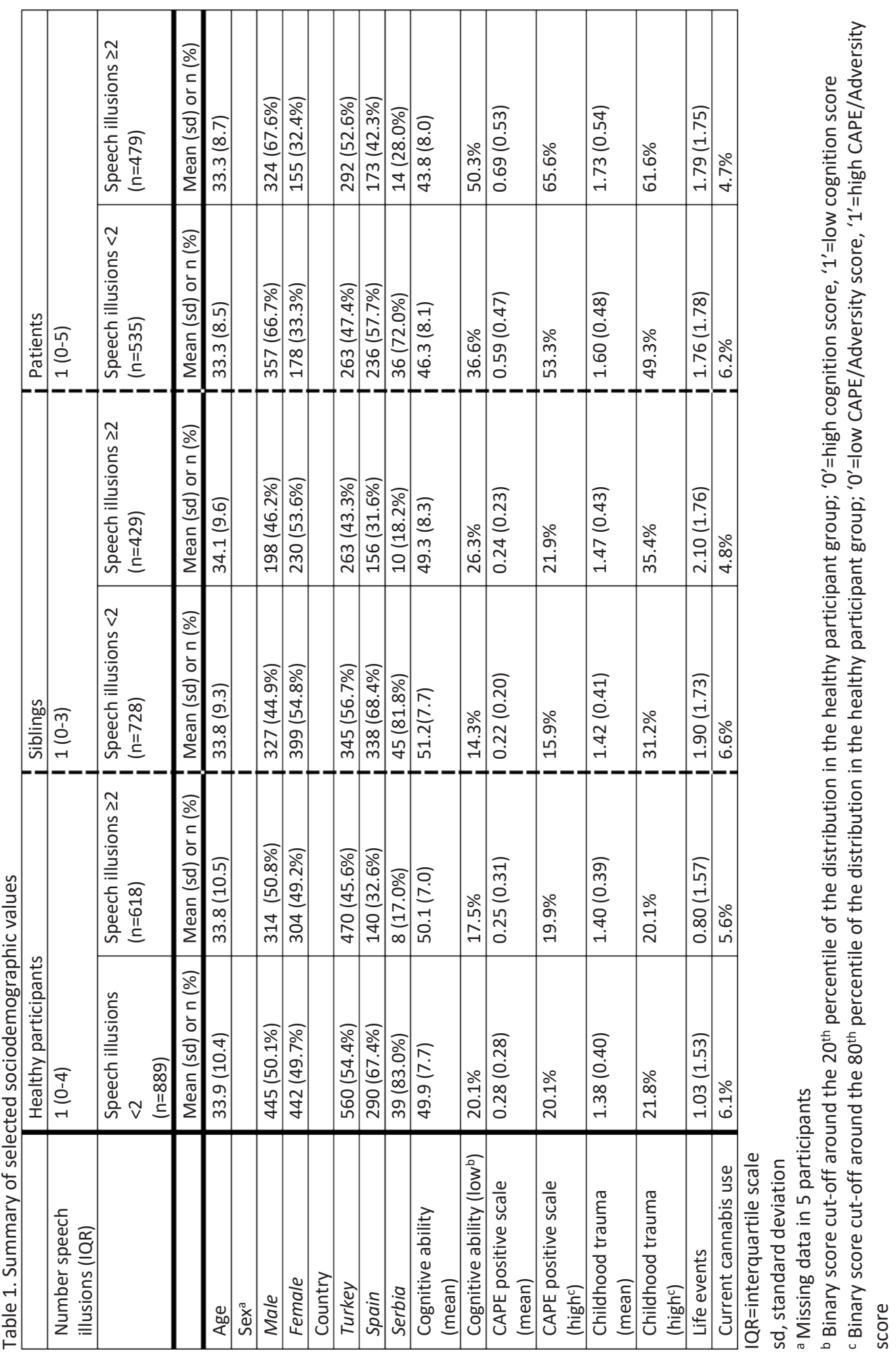




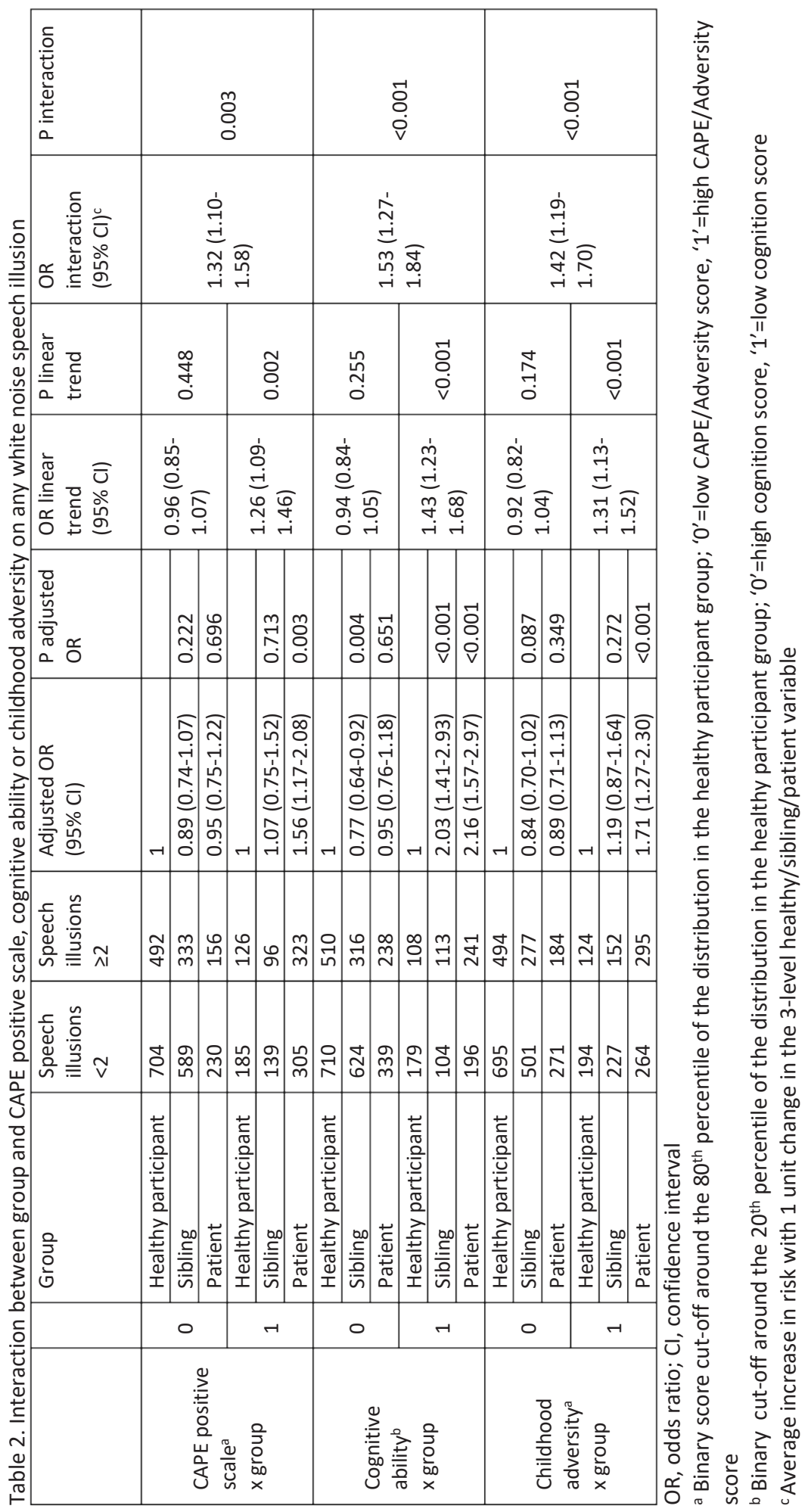




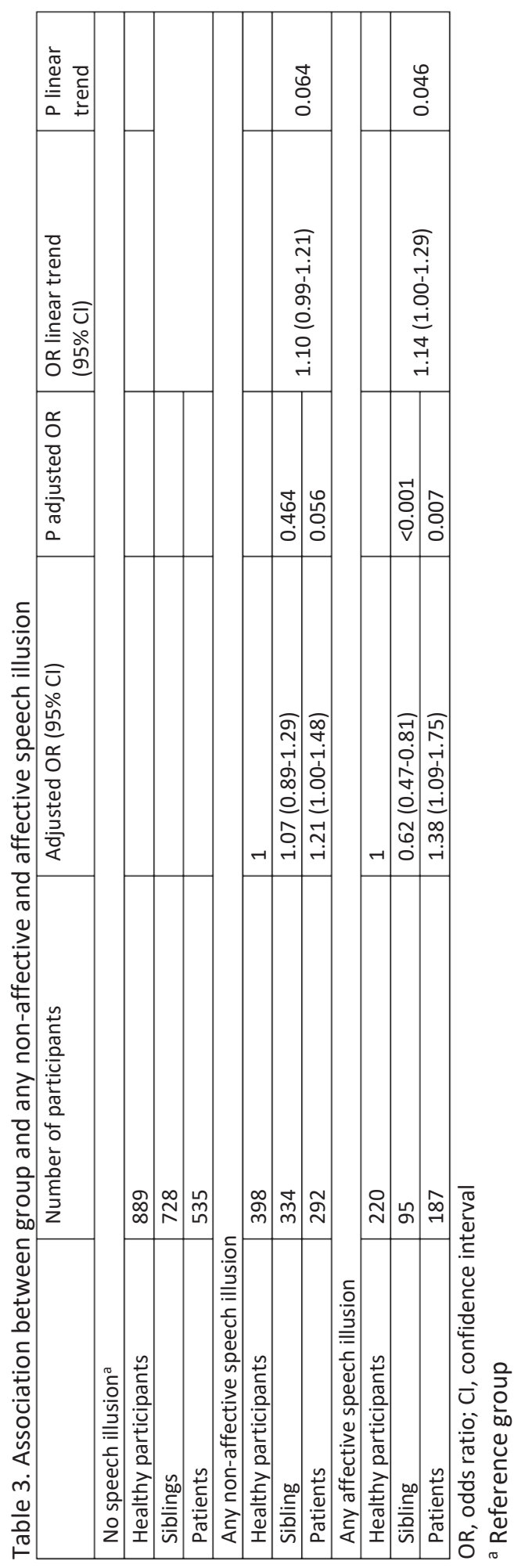




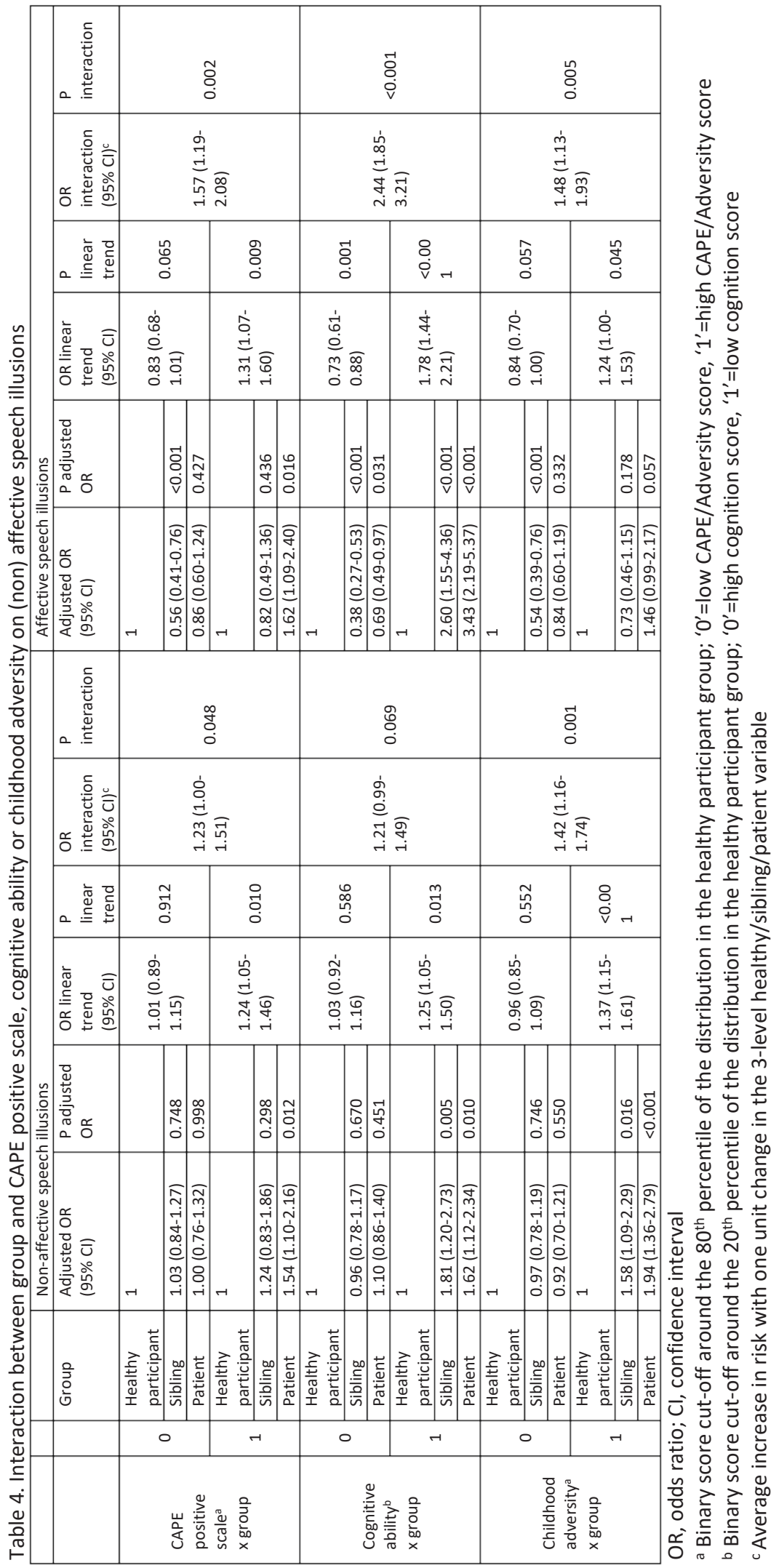




\section{Discussion}

This study investigated white noise speech illusions across different levels of familial risk. The analyses demonstrated that: (i) white noise speech illusions were significantly associated with familial risk, modelled as a linear effect, however there was no evidence for categorical association with sibling status; (ii) the association between speech illusions and familial risk, including categorical sibling status, was stronger if there was additional evidence for early environmental exposure or trait expression of psychosis proneness and cognitive alterations. The effect size of the interaction between familial risk on the one hand and cognitive ability, psychosis proneness and environmental exposure on the other was numerically greater for affective speech illusions than for non-affective speech illusions, but these differences were small.

Two or more speech illusions were reported by $47.2 \%$ of the patients compared to $41.0 \%$ of the healthy participants and $37.1 \%$ of the siblings. These are higher than the rates reported by Galdos et al. (15), who used another definition for speech illusions (any perceived speech illusion with positive, negative or neutral valence). The current study used the definition by Catalan et al. (16). A sensitivity analysis, however, revealed that the rate of speech illusions using the definition by Galdos et al. $(40 \%$ in healthy participants, $33 \%$ in siblings and $43 \%$ in patients) yielded a pattern of results that was similar to the results as presented above for the definition by Catalan and colleagues.

Speech illusions were not more prevalent in siblings of patients compared to healthy participants; overall siblings even tended to have lower rates than healthy participants. However, the association between sibling status and white noise speech illusions did increase when there was additional evidence for trait expression of psychotic experiences, cognitive alterations and childhood adversity, although this was not uniformly so, as sibling effects were most prominent for non-affective speech illusions in the presence of lower cognitive ability, more psychosis proneness and 
environmental exposure, whereas negative sibling associations were present for affective speech illusions in the absence of lower cognitive ability, more psychosis proneness and environmental exposure. In other words, in comparison to controls, siblings became more similar to patients only with respect to non-affective speech illusions in the subgroup selected for more risk traits and more exposure to risk factors. Therefore, white noise speech illusions appear to index a trait-dependent marker of risk: the power of white noise speech illusion to predict sibling and patient status is higher in the subgroup enriched with traits associated with genetic and environmental risk for the disorder.

Environmental risk factors $(10,11)$ for psychotic disorders have been observed to also drive variation at the level of subclinical psychotic experiences. The fact that the association between speech illusions and sibling and patient status, compared with controls, was stronger in the exposed subgroup may be suggestive of underlying geneenvironment interaction. However, the results suggest that this would only apply to distal environmental exposures life childhood adversity, but not proximal life stress. The window for crucial gene-environment interactions may be restricted to early developmental periods rather than the adult period (11).

Given that psychotic experiences and cognitive alterations are thought to reflect, in part, genetic risk for psychotic disorder $(9,40)$, the same underlying mechanism of gene-environment interaction may account for the dependence of patient-control and sibling-control speech illusion associations at higher levels of these traits. Thus, earlier studies have shown that in samples of the general population, no association exists between white noise speech illusions and the CAPE positive scale $(17,18)$. The CAPE positive scale mainly reflects alteration in delusional ideation, whereas the white noise task focusses on lower prevalence alterations in perception. The non-significant association between speech illusions and the CAPE positive scale in the non-clinical population suggests that alterations in perception may not necessarily index alterations in ideation. It has been shown that in clinical populations and relative of 
patients, alterations in perception are more strongly associated with alterations in ideation than in non-clinical populations (41). Thus, more evidence for association between white noise speech illusions and the CAPE positive scale in the trait-rich subgroup of sibling and patients, in comparison to controls, would be compatible with this observation.

The results did not suggest a uniform pattern of differentiation between affective and non-affective speech illusions in the pattern of associations between speech illusions, contrary to earlier research $(15,20)$. More work in this area is required.

There are some limitations. The CAPE positive scale and childhood trauma were modelled as binary variables, calculated around the $80^{\text {th }}$ percentile of the mean score of the healthy participant group, separately for each country. Cognitive ability was modelled as a binary variable, calculated around the $20^{\text {th }}$ percentile. In order to examine to what degree results were robust with regard to alternative cut-offs, sensitivity analyses were conducted with cut-off at the $70^{\text {th }} / 30^{\text {th }}$ percentile of the healthy participant group. A similar pattern of results was found.

The white noise task and associated outcomes were only administered once. It has been suggested that persistence of psychotic experiences may be particularly predictive of psychotic disorder. Therefore, a longitudinal design allowing to examine the association between white noise speech illusions and persistence of psychotic experience may be more informative.

The study was conducted across different countries and cultures, and although the pattern of white noise distribution across patients and healthy participants was similar across countries, there were differences in base rates, which may have to do with differences in language and culture impacting the experiment. As country was adjusted for, these differences will not impact effect estimates. 


\section{References}

1. van Os J, Linscott RJ, Myin-Germeys I, Delespaul P, Krabbendam L. A systematic review and meta-analysis of the psychosis continuum: evidence for a psychosis proneness-persistence-impairment model of psychotic disorder. Psychol Med. 2009;39(2):179-95.

2. Verdoux H, Van Os J. Psychotic symptoms in non-clinical populations and the continuum of psychosis. Schizophr Res. 2002;54(1-2):59-65.

3. Nuevo R, Van Os J, Arango C, Chatterji S, Ayuso-Mateos JL. Evidence for the early clinical relevance of hallucinatory-delusional states in the general population. Acta Psychiatr Scand. 2013;127(6):482-93.

4. Dhossche D, Ferdinand R, Van der Ende J, Hofstra MB, Verhulst F. Diagnostic outcome of self-reported hallucinations in a community sample of adolescents. Psychol Med. 2002;32(4):619-27.

5. Dominguez MD, Wichers M, Lieb R, Wittchen HU, van Os J. Evidence that onset of clinical psychosis is an outcome of progressively more persistent subclinical psychotic experiences: an 8-year cohort study. Schizophr Bull. 2011;37(1):84-93.

6. Wiles NJ, Zammit S, Bebbington P, Singleton N, Meltzer H, Lewis G. Self-reported psychotic symptoms in the general population: results from the longitudinal study of the British National Psychiatric Morbidity Survey. Br J Psychiatry. 2006;188:51926.

7. Poulton R, Caspi A, Moffitt TE, Cannon M, Murray R, Harrington H. Children's selfreported psychotic symptoms and adult schizophreniform disorder: A 15-year longitudinal study. Arch Gen Psychiatry. 2000;57(11):1053-8.

8. Cougnard A, Marcelis M, Myin-Germeys I, De Graaf R, Vollebergh W, Krabbendam $L$, et al. Does normal developmental expression of psychosis combine with environmental risk to cause persistence of psychosis? A psychosis pronenesspersistence model. Psychol Med. 2007;37(4):513-27.

9. van Os J, van der Steen Y, Islam MA, Guloksuz S, Rutten BP, Simons CJ, et al. Evidence that polygenic risk for psychotic disorder is expressed in the domain of neurodevelopment, emotion regulation and attribution of salience. Psychol Med. 2017;47(14):2421-37.

10. Guloksuz S, van Nierop M, Lieb R, van Winkel R, Wittchen HU, van Os J. Evidence that the presence of psychosis in non-psychotic disorder is environmentdependent and mediated by severity of non-psychotic psychopathology. Psychol Med. 2015;45(11):2389-401.

11. van Os J, Kenis G, Rutten BP. The environment and schizophrenia. Nature. 2010;468(7321):203-12.

12. Aleman A, Bocker KB, Hijman R, de Haan EH, Kahn RS. Cognitive basis of hallucinations in schizophrenia: role of top-down information processing. Schizophr Res. 2003;64(2-3):175-85. 
13. Hoffman RE, Woods SW, Hawkins KA, Pittman B, Tohen M, Preda A, et al. Extracting spurious messages from noise and risk of schizophrenia-spectrum disorders in a prodromal population. Br J Psychiatry. 2007;191:355-6.

14. Hugdahl K. "Hearing voices": auditory hallucinations as failure of top-down control of bottom-up perceptual processes. Scand J Psychol. 2009;50(6):553-60.

15. Galdos M, Simons C, Fernandez-Rivas A, Wichers M, Peralta C, Lataster T, et al. Affectively salient meaning in random noise: a task sensitive to psychosis liability. Schizophr Bull. 2011;37(6):1179-86.

16. Catalan A, Simons CJ, Bustamante S, Drukker M, Madrazo A, de Artaza MG, et al. Novel evidence that attributing affectively salient signal to random noise is associated with psychosis. PLoS One. 2014;9(7):e102520.

17. Pries LK, Guloksuz S, Menne-Lothmann C, Decoster J, van Winkel R, Collip D, et al. White noise speech illusion and psychosis expression: An experimental investigation of psychosis liability. PLoS One. 2017;12(8):e0183695.

18. Schepers E, van Os J, Lousberg R. White noise speech illusions in the general population: the association with psychosis expression and risk factors for psychosis. PLoS One. 2019.

19. Radhakrishnan R, Guloksuz S, Ten Have M, de Graaf R, van Dorsselaer S, Gunther $\mathrm{N}$, et al. Interaction between environmental and familial affective risk impacts psychosis admixture in states of affective dysregulation. Psychol Med. 2018:1-11.

20. Rimvall MK, Clemmensen L, Munkholm A, Rask CU, Larsen JT, Skovgaard AM, et al. Introducing the White Noise task in childhood: associations between speech illusions and psychosis vulnerability. Psychol Med. 2016;46(13):2731-40.

21. Daalman K, Boks MP, Diederen KM, de Weijer AD, Blom JD, Kahn RS, et al. The same or different? A phenomenological comparison of auditory verbal hallucinations in healthy and psychotic individuals. J Clin Psychiatry. 2011;72(3):320-5.

22. Catalan A, de Artaza MG, Fernandez-Rivas A, Angosto V, Aguirregomoscorta F, Bustamante $S$, et al. Affectively salient signal to random noise might be used to identify psychosis vulnerability in severe mental disorders. Eur Psychiatry. 2018;49:37-42.

23. European Network of National Networks studying Gene-Environment Interactions in S, van Os J, Rutten BP, Myin-Germeys I, Delespaul P, Viechtbauer W, et al. Identifying gene-environment interactions in schizophrenia: contemporary challenges for integrated, large-scale investigations. Schizophr Bull. 2014;40(4):729-36.

24. McGuffin P, Farmer A, Harvey I. A polydiagnostic application of operational criteria in studies of psychotic illness. Development and reliability of the OPCRIT system. Arch Gen Psychiatry. 1991;48(8):764-70.

25. Korver N, Quee PJ, Boos HB, Simons CJ, de Haan L, Group Investigators. Genetic Risk and Outcome of Psychosis (GROUP), a multi-site longitudinal cohort study focused on gene-environment interaction: objectives, sample characteristics, 
recruitment and assessment methods. Int J Methods Psychiatr Res. 2012;21(3):205-21.

26. Blyler CR, Gold JM, lannone VN, Buchanan RW. Short form of the WAIS-III for use with patients with schizophrenia. Schizophr Res. 2000;46(2-3):209-15.

27. Velthorst E, Levine SZ, Henquet C, de Haan L, van Os J, Myin-Germeys I, et al. To cut a short test even shorter: reliability and validity of a brief assessment of intellectual ability in schizophrenia--a control-case family study. Cogn Neuropsychiatry. 2013;18(6):574-93.

28. Wechsler D. WAIS-III, Wechsler adult intelligence scale: Administration and scoring manual. : Psychological Corporation; 1997.

29. Konings M, Bak M, Hanssen M, van Os J, Krabbendam L. Validity and reliability of the CAPE: a self-report instrument for the measurement of psychotic experiences in the general population. Acta Psychiatr Scand. 2006;114(1):55-61.

30. Mossaheb N, Becker J, Schaefer MR, Klier CM, Schloegelhofer M, Papageorgiou K, et al. The Community Assessment of Psychic Experience (CAPE) questionnaire as a screening-instrument in the detection of individuals at ultra-high risk for psychosis. Schizophr Res. 2012;141(2-3):210-4.

31. Bernstein DP, Stein JA, Newcomb MD, Walker E, Pogge D, Ahluvalia T, et al. Development and validation of a brief screening version of the Childhood Trauma Questionnaire. Child Abuse Negl. 2003;27(2):169-90.

32. Hernandez A, Gallardo-Pujol D, Pereda N, Arntz A, Bernstein DP, Gaviria AM, et al. Initial validation of the Spanish childhood trauma questionnaire-short form: factor structure, reliability and association with parenting. J Interpers Violence. 2013;28(7):1498-518.

33. Sar V, Akyuz G, Kundakci T, Kiziltan E, Dogan O. Childhood trauma, dissociation, and psychiatric comorbidity in patients with conversion disorder. Am J Psychiatry. 2004;161(12):2271-6.

34. Thombs BD, Bernstein DP, Lobbestael J, Arntz A. A validation study of the Dutch Childhood Trauma Questionnaire-Short Form: factor structure, reliability, and known-groups validity. Child Abuse Negl. 2009;33(8):518-23.

35. Mitkovic-Voncina M, Lecic-Tosevski D, Pejovic-Milovancevic M, Popovic-Deusic S. Linking child maltreatment history with child abuse potential: relative roles of maltreatment types. Arch Biol Sci. 2014;66:1681-7.

36. van Os J, Marsman A, van Dam D, Simons CJ, Investigators G. Evidence That the Impact of Childhood Trauma on IQ Is Substantial in Controls, Moderate in Siblings, and Absent in Patients With Psychotic Disorder. Schizophr Bull. 2017;43(2):316-24.

37. Brugha $T$, Bebbington $P$, Tennant $C$, Hurry J. The List of Threatening Experiences: a subset of 12 life event categories with considerable long-term contextual threat. Psychol Med. 1985;15(1):189-94.

38. Brugha TS, Cragg D. The List of Threatening Experiences: the reliability and validity of a brief life events questionnaire. Acta Psychiatr Scand. 1990;82(1):77-81. 
39. StataCorp. STATA Statistical Software: Release 13. Texas: College Station; 2013.

40. Toulopoulou T, Picchioni M, Rijsdijk F, Hua-Hall M, Ettinger U, Sham P, et al. Substantial genetic overlap between neurocognition and schizophrenia: genetic modeling in twin samples. Arch Gen Psychiatry. 2007;64(12):1348-55.

41. Smeets $F$, Lataster $T$, van Winkel $R$, de Graaf $R$, Ten Have $M$, van Os J. Testing the hypothesis that psychotic illness begins when subthreshold hallucinations combine with delusional ideation. Acta Psychiatr Scand. 2013;127(1):34-47. 
White noise speech illusions:

a trait dependent risk marker for psychotic disorder? | 109 

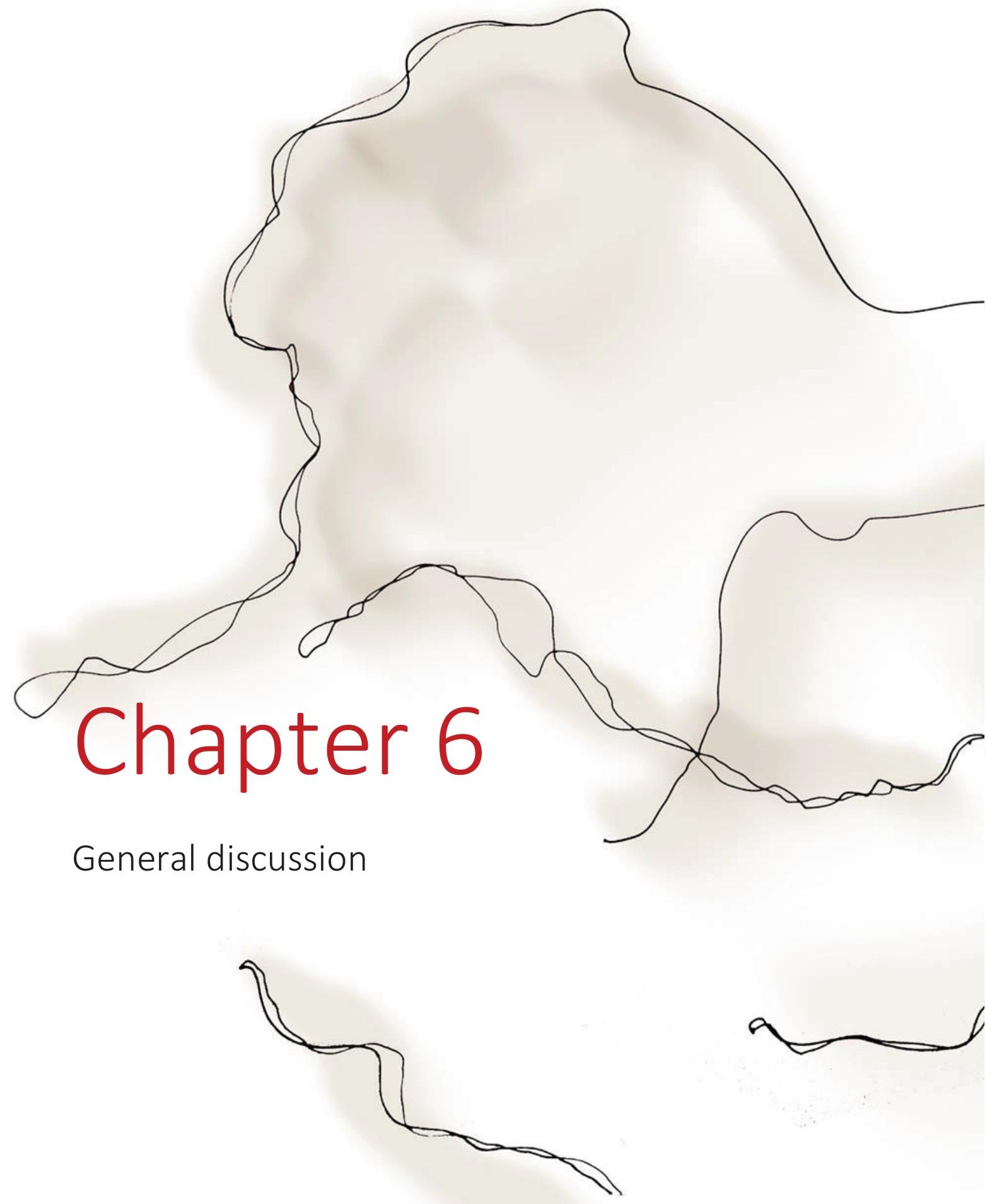


$$
=3
$$




\section{General discussion}

The aim of this thesis was to obtain more insight into the mechanisms underlying the white noise task. The first part, Chapters 2 and 3, focused on the neurophysiological mechanisms underlying white noise speech illusions in the general population. In these two chapters, EEG activity during the white noise task was examined. Alpha activity during a white noise fragment appeared to be lower in speech illusions than in correctly judged fragments. Dependence on trait and environmental risks was investigated in the general population (Chapter 4) and across different levels of familial risk (Chapter 5). In the general population, white noise speech illusions showed no association with either subclinical psychotic experiences or environmental risks. The association between familial risk and speech illusions was stronger if there was additional evidence for early environmental exposure or trait expression of psychosis proneness and cognitive alterations.

The current chapter provides a critical review of the methodology used and ideas on directions for further research.

\section{Neurophysiological mechanisms}

Several studies have investigated the cortical mechanisms of experimentally elicited perceptual experiences. Müller and colleagues used a study design in which participants listen to music fragments embedded in noise, partly replaced by gaps of only pink noise. Illusory perception of music during the noise gap was associated with reduced alpha activity, indicating high excitability (1). Leske and colleagues investigated oscillatory activity during a Zwicker Tone illusion and reported similar findings. Stronger perceptions of an 'auditory afterimage', induced by notch-filtered noise (i.e., Zwicker Tone illusion), were associated with decreased alpha power (2). Our findings were consistent with these studies: speech illusions were found to be characterised by reduced alpha activity in the non-clinical population. 
White noise speech illusions appeared to be associated with reduced alpha activity at seven cortical locations. The most significant association was found at the temporal region, both left and right. Given that the auditory cortex is located in the temporal lobe, higher excitability of the temporal lobes conforms to our expectations. Furthermore, research has shown that the same area is involved in hallucinations (3). Evidence has been found for altered cortical activity in the left temporal lobe during hallucinatory states. More specifically, the left insula and bilateral temporal gyri were shown to be activated (3).

In the present study, however, significantly reduced alpha activity was also found in other cortical regions. Thus, regions other than the temporal might also be involved in cortical processing of illusions. With respect to this latter finding, a critical note can be observed. It is known that EEG has a high temporal resolution in contrast to a low spatial resolution. To gain more insight into the brain regions involved in illusions, functional magnetic resonance imaging may provide valuable additional information. Moreover, theta $(4)$, alpha $(5)$, beta $(6,7)$ and gamma bands $(8,9)$ have all been reported to be associated with hallucinations. During white noise speech illusions, altered cortical activity was found only in the alpha band, indicating high excitability.

Previous research has found evidence that alpha activity before stimulus onset influences (visual) illusory perception (10). This finding was not confirmed by our results: no significant association was found between baseline alpha activity and white noise speech illusions (Chapter 3). The apparent disconfirmation may be attributable to methodological differences. In research that demonstrated an association between perception and EEG baseline activity, participants had to indicate whether they perceived a stimulus (e.g., transcranial magnetic stimulus) (11-13). During the white noise task, however, subjects have to judge the content of a fragment. Cortical mechanisms may differ between judging the presence of a stimulus and interpreting the content of a stimulus. Cortical activity may therefore be dependent on the method used to elicit an illusion. 
In summary, speech illusions are accompanied by reduced alpha activity during a white noise fragment, and no association was found between baseline alpha activity and white noise speech illusions in the general population. In other words, speech illusions are accompanied by a temporal reduction of alpha activity (state variation) and therefore may not reflect trait psychosis proneness.

\section{Trait-dependence}

A positive association between subclinical psychotic experiences and speech illusions is expected when both measures reflect the same mechanism of psychosis liability. Both the Structured Interview for Schizotypy-Revised (SIS-R) (14) and the Community Assessment of Psychic Experiences (CAPE) $(15,16)$ are designed to reflect positive psychotic experiences in the general population. In the scientific literature, inconclusive findings have been reported about the association between white noise speech illusions and subclinical expression of psychosis. Galdos and colleagues reported a significant association between any speech illusion and SIS-R positive schizotypy in healthy controls (odds ratio 2.4) (17). Catalan and colleagues, however, failed to demonstrate an association between speech illusions and either SIS-R positive schizotypy $(O R=1.1)$ or the CAPE positive scale $(O R=1.4)(18)$. In novel analyses of the expanded sample of Catalan et al., a significant association between positive schizotypy and speech illusions appeared to be mediated (to a large extent) by cognitive ability (19). Different methodologies (such as definitions and cut-off values) were used by Galdos and Catalan. Pries and colleagues examined whether inconsistent findings were the result of variation in methodology. They demonstrated that white noise speech illusions were not associated with either schizotypy or CAPE score, regardless of the method used (20).

In line with the results of Catalan et al. and Pries et al., the present study found no significant association between the CAPE positive scale and the number of speech illusions in a sample of the general population (Chapter 4). The association between white noise speech illusions and the CAPE positive scale was further investigated 
across different levels of familial risk. Evidence was found that the association between familial risk and white noise speech illusions was significantly influenced by the trait-expression of psychotic experiences (Chapter 5). In other words, white noise speech illusions are more pronounced in patients and siblings with higher scores on the CAPE positive scale. This finding can be explained by the theory that the CAPE positive scale mainly focuses on alterations in delusional ideation, whereas white noise speech illusions reflect alterations in perception. The non-significant association between the CAPE scale and white noise speech illusions in the general population suggests that alterations in perception do not always induce alterations in ideation (expression of subclinical symptoms). It has been theorised that, in a clinical state, alterations in perception may give rise to delusional explanations (21). This theory is supported by empirical evidence (22-25). Thus, the larger body of evidence for an association between white noise speech illusions and the CAPE positive scale in the trait-rich subgroup of siblings and patients, in comparison to controls, supports this observation.

\section{Dependence on environmental risk}

Childhood adversity (23) and life events (26) are thought to be associated with psychotic disorders. A positive association between known risk factors for psychotic disorders on the one hand and psychotic experiences on the other would be compatible with the hypothesis of psychotic experiences lying on the causal pathway between psychosis risk factors and psychosis outcome. Meta-analysis supports this observation (27). For example, in a sample of children reporting subclinical psychotic experiences, $86 \%$ reported traumatic and stressful events (28). Individuals with psychotic experiences were more likely to report recent life events than were individuals without psychotic experiences (26).

The present thesis investigated to what degree experimentally elicited speech illusions and self-reported psychotic experiences show the same pattern of association with childhood adversity and life events in a sample of the general 
population (Chapter 4). Childhood adversity and life events were associated with higher scores on the CAPE positive scale. In the general population, no significant association was found between environmental risk and white noise speech illusions. The association between white noise speech illusions and early and late environmental exposure was further investigated across different levels of familial risk (Chapter 5). The association between speech illusions and familial risk, including categorical sibling status, was stronger if there was additional evidence for childhood adversity. This significant association may be suggestive of underlying geneenvironment interaction. Exposure to recent life events, however, did not influence the association between white noise and familial risk. In other words, early and late adverse events appeared to differ in their effect on the expression of speech illusions. The window for crucial gene-environment interactions may be restricted to early developmental periods rather than adulthood (29).

\section{Speech illusions with an affective content}

Evidence has been found that psychotic patients are more likely to assign affective meaning to neutral stimuli (30). Furthermore, it has been suggested that affective salience differentiates speech illusions in clinical samples from speech illusions in general population samples. In one study, negative emotional valence of speech content had a positive predictive value of $88 \%(31)$. In a sample of healthy children, hallucinations were only associated with speech illusions when focusing on affectively salient speech illusions (32).

The present thesis investigated to what degree underlying mechanisms differed between non-affective and affective speech illusions (Chapter 5). The effect size of the interaction between familial risk on the one hand and cognitive ability, psychosis proneness and environmental exposure on the other was greater for affective speech illusions than for non-affective speech illusions, but these differences were small. Evidence for significant trait- and environment-dependent associations between speech illusions and sibling status was not uniform for non-affective and affective 
speech illusions. Sibling effects were most prominent for non-affective speech illusions in the presence of lower cognitive ability, more psychosis proneness and environmental exposure, whereas negative sibling associations were present for affective speech illusions in the absence of lower cognitive ability, more psychosis proneness and environmental exposure. In other words, in the presence of psychosis trait risk, non-affective speech illusions are associated with familial risk of psychosis; and, in the absence of psychosis trait risk, affective speech illusions predict the absence of familial risk of psychosis. Given that affective speech illusions are rare and therefore likely to produce chance findings, these results require replication in a larger sample. Moreover, the distinction between affective and non-affective speech illusions may be difficult to capture reliably. This merits more psychometric research of the white noise paradigm. 
Figure 1. Summary of findings

\begin{tabular}{|l|l|}
\hline Psychotic experiences & White noise speech \\
\hline Cognitive impairment & illusions \\
\hline Childhood adversity & Wiblings of patients \\
\hline Life events & White noise speech \\
\hline Psychotic experiences & illusions \\
\hline Cognitive impairment & \\
\hline Childhood adversity & \\
\hline Cife events
\end{tabular}

White noise speech illusions showed no association with the CAPE positive scale, life events or childhood adversity in the general population (Chapter 4). Associations between sibling status and white noise speech illusions were found when there was additional evidence for trait expression of psychotic experiences, cognitive impairment and childhood adversity and larger associations were found between speech illusions and patient status in the exposed groups (Chapter 5). 


\section{White noise speech illusions as an exophenotype}

Gottesman and colleagues described endophenotypes as 'measurable components along the pathway between disease and distal genotype' (33). It has been proposed that an endophenotype must meet the following five criteria: (i) association with disorder in the population, (ii) heritability, (iii) manifestation in an individual whether or not the illness is active, (iv) co-segregation with the disorder within families and (v) greater display of the endophenotype in non-affected family members than in the general population. Endophenotypes may be neurophysiological, biochemical, endocrinological, neuroanatomical or cognitive, or they may represent a personality trait (34).

It has been suggested that subclinical psychotic experiences and schizotypal traits constitute an endophenotype (35). For white noise speech illusions, no such status can be claimed, however. While Galdos and colleagues (17) found that speech illusions are more often present in patients with psychotic disorders and in their siblings than in the general population, the present thesis, which uses a much larger sample, reports the same rate of speech illusions in the general population as in siblings. It did, however, find evidence that the association with sibling status was positive if there was higher loading of psychosis trait risk, indicating trait-dependence. It might therefore be concluded that speech illusions can be seen as a proxy for symptoms of psychotic disorders, thus reflecting expression of the psychosis exophenotype. Although experimentally induced speech illusions cannot serve as a marker of psychosis risk, the white noise task might be used as an objective measure of the psychosis exophenotype.

\section{Methodological strengths}

1) Multilevel random regression analyses were conducted on the hierarchically organised EEG dataset, consisting of white noise fragments (level 1) clustered within individuals (level 2), clustered within two experimental sessions (level 3). Although software applications for multilevel regression analysis have 
been available for at least 10 years, in the analyses of EEG data, these statistical techniques have rarely been used. The necessity for multilevel regression analyses in this thesis became evident from the highly significant autoregressive structure, random intercepts and random slopes. Random intercepts allow the outcome to be higher or lower for each individual, and random slopes allow fixed effects to vary for each individual. In other words, variability between individuals is incorporated into the association between alpha activity and white noise speech illusions. In the autoregressive model, each observation is regressed linearly on the previous observation.

2) The EUGEI dataset contains a large sample of patients, siblings and healthy comparison participants on which the white noise task was administered. This enabled us to make reliable estimations of associations.

\section{Methodological limitations}

1) In the present thesis, EEG activity was measured during the white noise task. An EEG provides a non-invasive method and has a high temporal resolution. The spatial resolution, however, is low. To gain more insight into the brain regions involved in illusions, it may be more productive to use $\mathrm{fMRI}$ in combination with EEG.

2) In the current white noise speech illusion paradigm, five options were shown on the computer screen immediately after the end of each fragment. A new fragment was started 1 second after a response was given. We suggest extending this inter-stimulus interval for two reasons. First, in the current design, it cannot be ruled out that the pre-stimulus segment (treated as a 'baseline' measure) still contains effects of the previous fragment. A longer interval between button-push (to indicate the response) and a new sound fragment might reduce the possibility of contamination. Second, it may be productive to investigate EEG activity after the end of a fragment. In the current paradigm, we were not able to discriminate between cortical activity associated with the processing of a noise fragment and cortical activity 
associated with the preparation of a button push. These two associations might be distinguished by extending the interval between the end of a fragment and the appearance of the response options.

3) In the literature, several methodologies and definitions have been used to analyse white noise speech illusions. Whereas Galdos and colleagues defined a speech illusion as a white noise fragment in which clearly audible speech with positive, negative or neutral content was heard (17), Catalan and colleagues described a speech illusion as noise in which any modality was heard, even if the listener was not certain to what degree it was neutral, positive or negative (18). Furthermore, different cut-off values have been used for the dichotomised speech illusion variable: any speech illusion (17) and two or more speech illusions (18). Consensus in definitions is preferable to enable comparison of the findings.

The results produced using the definition of Galdos and colleagues was similar to those produced using the definition of Catalan and colleagues (Chapters 4 and 5). Similarly, when post-hoc analyses were carried out on the dataset of Chapter 2, no differences were found between the two definitions. Thus, the analyses were re-run for a sample of participants having reported fewer than two speech illusions. If a single speech illusion reflects a buttonpush error instead of an auditory illusion, the expectation is that the alpha effect should completely diminish. Post-hoc analyses, however, indicated lower but still significant reduced alpha activity.

\section{Directions for further research}

\section{EEG activity during white noise speech illusions in siblings and patients}

Although psychotic experiences in the general population are thought to reflect stable differences below the level of illness (36), in some individuals psychotic experiences may be an indicator of the development of a psychotic disorder $(37,38)$. The present thesis has demonstrated that white noise speech illusions are associated with reduced 
alpha activity in the general population. It can be questioned, however, to what degree similar mechanisms are at play in clinical and subclinical populations. The finding that speech illusions are not associated with self-reported psychotic experiences in the general population suggests that mechanisms of perceptual abnormalities may be different for psychotic patients than for the non-clinical population. The question is to what degree these differences are also reflected in EEG oscillations.

We therefore suggest that further investigation be conducted into cortical activity associated with white noise speech illusions in controls, siblings, siblings with environmental risk for psychotic disorders and patients. There are two possible outcomes: a comparable or an incomparable change in alpha activity at different levels of familial risk. If a comparable reduction is found, it might be concluded that alpha activity reflects the cortical mechanism of a misinterpretation of an external stimulus, independent of the clinical significance of this misinterpretation. However, difference in the change of alpha activity during a speech illusion between siblings and siblings with environmental risk might suggest that cortical activity during a speech illusion reflects risk of psychotic disorders.

\section{Focus on subgroups}

In comparison to controls, siblings became more similar to patients with respect to speech illusions in the subgroup selected for more risk traits and more exposure to risk factors. White noise speech illusions therefore appear to reflect a trait-dependent marker of risk: the power of white noise speech illusions to predict sibling and patient status is higher in the subgroup with traits associated with genetic and environmental risk for psychotic disorders.

We suggest that white noise speech illusions of siblings be investigated using a longitudinal study. As suggested in this thesis, white noise speech illusions might be a marker of the psychosis phenotype. One hypothesis is that the transition from the 
subclinical psychotic phenotype to the clinical phenotype in the subgroup with genetic and environmental risk of psychotic disorders is also reflected in white noise speech illusions. If this hypothesis were confirmed, the white noise task might be used for the monitoring and follow-up of high-risk siblings.

\section{White noise speech illusions in patients}

We suggest that white noise speech illusions represent an index of the exophenotype of psychotic disorders. It might be interesting to investigate whether white noise speech illusions correlate with the severity of positive psychotic symptoms. For example, it may be hypothesised that a positive response to anti-psychotic medication or psychotherapy will also be reflected in alterations in white noise speech illusions. If a correlation is found, this would mean that the white noise task might also be used for the treatment-response monitoring and follow-up of psychotic patients.

\section{The white noise task and source-monitoring studies}

In studies focusing on auditory hallucinations, three distinct experimental paradigms have been employed: auditory-signal detection (detecting stimuli in situations of uncertainty, such as detecting voices against background noise), verbal selfmonitoring (on-line monitoring of self-generated speech, such as discriminating one's own and someone else's generated speech) and source-monitoring (distinguishing memories of self-generated words and externally generated stimuli). The white noise task is an example of an auditory-signal detection paradigm.

In a recent meta-analysis, comparable effects were observed in source-monitoring and auditory-signal detection paradigms: hallucinating patients and non-clinical hallucination-prone individuals displayed increased tendencies to misattribute internally generated events compared with non-prone controls (39). This might suggest that these paradigms are assessing biases in a shared cognitive domain. Given the substantial differences in these paradigms, however, it might be unlikely that they tap into identical cognitive mechanisms. More research is required to determine 
whether auditory-signal detection paradigms, such as the white noise task, and source-monitoring studies are affected by common or distinct top-down influences and whether they make independent contributions to the onset of hallucinations.

\section{Linking experimental research with clinical practice}

A distinction between clinically relevant and 'benign' psychotic experiences may be useful to predict the presence or absence of clinical needs. Psychotic experiences can be elusive and non-specific in the early stages and may become relevant only after reaching a threshold of severity. The Diagnostic and Statistical Manual of Mental Disorder, Fifth Edition (DSM-V), is not very helpful for the distinction of clinical needs, as individuals with psychotic experiences that are less severe and more transient than observed in the diagnosis 'schizophrenia', or individuals with persistent auditory hallucinations in the absence of other psychotic features, are members of subgroups of 'unspecified schizophrenia spectrum and other psychotic disorder' (40).

While the white noise task might not serve as a marker of risk for psychotic disorders, white noise speech illusions might reflect expression of the psychosis exophenotype. A substantial advantage of an experimental task compared to a self-report instrument or a structured interview might be that individuals are less confronted with their unusual ideas and misattributions. A simple and inexpensive experimental psychosis task is of practical interest, as it would allow for easy and large-scale investigation of risk and mechanisms underlying psychotic disorders. 


\section{References}

1. Muller N, Keil J, Obleser J, Schulz H, Grunwald T, Bernays RL, et al. You can't stop the music: reduced auditory alpha power and coupling between auditory and memory regions facilitate the illusory perception of music during noise. Neuroimage. 2013;79:383-93.

2. Leske S, Tse A, Oosterhof NN, Hartmann T, Muller N, Keil J, et al. The strength of alpha and beta oscillations parametrically scale with the strength of an illusory auditory percept. Neuroimage. 2014;88:69-78.

3. Shergill SS, Brammer MJ, Amaro E, Williams SC, Murray RM, McGuire PK. Temporal course of auditory hallucinations. Br J Psychiatry. 2004;185:516-7.

4. Ishii R, Shinosaki K, Ikejiri Y, Ukai S, Yamashita K, Iwase M, et al. Theta rhythm increases in left superior temporal cortex during auditory hallucinations in schizophrenia: a case report. Neuroreport. 2000;11(14):3283-7.

5. Sritharan A, Line P, Sergejew A, Silberstein R, Egan G, Copolov D. EEG coherence measures during auditory hallucinations in schizophrenia. Psychiatry Res. 2005;136(2-3):189-200.

6. Nathou C, Etard O, Simon G, Dollfus S. How do high- and low-frequency repetitive transcranial magnetic stimulations modulate the temporal cortex. Psychophysiology. 2015;52(2):192-8.

7. Ropohl A, Sperling W, Elstner S, Tomandl B, Reulbach U, Kaltenhauser M, et al. Cortical activity associated with auditory hallucinations. Neuroreport. 2004;15(3):523-6.

8. Spencer KM, Niznikiewicz MA, Nestor PG, Shenton ME, McCarley RW. Left auditory cortex gamma synchronization and auditory hallucination symptoms in schizophrenia. BMC Neurosci. 2009;10:85.

9. Steinmann S, Leicht G, Andreou C, Polomac N, Mulert C. Auditory verbal hallucinations related to altered long-range synchrony of gamma-band oscillations. Sci Rep. 2017;7(1):8401.

10. Lange J, Keil J, Schnitzler A, van Dijk H, Weisz N. The role of alpha oscillations for illusory perception. Behav Brain Res. 2014;271:294-301.

11. Dugue L, Marque $P$, VanRullen R. The phase of ongoing oscillations mediates the causal relation between brain excitation and visual perception. J Neurosci. 2011;31(33):11889-93.

12. Lange J, Oostenveld R, Fries P. Reduced occipital alpha power indexes enhanced excitability rather than improved visual perception. J Neurosci. 2013;33(7):321220.

13. Romei V, Brodbeck V, Michel C, Amedi A, Pascual-Leone A, Thut G. Spontaneous fluctuations in posterior alpha-band EEG activity reflect variability in excitability of human visual areas. Cereb Cortex. 2008;18(9):2010-8. 
14. Vollema MG, Ormel J. The reliability of the structured interview for schizotypyrevised. Schizophr Bull. 2000;26(3):619-29.

15. Konings M, Bak M, Hanssen M, van Os J, Krabbendam L. Validity and reliability of the CAPE: a self-report instrument for the measurement of psychotic experiences in the general population. Acta Psychiatr Scand. 2006;114(1):55-61.

16. Mossaheb N, Becker J, Schaefer MR, Klier CM, Schloegelhofer M, Papageorgiou K, et al. The Community Assessment of Psychic Experience (CAPE) questionnaire as a screening-instrument in the detection of individuals at ultra-high risk for psychosis. Schizophr Res. 2012;141(2-3):210-4.

17. Galdos M, Simons C, Fernandez-Rivas A, Wichers M, Peralta C, Lataster T, et al. Affectively salient meaning in random noise: a task sensitive to psychosis liability. Schizophr Bull. 2011;37(6):1179-86.

18. Catalan A, Simons CJ, Bustamante S, Drukker M, Madrazo A, de Artaza MG, et al. Novel evidence that attributing affectively salient signal to random noise is associated with psychosis. PLoS One. 2014;9(7):e102520.

19. Gonzalez de Artaza M, Catalan A, Angosto V, Valverde C, Bilbao A, van Os J, et al. Can an experimental white noise task assess psychosis vulnerability in adult healthy controls? PLoS One. 2018;13(2):e0192373.

20. Pries LK, Guloksuz S, Menne-Lothmann C, Decoster J, van Winkel R, Collip D, et al. White noise speech illusion and psychosis expression: An experimental investigation of psychosis liability. PLoS One. 2017;12(8):e0183695.

21. Varese F, Smeets F, Drukker M, Lieverse R, Lataster T, Viechtbauer W, et al. Childhood adversities increase the risk of psychosis: a meta-analysis of patientcontrol, prospective- and cross-sectional cohort studies. Schizophr Bull. 2012;38(4):661-71.

22. Smeets F, Lataster T, Dominguez MD, Hommes J, Lieb R, Wittchen HU, et al. Evidence that onset of psychosis in the population reflects early hallucinatory experiences that through environmental risks and affective dysregulation become complicated by delusions. Schizophr Bull. 2012;38(3):531-42.

23. Smeets $F$, Lataster $T$, van Winkel $R$, de Graaf $R$, Ten Have $M$, van Os J. Testing the hypothesis that psychotic illness begins when subthreshold hallucinations combine with delusional ideation. Acta Psychiatr Scand. 2013;127(1):34-47.

24. Smeets F, Lataster T, Viechtbauer W, Delespaul P, G.R.O.U.P. Evidence that environmental and genetic risks for psychotic disorder may operate by impacting on connections between core symptoms of perceptual alteration and delusional ideation. Schizophr Bull. 2015;41(3):687-97.

25. Krabbendam L, Myin-Germeys I, Hanssen M, Bijl RV, de Graaf R, Vollebergh W, et al. Hallucinatory experiences and onset of psychotic disorder: evidence that the risk is mediated by delusion formation. Acta Psychiatr Scand. 2004;110(4):264-72.

26. Beards S, Gayer-Anderson C, Borges S, Dewey ME, Fisher HL, Morgan C. Life events and psychosis: a review and meta-analysis. Schizophr Bull. 2013;39(4):740-7. 
27. Linscott RJ, van Os J. An updated and conservative systematic review and metaanalysis of epidemiological evidence on psychotic experiences in children and adults: on the pathway from proneness to persistence to dimensional expression across mental disorders. Psychol Med. 2013;43(6):1133-49.

28. Escher S, Romme M, Buiks A, Delespaul P, Van Os J. Independent course of childhood auditory hallucinations: a sequential 3-year follow-up study. Br J Psychiatry Suppl. 2002;43:s10-8.

29. van Os J, Kenis G, Rutten BP. The environment and schizophrenia. Nature. 2010;468(7321):203-12.

30. Holt DJ, Titone D, Long LS, Goff DC, Cather C, Rauch SL, et al. The misattribution of salience in delusional patients with schizophrenia. Schizophr Res. 2006;83(2-

3):247-56.

31. Daalman K, Boks MP, Diederen KM, de Weijer AD, Blom JD, Kahn RS, et al. The same or different? A phenomenological comparison of auditory verbal hallucinations in healthy and psychotic individuals. J Clin Psychiatry. 2011;72(3):320-5.

32. Rimvall MK, Clemmensen L, Munkholm A, Rask CU, Larsen JT, Skovgaard AM, et al. Introducing the White Noise task in childhood: associations between speech illusions and psychosis vulnerability. Psychol Med. 2016;46(13):2731-40.

33. Gottesman, II, Gould TD. The endophenotype concept in psychiatry: etymology and strategic intentions. Am J Psychiatry. 2003;160(4):636-45.

34. Fonseca Pedrero E, Debbane M. Schizotypal traits and psychotic-like experiences during adolescence: An update. Psicothema. 2017;29(1):5-17.

35. Weiser M, van Os J, Davidson M. Time for a shift in focus in schizophrenia: from narrow phenotypes to broad endophenotypes. Br J Psychiatry. 2005;187:203-5.

36. Hugdahl K. "Hearing voices": auditory hallucinations as failure of top-down control of bottom-up perceptual processes. Scand J Psychol. 2009;50(6):553-60.

37. Poulton R, Caspi A, Moffitt TE, Cannon M, Murray R, Harrington H. Children's selfreported psychotic symptoms and adult schizophreniform disorder: A 15-year longitudinal study. Arch Gen Psychiatry. 2000;57(11):1053-8.

38. Wiles NJ, Zammit S, Bebbington P, Singleton N, Meltzer H, Lewis G. Self-reported psychotic symptoms in the general population: results from the longitudinal study of the British National Psychiatric Morbidity Survey. Br J Psychiatry. 2006;188:51926.

39. Brookwell ML, Bentall RP, Varese F. Externalizing biases and hallucinations in source-monitoring, self-monitoring and signal detection studies: a meta-analytic review. Psychol Med. 2013;43(12):2465-75.

40. Arciniegas DB. Psychosis. Continuum (Minneap Minn). 2015;21(3 Behavioral Neurology and Neuropsychiatry):715-36. 

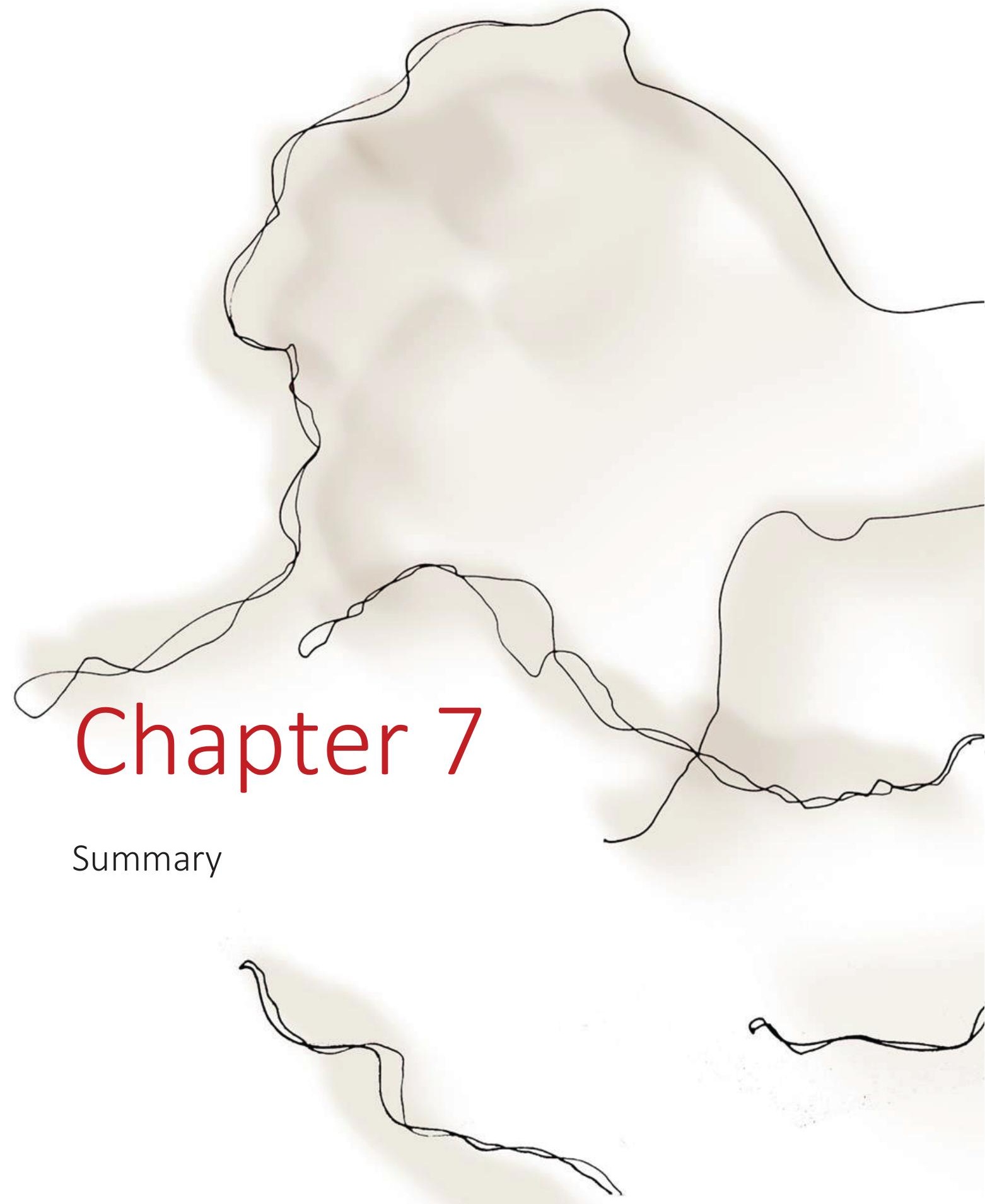


$$
=3
$$




\section{Summary}

A psychosis continuum implies that psychotic experiences can be measured in both heathy and ill individuals, shifting towards more intense levels along the continuum. The white noise task was designed to test the process of eliciting meaning from a meaningless sound (i.e., auditory illusion) and is thought to reflect individual differences in risk of psychotic disorders (non-clinical versus clinical population). The question remains, however, whether the white noise task can be used to detect psychosis risk associated with perceptual alterations in the non-clinical population. More insight is therefore necessary into the mechanisms underlying the white noise task.

The first part of this thesis focused on the neurophysiological mechanisms underlying white noise speech illusions in the general population (Chapters $\mathbf{2}$ and $\mathbf{3}$ ). The second part focused on the dependence of white noise speech illusions on trait and environmental risks in the general population (Chapter 4 ) and across different levels of familial risk (Chapter $\mathbf{5})$.

Chapter 1 provided an overview of the epidemiology, aetiology and genetics of psychotic disorders. It introduced the experimental paradigms and findings of previous research using the white noise task.

In Chapter 2, cortical oscillations of white noise fragments were investigated. In a follow-up design with two measurement moments (baseline and 6 months), participants $(n=83)$ underwent the white noise task while being recorded with a 14lead EEG. White noise speech was defined as a white noise fragment in which any speech was heard. The total number of speech illusions generated by the participants was $7.1 \%$ at baseline and $6.5 \%$ at follow-up. Alpha activity during a white noise fragment appeared to be lower in speech illusions than in correctly judged fragments, most significantly involving a decrease in activity at the left temporal region. Other 
EEG frequency bands showed no significant associations. These result suggest that, in the general population, speech illusions are characterised by heightened excitability (reduced alpha power) during a white noise fragment.

Chapter 3 investigated whether baseline alpha activity predicts the interpretation of a white noise fragment in the general population. In Chapter 2, evidence was found for an association between alpha activity and white noise speech illusions. It has been suggested that baseline alpha oscillations may mediate illusory perceptions. In the present study, however, no significant associations were found between baseline alpha band power and white noise speech illusions. In other words, while it has been suggested that alpha activity before stimulus onset may be involved in shaping cortical networks for upcoming stimuli, no evidence was found for an association between baseline alpha activity and the interpretation of a white noise fragment.

Chapter 4 investigated in the general population the associations between white noise speech illusions and the Community Assessment of Psychic Experiences (CAPE) questionnaire. Previous research has reported inconclusive results as to what degree subclinical expression of psychotic disorders may be associated with speech illusions. No association was found in the present study, suggesting that the association between speech illusions and subclinical expression of psychotic disorders is a marker of illness rather than risk. This chapter also investigated associations with childhood adversity and recent life events. The CAPE positive scale was significantly associated with childhood adversity and life events. The number of speech illusions showed no association with either life events or childhood adversity. In the non-clinical population, the pathway from risk factors to expression of subclinical psychotic experiences does not appear to involve white noise speech illusions as an intermediate outcome.

In Chapter 5, white noise speech illusions were investigated in patients, their siblings and the general population. This chapter examined to what degree the rate of white 
noise speech illusions in siblings of patients is contingent on exposure to childhood adversity, recent life events and levels of known endophenotypic dimensions of psychotic disorders (CAPE scale and cognitive ability). The sample was derived from WP6 (vulnerability and severity) of the international EUGEI project. The white noise task was undertaken by 1,014 patients, 1,157 siblings and 1,507 healthy participants (controls). White noise speech illusions were significantly associated with familial risk. The association between speech illusions and familial risk was stronger if there was additional evidence for early environmental exposure or trait expression of psychosis proneness and cognitive alterations. This suggests that white noise speech illusions are a state-dependent familial trait characteristic.

Chapter 6 offered a general discussion of the contents of this thesis. The findings were placed within the context of the existing literature. In addition, a critical review of the methodology and suggestions for further research were presented. 

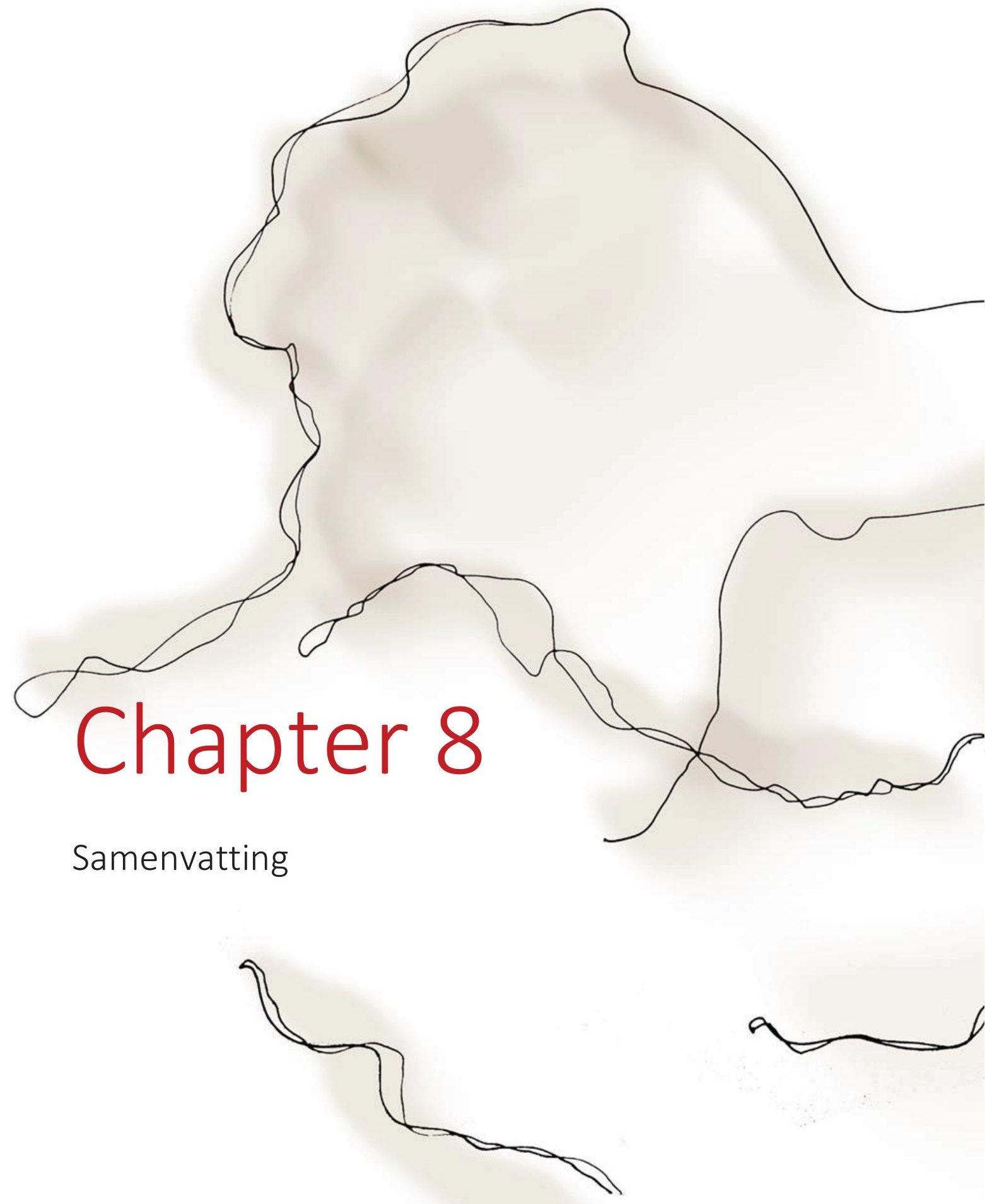


$$
=3
$$




\section{Samenvatting}

Wanneer het begrip psychose als een continuüm wordt beschouwd, betekent dit dat psychotische ervaringen aanwezig zijn in zowel de gezonde als de klinische populatie, waarbij de intensiteit van de ervaringen zal toenemen binnen het continuüm. De 'white noise' taak is ontwikkeld om betekenis te kunnen ontlokken aan een betekenisloos geluid. In een dergelijke situatie spreken we van een auditieve illusie. Er zijn aanwijzingen dat de white noise taak differentieert tussen het risico op een psychotische aandoening binnen een niet-klinische populatie en patiënten met een psychotische aandoening. Om te kijken of de white noise taak ook gebruikt kan worden om abnormale waarnemingen te detecteren binnen een gezonde populatie wordt getracht meer inzicht in de onderliggende mechanismen van de 'white noise' taak te verkrijgen. Het eerste deel van dit proefschrift richt zich op de neurofysiologische mechanismen die ten grondslag liggen aan 'white noise' illusies in de gezonde populatie (hoofdstuk 2 en 3). Het tweede deel richt zich op de associatie tussen 'white noise' illusies en persoonlijkheids- en omgevingsrisicofactoren in de gezonde populatie (hoofdstuk 4) en binnen patiënten, hun verwanten en de controle groep (hoofdstuk 5).

Hoofdstuk 1 geeft een overzicht weer van de epidemiologische, etiologische en genetische achtergrond van psychotische aandoeningen. Het experimentele paradigma en eerder onderzoek naar de 'white noise' taak wordt beschreven.

In hoofdstuk 2 wordt de corticale activiteit tijdens de 'white noise' taak onderzocht. In een follow-up design met twee meetmomenten (baseline en na 6 maanden) ondergingen 83 personen de 'white noise' taak, terwijl er gelijktijdig EEG-activiteit werd gemeten. Een 'white noise' illusie werd gedefinieerd als een ruis fragment waarin spraak werd gehoord. In totaal rapporteerde 7,1\% van de deelnemers een illusie tijden de baseline meting en 6,5\% tijdens de follow-up meting. Er is gebleken dat de alpha activiteit tijdens een ruis fragment lager is bij een illusie dan bij een juist 
geïnterpreteerd fragment. De verlaging bleek het meest significant in de linker temporale regio. Andere EEG-frequentiebanden lieten geen significante associaties zien met illusies. Deze resultaten suggereren dat 'white noise' illusies in de gezonde populatie worden gekenmerkt door verhoogde corticale activiteit in de temporaalkwab (verlaagde alpha activiteit) tijdens een ruis fragment.

In hoofdstuk $\mathbf{3}$ werd onderzocht of de alpha activiteit van de baseline een voorspeller is voor de interpretatie van een ruis fragment in de gezonde populatie. Immers, in hoofdstuk 2 werd aangetoond dat een 'white noise' illusie geassocieerd is met daling van de alpha activiteit. Eerder onderzoek suggereert dat alpha activiteit voor het begin van een stimulus de perceptie van een geluid zou kunnen beïnvloeden. Er kon geen significante associatie worden aangetoond tussen baseline alpha activiteit en 'white noise' illusies. Met andere woorden, al hoewel enkele studies aanwijzingen hebben gevonden dat de alpha activiteit van de baseline betrokken is in bij het vormgeven van de corticale activiteit van een naderende stimulus, werd er tijdens dit onderzoek geen associatie gevonden tussen baseline alpha activiteit en de interpretatie van 'white noise' .

In hoofdstuk 4 werd de associatie tussen 'white noise' illusies en de positieve CAPE schaal (subjectief meetinstrument voor psychotische ervaringen) in de gezonde populatie onderzocht, gezien er tegenstrijdige resultaten zijn gepubliceerd. Er werd geen associatie gevonden, wat impliceert dat deze associatie eerder een marker is voor de aanwezigheid van ziekte dan het risico op een ziekte. Daarnaast werd de relatie met traumatische gebeurtenissen in de kindertijd en recente life events onderzocht. De positieve CAPE schaal liet associaties zien met beide variabelen. Met 'white noise' illusies konden daarentegen geen statistisch significante associaties worden aangetoond. In een gezonde populatie lijken 'white noise' illusies geen intermediaire uitkomst te zijn van de relatie tussen risico factoren en expressie van psychotische ervaringen. 
In hoofdstuk 5 werden 'white noise' illusies onderzocht in patiënten, hun verwanten en de gezonde populatie. Er werd gekeken of het aantal 'white noise' illusies gerelateerd is aan blootstelling aan life events, traumatische gebeurtenissen in de kindertijd, de CAPE schaal en cognitieve vaardigheden. De onderzoeksgroep werd verkregen uit WP6 binnen het internationale EU-GEI project. De 'white noise' taak werd uitgevoerd door 1014 patiënten, 1157 verwanten en 1507 gezonde controle personen. 'White noise' illusies bleken geassocieerd te zijn met het familiaire risico op een psychotische aandoening. Deze associatie tussen 'white noise' illusies en familiair risico, was sterker aanwezig in personen met rapportage van psychotische ervaringen, lagere cognitieve vaardigheden en aanwezigheid van kindermishandeling.

Hoofdstuk 6 bevat de algemene discussie van de thesis. De bevindingen worden geïntegreerd en geplaats in de context van de bestaande literatuur. Daarnaast worden een kritische beschouwing van de methodologie en suggesties voor verder onderzoek gegeven. 

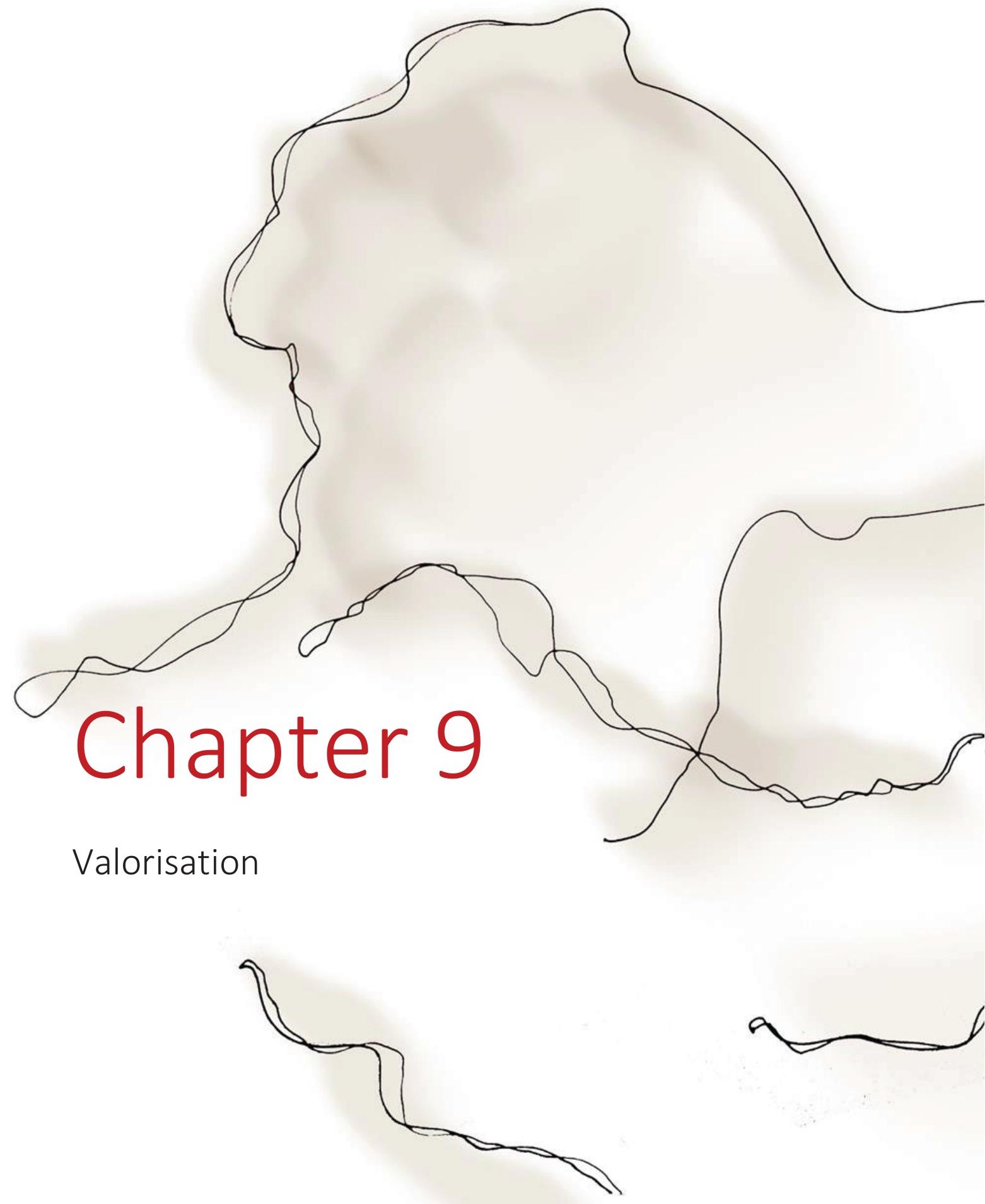


$$
=3
$$




\section{Valorisation}

Psychotic disorders remain among the most disabling mental disorders. They are often associated with persistent health and social burdens, not only for patients but also for families and caregivers. The costs of psychotic disorders are substantial. In Europe in 2010, the cost was estimated at $€ 94$ billion (1), including the direct costs of treatment and the indirect costs (e.g., long-term unemployment). The aetiology of the disease is largely unknown, and there is still a considerable delay to diagnosis. The delay is partly the result of the symptoms of psychotic disorders, which can be elusive and non-specific in the early stages (2). Psychotic experiences below the threshold of clinical severity - in the form of attenuated reality distortions, including perceptual abnormalities and persecutory ideas - can also be found in the general population. Psychotic experiences may become clinically relevant after reaching a threshold of severity. There is interest in gaining a clearer understanding of the phenomenology, neurobiology and course of subthreshold psychotic experiences, as this may help to identify earlier the onset of clinically relevant symptoms.

Recently, an experimental paradigm was developed to elicit experiences resembling psychotic phenomena in the form of white noise speech illusions. As psychosis is thought to represent a continuum of human experience that is also present, in attenuated form, in healthy individuals in the general population, the task can be used not only for patients but also for healthy controls. A simple and inexpensive experimental psychosis task for use in both clinical and non-clinical populations is of great practical interest, as it would allow for easy and large-scale investigation of risk and mechanisms underlying psychotic disorders. Previous work has shown that experimentally induced speech illusions clearly distinguish patients from healthy controls, which is promising.

In the present study, the white noise paradigm was used to examine to what degree speech illusions reflect individual differences in risk of psychotic disorders beyond 
case-control differences, for example by comparing healthy controls with individuals at higher-than-average genetic risk, such as the healthy siblings of patients. We additionally investigated to what degree environmental and familial risk factors associated with psychotic disorders may predict white noise-induced speech illusions. Finally, we attempted to identify the cortical mechanisms of speech illusions using EEG.

We found that, although speech illusions in the general population cross-sectionally are characterised by reduced alpha activity during a noise fragment, baseline EEG oscillatory activity did not show any association with the expression of speech illusions at the follow-up of the same sample. The practical significance of this is that the crosssectional, 'diagnostic' association of EEG activity and our experimental psychosis task has no predictive value, which limits the practical significance of the cross-sectional finding.

In addition, the analyses showed that there were no associations between white noise speech illusions and self-reported psychotic experiences in the general population, nor were there associations between speech illusions and known risk factors for psychotic disorders in the general population. From a practical perspective, this is disappointing, because it suggests that experimentally induced speech illusions cannot serve as a marker of subthreshold psychosis. There was some evidence, however, that speech illusions could serve as a marker in the healthy siblings of patients with psychotic disorders, but only if they already showed high levels of trait-like risks. This again limits the practical use of speech illusions as a marker in this group, as the group already has high levels of trait-like markers.

To acquire further practical significance, we recommend investigating cortical activity of speech illusions in the trait-rich subgroup of siblings and patients. This may not only help in determining the (biological) basis of psychosis, but may also provide insight 
into the mechanisms differentiating between healthy individuals with speech illusions who do and those who do not develop psychotic disorders. 


\section{References}

1. Olesen, J., et al. The economic cost of brain disorders in Europe. European journal of neurology. 2012;19(1):155-162.

2. Lieberman, Jeffrey A., and Wayne S. Fenton. Delayed detection of psychosis: causes, consequences, and effect on public health. American Journal of Psychiatry. 2000;157(11):1727-1730. 

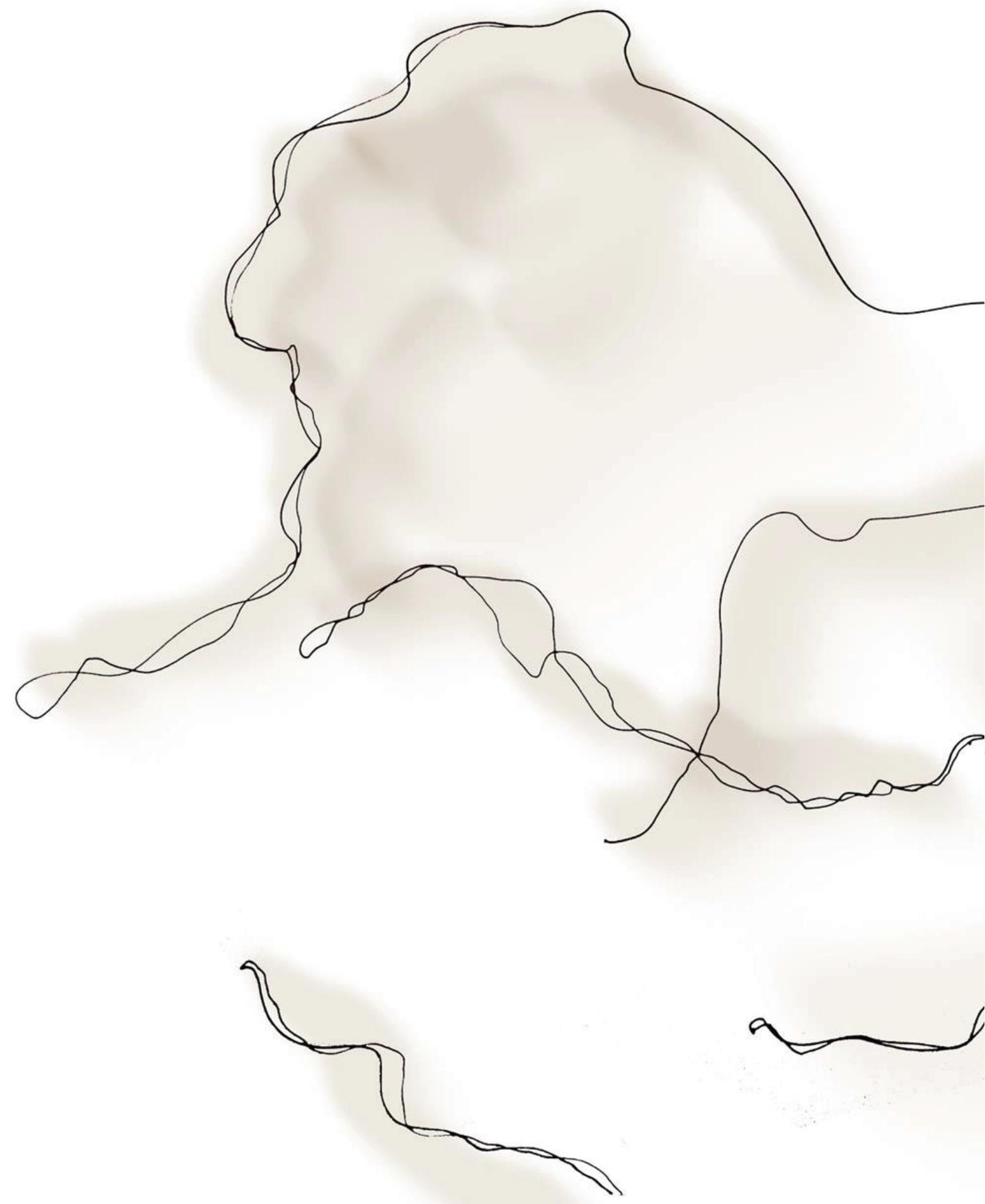


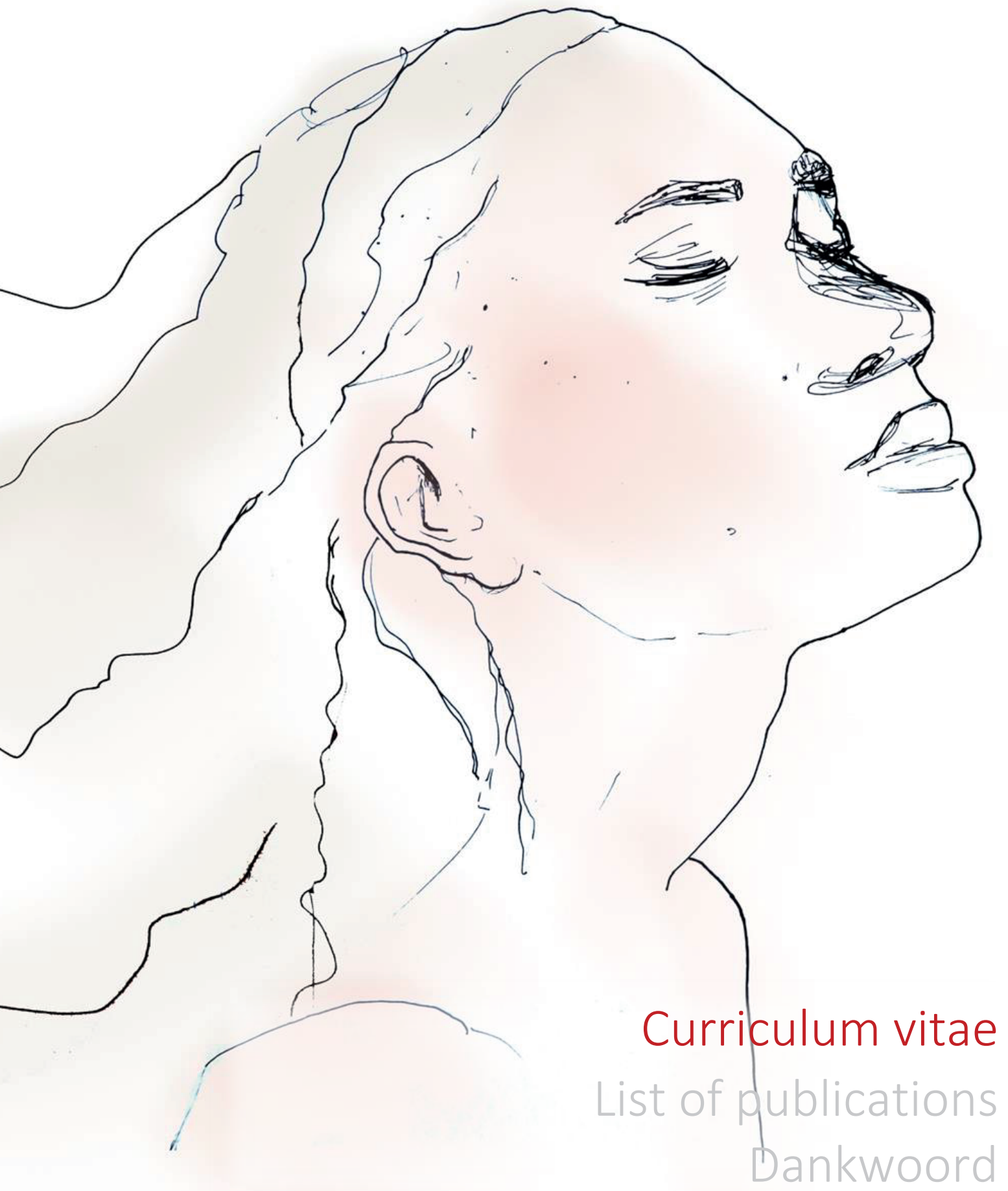


148 | Curriculum vitae 


\section{Curriculum vitae}

Elaine Schepers werd op 6 november 1994 geboren in Hengelo (Gelderland), waar zij tevens is opgegroeid. In 2012 haalde zij haar VWO/gymnasium diploma aan het Ludger college te Doetinchem. De studie geneeskunde volgde zij aan de Universiteit van Maastricht. Tijdens haar studie geneeskunde ging haar promotietraject aan de Universiteit van Maastricht van start onder leiding van dr. Richel Lousberg en prof. Jim van Os. In 2018 behaalde zij haar artsexamen. Eenmaal arts, werkte zij twee jaar als arts-assistent gynaecologie in het Maasstad Ziekenhuis te Rotterdam. Momenteel is zij werkzaam als arts-assistent gynaecologie in het Radboudumc te Nijmegen. 

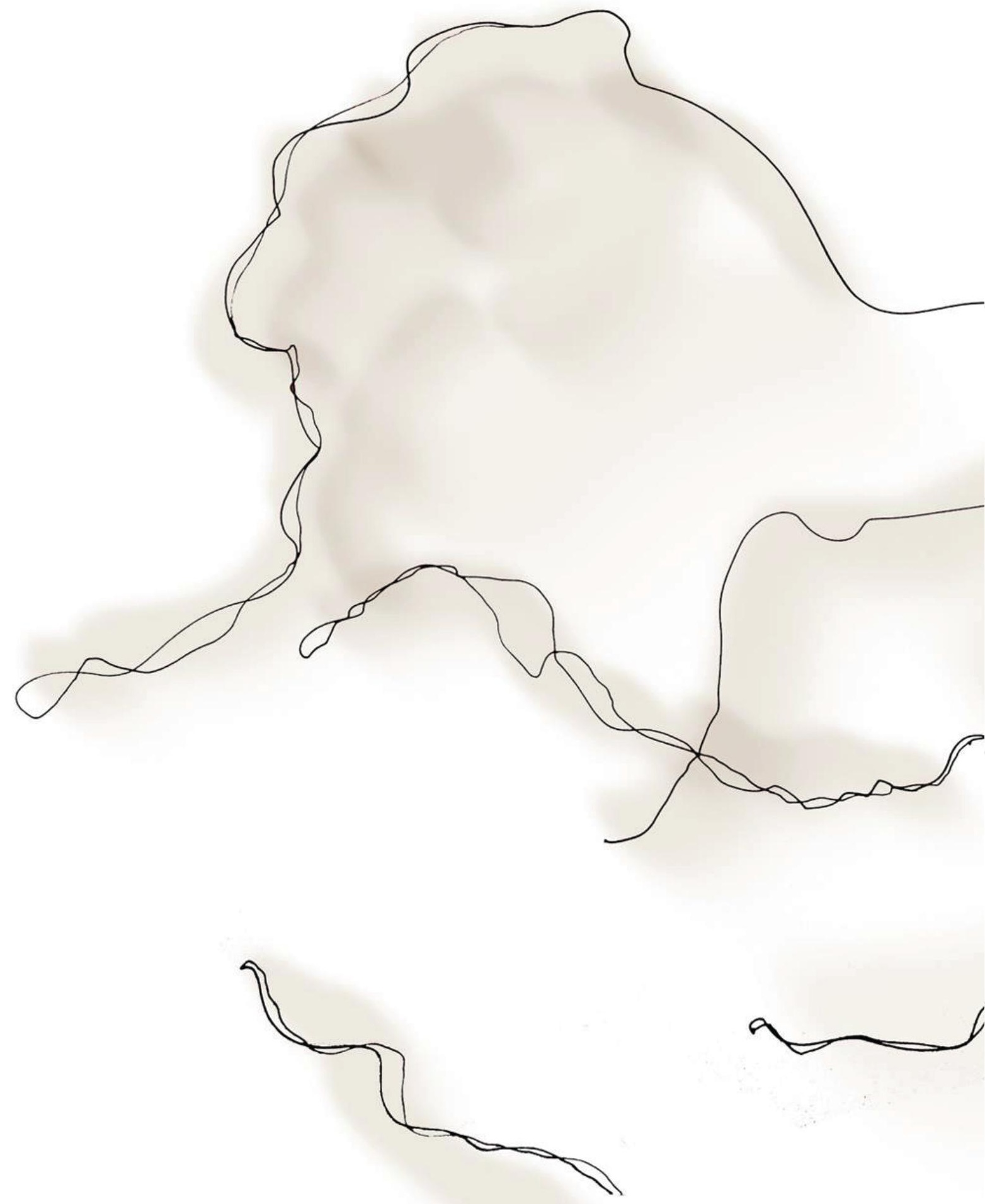


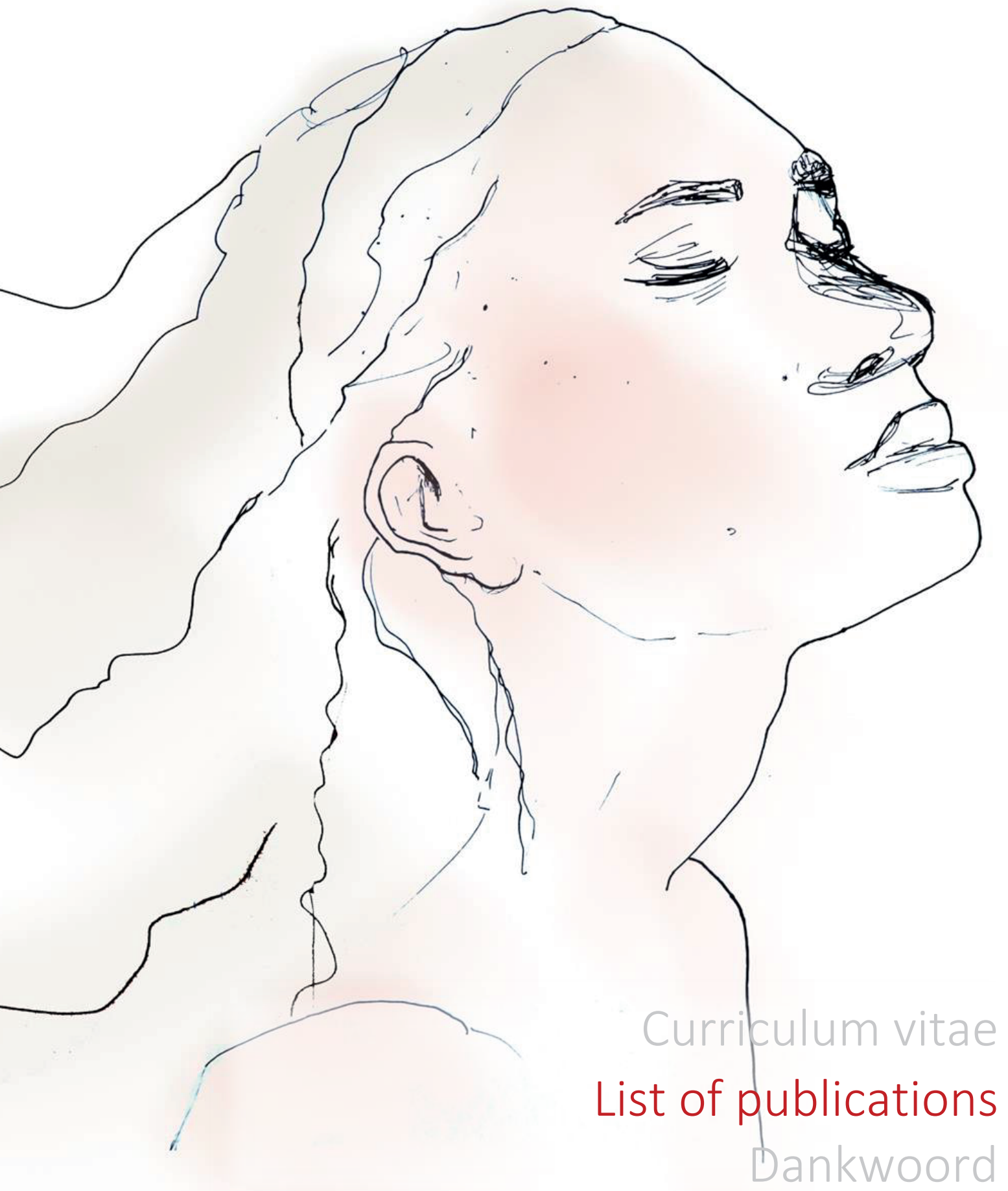


152 | List of publications 


\section{List of publications}

Schepers, E., et al. Cortical processes of speech illusions in the general population. BMC neuroscience. 2016;17.1:65.

Schepers, E., J. van Os, and R. Lousberg. Baseline alpha activity: A predictor of white noise speech illusions in the general population? Submitted.

Schepers, E., J. van Os, and R. Lousberg. White noise speech illusions in the general population: The association with psychosis expression and risk factors for psychosis. PloS one. 2019;14.2: e0211914.

Schepers, E., et al. White noise speech illusions: a trait-dependent risk marker for psychotic disorder? Frontiers in Psychiatry. 2019;10:676. 

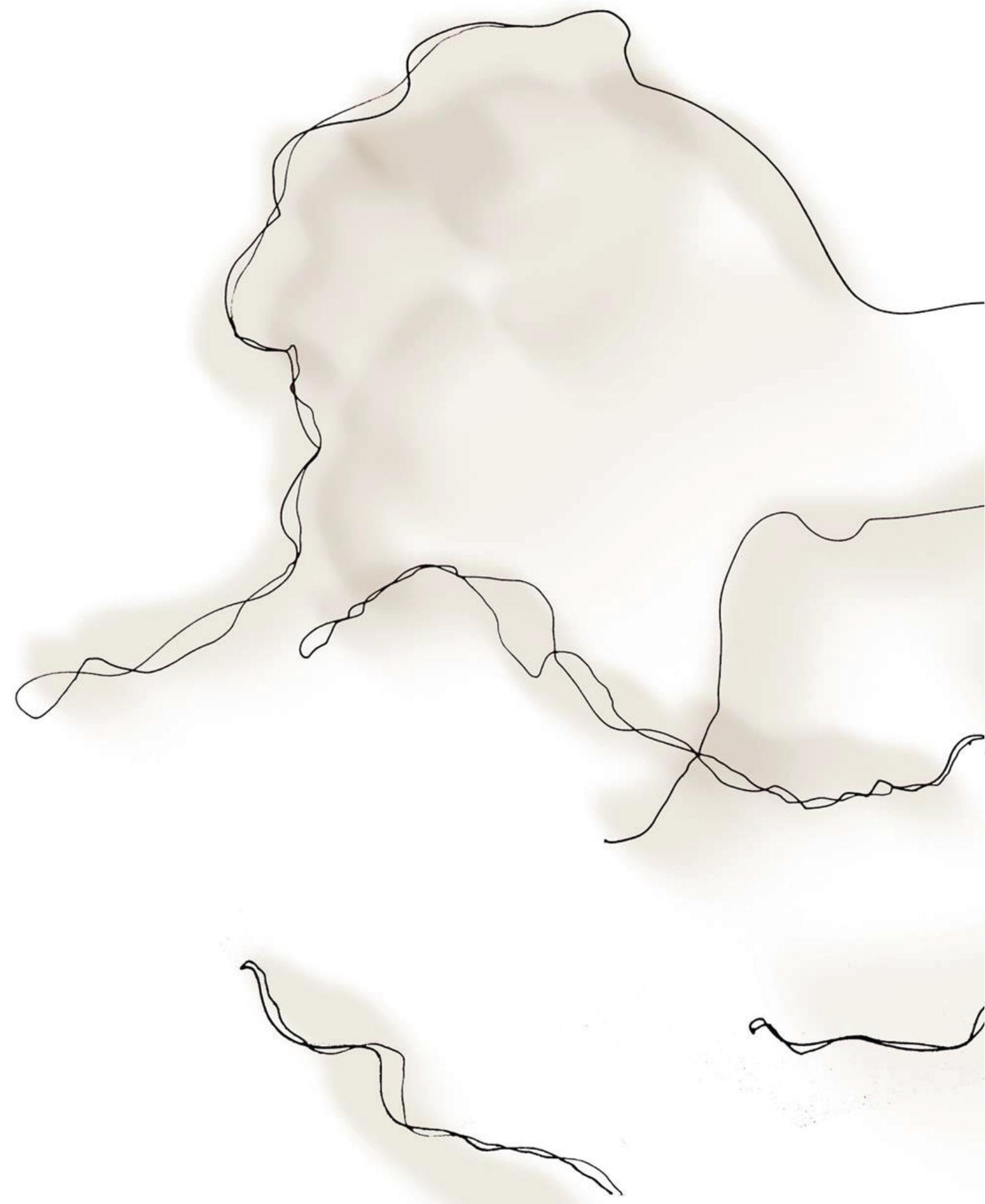


\section{Dankwoord}

Ten eerste wil ik jou bedanken, Richel. Aan het eind van mijn tweede studiejaar kwamen wij elkaar tegen en kijk waar we nu zijn. Ik wil je bedanken voor de kans, die je mij hebt gegeven om in dit project te stappen. Ik waardeer het enorm dat je iedere keer opnieuw veel energie investeert in jonge studenten, die van jou leren om een goede gedegen onderzoeker te worden. We hebben intensief samengewerkt en ik heb veel van je mogen leren, zonder jou was dit niet gelukt! Veelvuldig heb je advies en feedback geven op meerdere vlakken, waarvoor dank.

$\mathrm{Jim}$, het is een eer om jou als promotor te hebben. Ik heb je ervaren als een zeer toegankelijke promotor met doortastende feedback en een heldere kijk. Je stond open voor het geven van uitleg en suggesties. Je bent een inspirator voor mij en voor vele collega's en patiënten.

Verschillende mensen heb ik ontmoet op Vijverdal. Carine, Rosan en Suzanne jullie waren al langer betrokken bij de projecten op het lab, voordat ik met jullie kennis maakte. Ik wil jullie ten eerste bedanken voor de gezellige momenten. Daarnaast heb ik jullie adviezen over de af te leggen weg gedurende het promotietraject erg gewaardeerd. Marga je bent van grote meerwaarde geweest op het lab. Dank voor al je energie, die je hebt gestoken in de dataverzameling, maar ook voor je liefdevolle interesse. Anne, de laatste en meest intensieve periode van mijn traject hebben wij elkaar veelvuldig gezien. Ik heb met bewondering gekeken hoe jij alles wist te managen als je weer eens de weg van Maastricht naar Utrecht moest afleggen.

Wolfgang Viechtbauer, Ron Mengelers, Lotta Pries en Sinan Guloksuz hartelijk dank voor jullie samenwerking.

Tevens wil ik de leescommissie bedanken voor hun tijd en interesse. 
Veel dank gaat uit naar mijn lieve vriendinnen van Topaas en huisgenoten van huize 21 in het bijzonder. Dank dat jullie vol belangstelling wilden luisteren naar mijn verhalen. Ik heb enorm veel mooie herinneringen aan een fantastische studententijd en ik ben dankbaar dat ik dit heb kunnen combineren met dit promotietraject. Daarbij wil ik jullie, Leonie en Roos, speciaal bedanken. Bedankt dat jullie mijn paranimfen willen zijn en bedankt dat jullie altijd voor mij klaar staan. Zonder jullie was dit niet gelukt. Jullie vriendschap is mij zeer dierbaar.

Lieve papa, mama, Jesse en Romy, dank voor jullie onvoorwaardelijke steun. Lieve Romy, ik heb het als zeer bijzonder ervaren dat wij hebben mogen samenwonen, jij aan het begin van je studententijd en ik aan het eind. Dank voor je zusterlijke advies en de gezellige avonden.

Lieve Martijn, wij zijn elkaar tegen gekomen terwijl ik in de afrondende fase van mijn promotietraject zat. Dank voor de vele fijne momenten samen, maar ook voor je luisterend oor en je adviezen. Bedankt dat je er altijd voor mij bent. 